\title{
$D R-1806$
}

ORNL -46N:L

IJC-80-Reactor Technology

THE EFFECT OF IODINE DECAY HEAT

ON CHARCOAL ADSORBERS

R. P. Shields

M. Simon-Tor

OAK RIDGE NATIONAL LABORATORY

operated by

UNION CARBIDE CCRPORATIOK

for the

U. S. ATOMIC ENERGY COMMISSION 


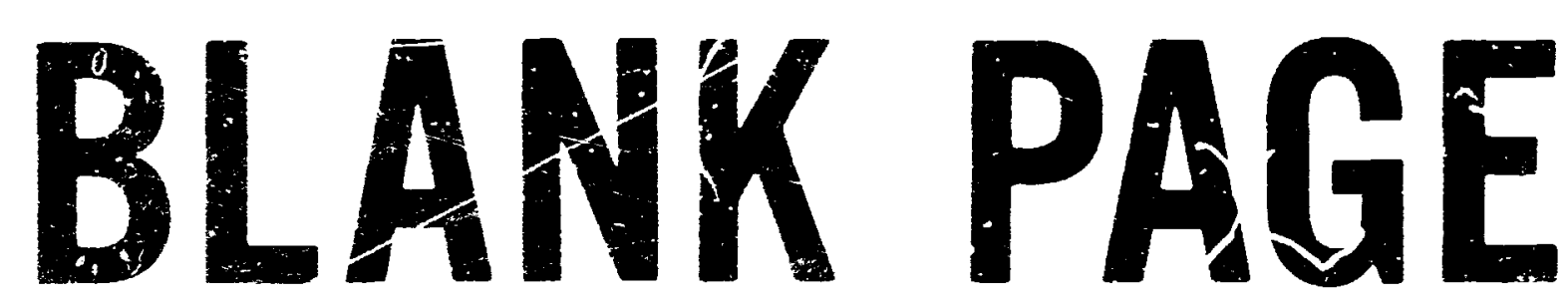




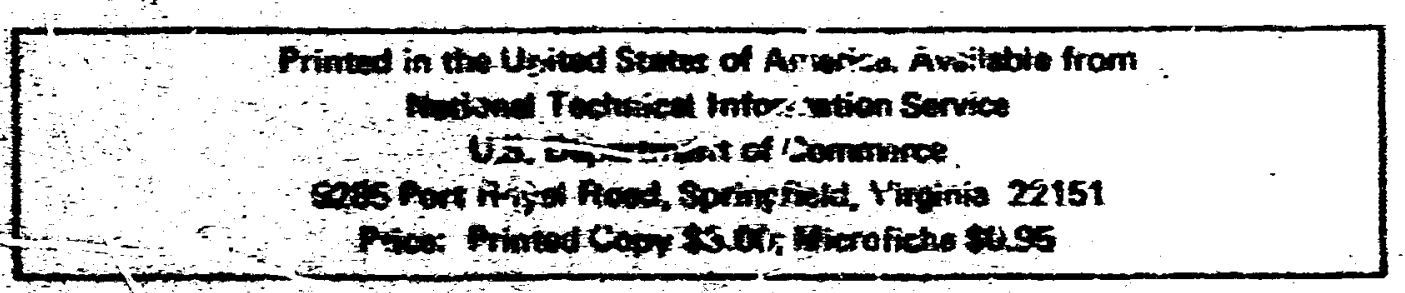

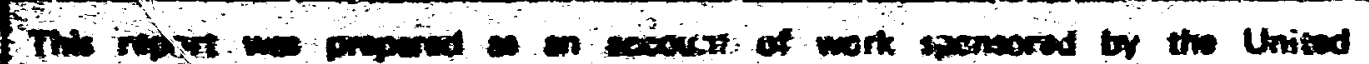

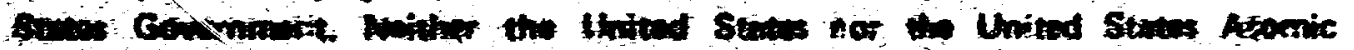

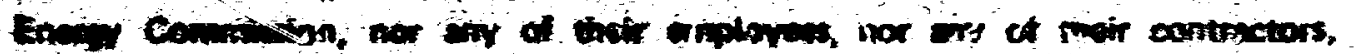

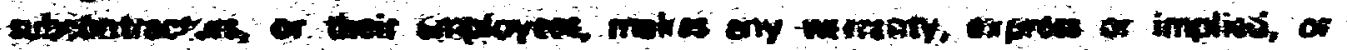

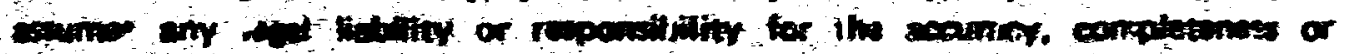

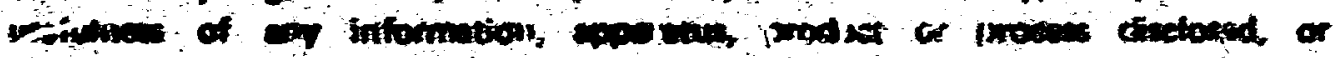

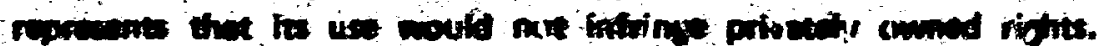




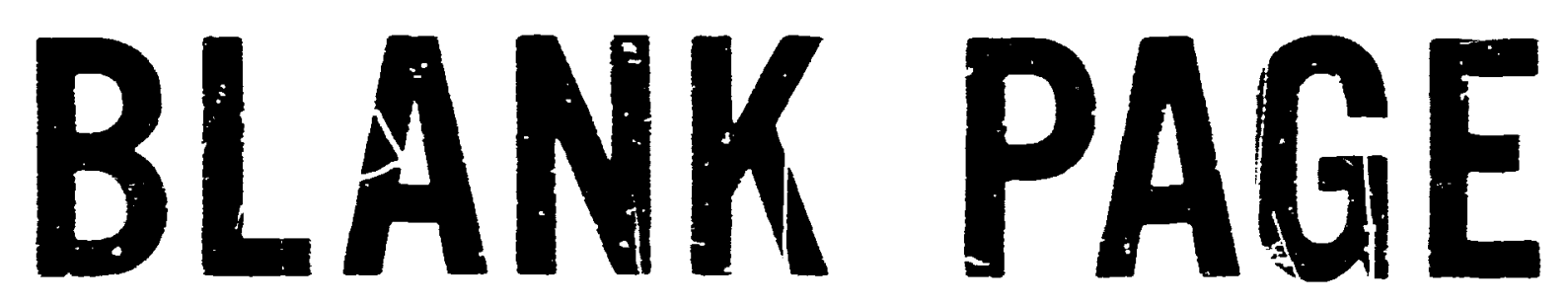


ORNL-4602

Contract No. w-7405-eng-2€

THE EFEECT IF ICDINE DECAY HEAT ON CHARCOAL ADSORBERS

R. P. Shields

keactor Chemistry Division

ii. Siman-Tov

General Engineering Division

This report wes prepered so in account of work sponsored by the United States Government. Neither the Unttel States nor the United States Kiomic Energy Commiacion, nor any of their employees, nor any of their contractors, subcontractors, or their employees, makes any warranty, express or implind, of entres any itgai inointy or responsibility for the eccuracy, completenoses or usefulnes of any informution, apparatus, product or process lisclosed, or represents that its use would not infring ${ }^{2}$ privtely owned rights.

\section{APRIL 1971}

OAK RIDGE NATIONAL LABORATORY

Oak Ridge, Tennessee

operated by

UNION CARBIDE COFPORATION

for the

U.S. ATOMIC ENERGY COMMISSION 
TABLE OF CONTENTS

I. Introduction 1

II. Charcoal Adsorption Systems 2

Charcoal Adsorber Units 2

Containment Fiiter Systems 5

III. Mathematical Basis for the Thermal Analysis of a Charcoal Áàsorber 9

T.le General Heat Balance Equation 9

Singlified Mathematical Models of Charcoal Adsorber Unit 11

IV. Development of Computer Codis 13

$\begin{array}{ll}\text { Heat Source } & 14\end{array}$

$\begin{array}{ll}\text { Charcoal Characteristics } & 17\end{array}$

volumetric Heat Transfer Coefficient 17

Computer Codes 19

ENIS Code 19

CHART Codes $\quad 21$

V. Applic.ation of Computer Codes $\quad 24$

Heat Generation by Decay of Radioiodine $\quad 24$

$\begin{array}{ll}\text { Charcoal Parameters } & 29\end{array}$

Volumetric Heat Iransfer Coefficient 31

Examples of Code Applications 32

VI. Cooling the Charcoa]. Adsorber by Natural Air Convection 44

VII. Summary $\quad 49$

ENIS Code $\quad 52$

CHART Code $\quad 53$

Appendices 55

Appendix A. Analytical Solution of the Diffusion Equation
for the Infinite Slab Hodel (Derivation of Equation 23)

Appendix B. A Ccmputer Program for Calculating Heat

Generation, in a Charcoal Adsorber, Due to Iodine Decay 72

Appendix C. CHART Code. 76

Appendix D. Application of CHART to a Research or
Production Type Reactor

Appendix E. STACK: An XTRAN Computer Program for Calcuiating Stack Parameter vs Fractior: of Decay heat Removed from Charcoal Adsorbers 93

References $\quad 98$ 
ABST. .ACT

A prosedure for the thermal anilysis of the cha:coal adsorbir, ir. a reactor ccntiainment system, has been developed to es :imate maximum temperatures which mìy prevail under accident conditions. A differential equat:-on which relates the charcoal tiemperature to the heat generation rate, air flow rate, and the neat paramaters of air and charcoal has been solved both malytically and numerically. The anaj. tical method assumes a two inch thi ik slab c charcoal only and is applica.le tc high flow rates. A computer code has been develcped for nume ical solution cf the equation for the charcoal slab in both one and thre?-dimensions. The principal considerations have been given to very $1 \mathrm{~N}$ flows and for times soon after onset of the accident; conditions which pose the greatest threat to tife charcoal. Examfles are given of the application of this code to reactor off-gas charcoal adsorbers. 


\section{INTROPUCTION}

Mojern nuclear reactors are equipped with many sophisticated engineered safeguards to prevent or to limit the release of fission products in the event of a reactor malfuriction. All safety measures initiated after an accident are directed toward fixing the fission products into some controllable form such as in solution or in suspension in the case of containment spray systems or onto solid surfaces as in the case of particulate filters and charcoal adsorher inits.

In any process that coliects the fission produrts some means must be provided for dissipating the heat generated by radioactive decay. Air flow through the charcoal normally provides this feature for lodine adsorption units; however, certain combinations of iodine loading and reduced atr flow can be assumed which will produce a temperature rise into the critical range. Since charcoal is combustible and considering the relative importance of the positive containment of lodine isotopes in safety analyses, it is of importance to investigate the various factors which affect the temperature development and distribution in charcoal adsorbers caused by iodine adsorption under accident conditions.

This report covers part of a continuing program sponsored by the USAEC Division of Operational Safety on the general subjest of charcoal adsorbers by iodine decay heat. Earlier phases of the work involved an investigation of the ignition process in charcoal ${ }^{1}$ and the influence of fodine fission products on the ignition process. ${ }^{2,3}$ The latter tests were conducted with real todine fission products produced in an in-pile facility. This report and a brief paper at the Eleventh AEC Air Cleaning Conference ${ }^{4}$ cover the effort to develop and apply a computer prograil to allow an estimation of the temperature development in full-scale charcoal adsorption systems to be made. During this phase of the program it was necessary that some laboratory measurements be mads of certain parameters such as volumetric heat transfer coeffscienta; heat capactitico, charcoal properties, etc; these measurements are essentialiy complete and will be cietailed in a companion report to be issued in the near future. Therefore, this report will be limited to a discussion of the computer programs and their applicability; certain parametric values will be estimated for the purpose of illustrating the use of the program. 


\section{CHSRCOAL ADSORPTION SYSTEMS}

Charcoal adsorption systems of various configurations are used in the containment schemes of the several types of nuclear reactors. AEC research and production reactors utilize negative pressure containment with continuous ventilation through gas decontamination systems utilizing, charcoal and other components; suclear power reactris of the boiling water type (BWR) utilize a single-pass gas decontamination system, containing charcol, lecated cutside the primary containiment; some of the nuclear power reactors of the pressurized water type (PWR) utilize large recirculating gas decontamination systems iocated within the containnent. Each type of charcoal system will be subjected to differing iodine loadings and operating conditions following an accident. Systams used in the PWR's will probably be subjected to the most severe combination of iodine loading and operating conditions. Figure 1 is a composite illustration of several of these systems.

\section{Charcoal Adsorber Urits}

The individual adsorber units which make up the adsorber system for nuclear reactors are available in two configurations. Both types contain a layer of granular charcual held between perforated sineet metal through which the air flows. The method used for supporting the enclosed layer of charcoal gives rise to the two types of adsorber units generally used.

In one type of unit the charcoal is held between perforated sheet folded in an accordian-like pleat so that about $15 \mathrm{ft}^{2}$ of face area can be contained in a $2 \mathrm{ft} \times 2 \mathrm{ft}$ frame - the so-called pleated adsorber units. Figure 2 contains a photograph of this type of unit as well as a sketch of construction detail. Such units contain about 55 pounds of charcoal and provide a charcoal depth of approximately one inch. Charcoal adsorber units of the pleated type are generally utilized by the AEC research and production reactors which have the continuous ventilation, negative pressure containments.

The second type of adsorber unit contains two individual layers of charcoal held between perforated metal sheet. These layers are fixed one above the other in a drawer-like metal assembly; these units contain 


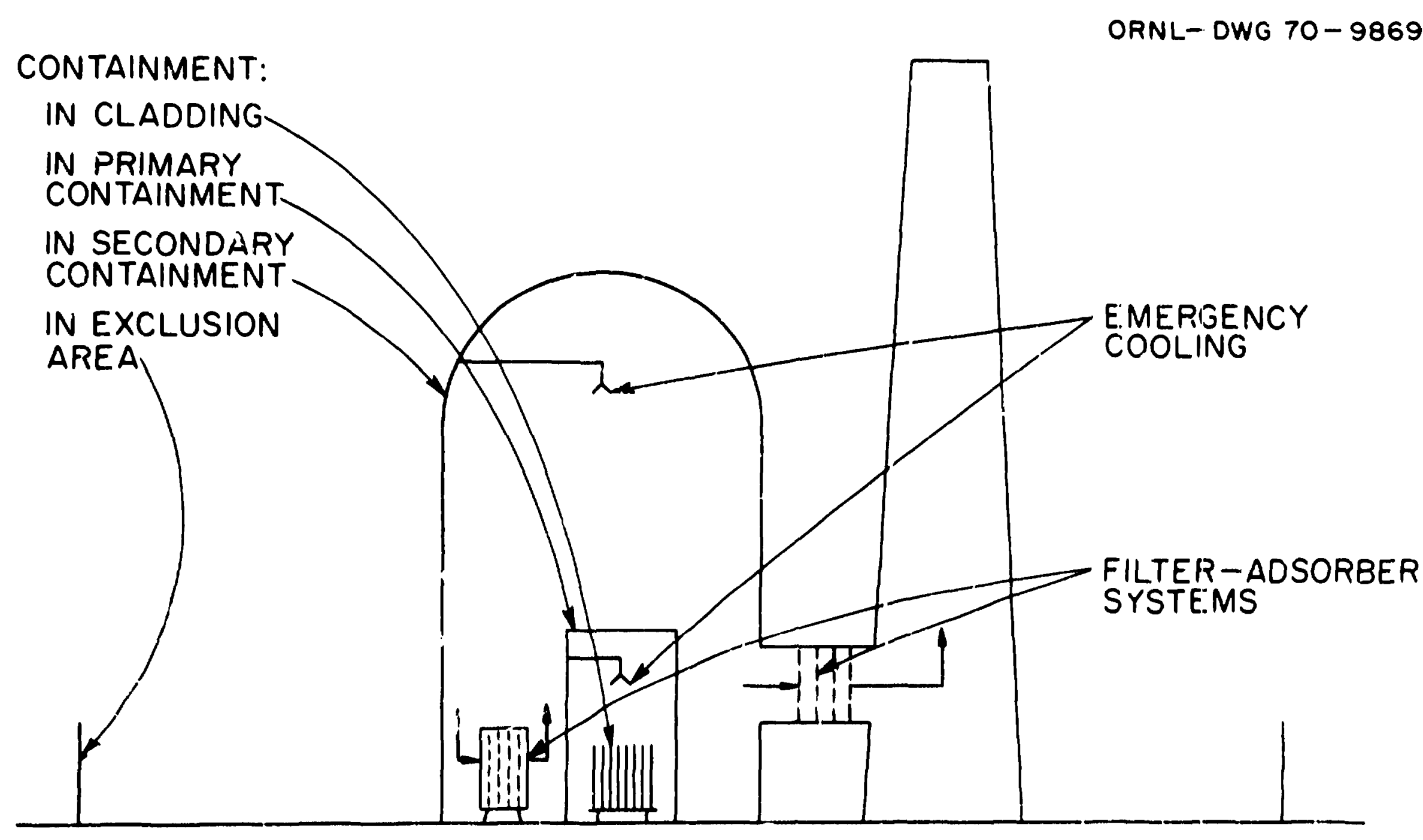

Figure 1. Son's Features of Fission Product Containment system. 

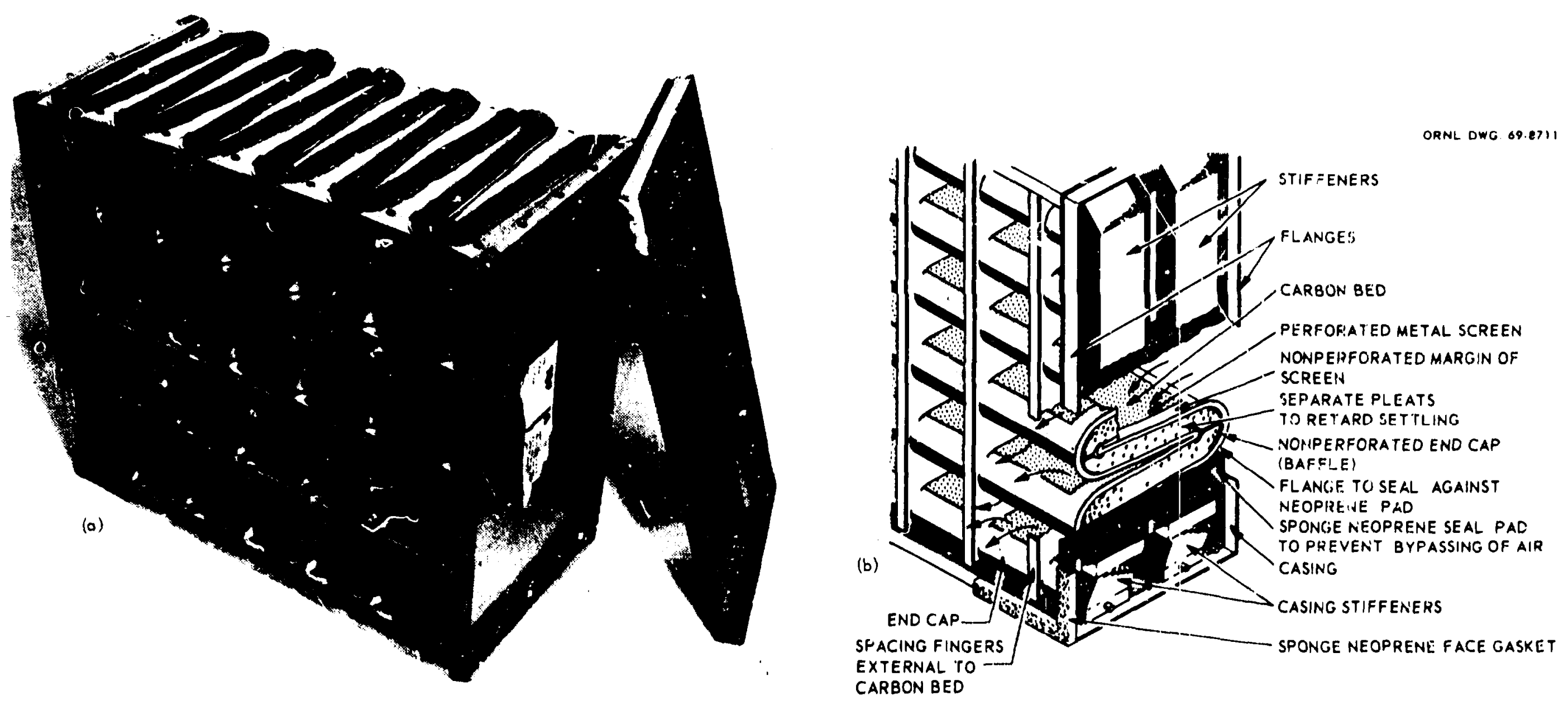

Figure 2. (a) Pleated-Bed Charcoal Adsorber. End plate removed. (Photgraph courtesy of Barnebey-Cheney Co.) (b) Cutaway of 1-in.-pleated-bed adsorber. 
approximately 4: pourds of charcoal and present about $8 \mathrm{ft}^{2}$ of face area. These units, ofte: called tray-type adsorbers, present a 2 inch depth of charcoal for the air :o pass through. Air enters the outside face, as showa by the arrows in Fig. 3, travels through the charcoal mass, into the void space between the charcoal layers, and firally into the exhaust plenum. In prac:ice, many of these units can be fitted, one above the cther, into a metal framework section, as illustrated in Fig. 4, and as many of these sections as needed can be aligned to form the desired adsorber system. Charcoal adsorber units of the tray type are generally utilized in off-gas systems contained in nuclear power reartors of both the BWR and PWR types.

\section{Containment Filter Systems}

A complete fil_er system which serves to remuve volatile fission products from containment air following an arcident can contain as many as four different types of filters or adsorbers. At the entrance to the system a demister unit may be employed to remove entrained water droplets which could be present in the containment atmosphere following a loss-ofcoolant type accident. These water droplets are removed to prevent waterblinding of the particle filtering media following the demister unit. Following the demister one may find a low efficiency particle filter referred to as a roughing or pre-filter. This unit serves to limit the buildup of particle deposits on the high efficiency particle filter (HFPA) units whici. follow. The charcoal adsorber units are usually located downstream of these HEPA units to remove (or decontaminate) the various forms of adioiodine. In some cases the charcoal adsorbers are followed by a second bank of HEPA filter units to trap any charcial containing radioiodine which may be blown from the adsorbers. of course, all these filter-adsorber units will tráp some of the released radioiodine and will be subjected to decay heating; however, the charcoal adscrber will be the only unit considered in this report.

$\mathrm{AEC}$ research and production reactors are provided with continuouslyoperating off-gas systems contained in widerground concrete cells or in separately-cont-ined aboveground enclosures; these systems exhaust to a gas disposal stack. An example of an underground filter-adsorber system for one AEC reactor is provided in Fig. 5. Nuclear power reactors of the 


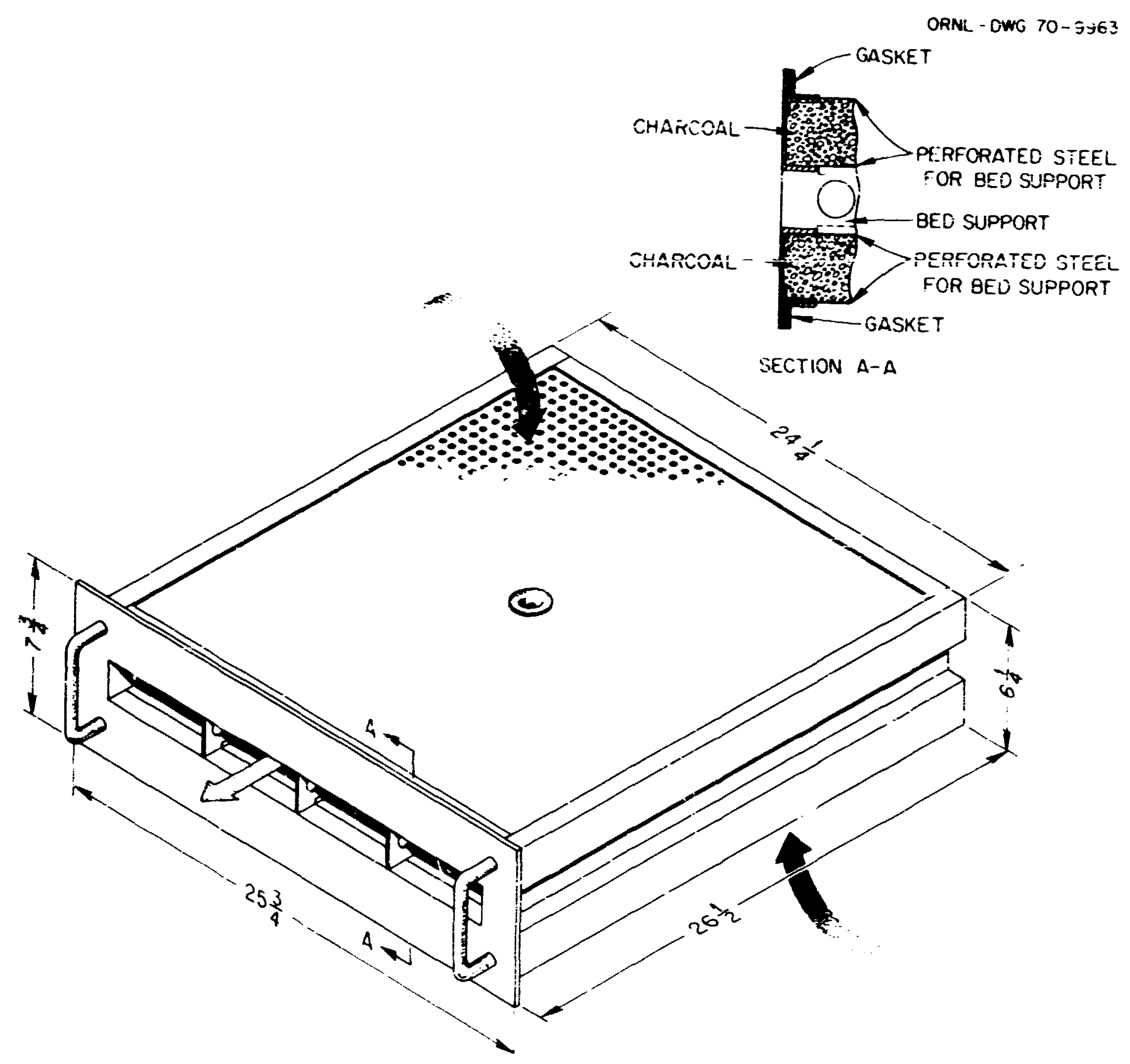

Figure 3. Tray-Type Charcoal Adsorber. 


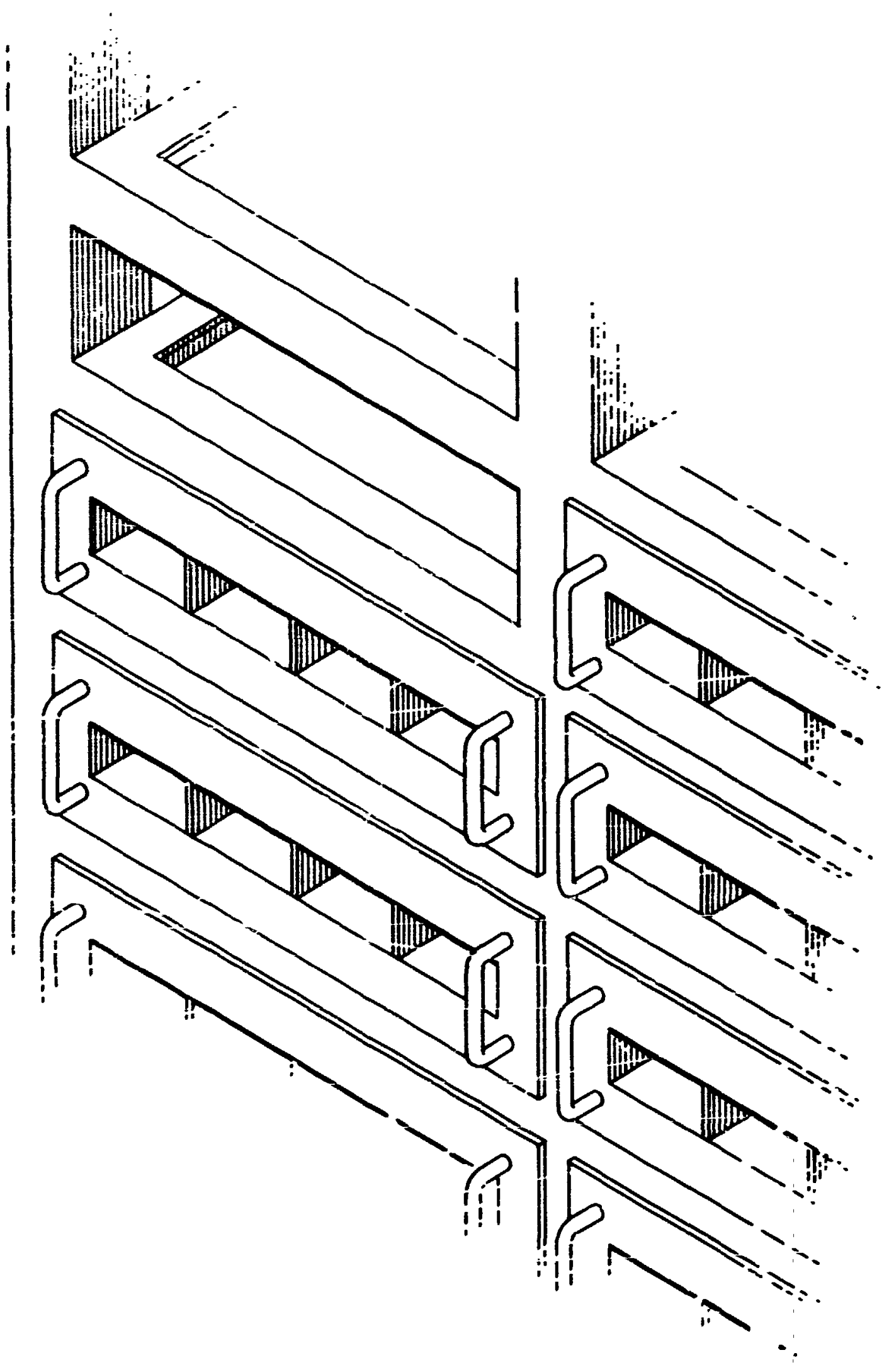

Figure 4. Assembly of Tray-Type Charcoal Adsorber. 


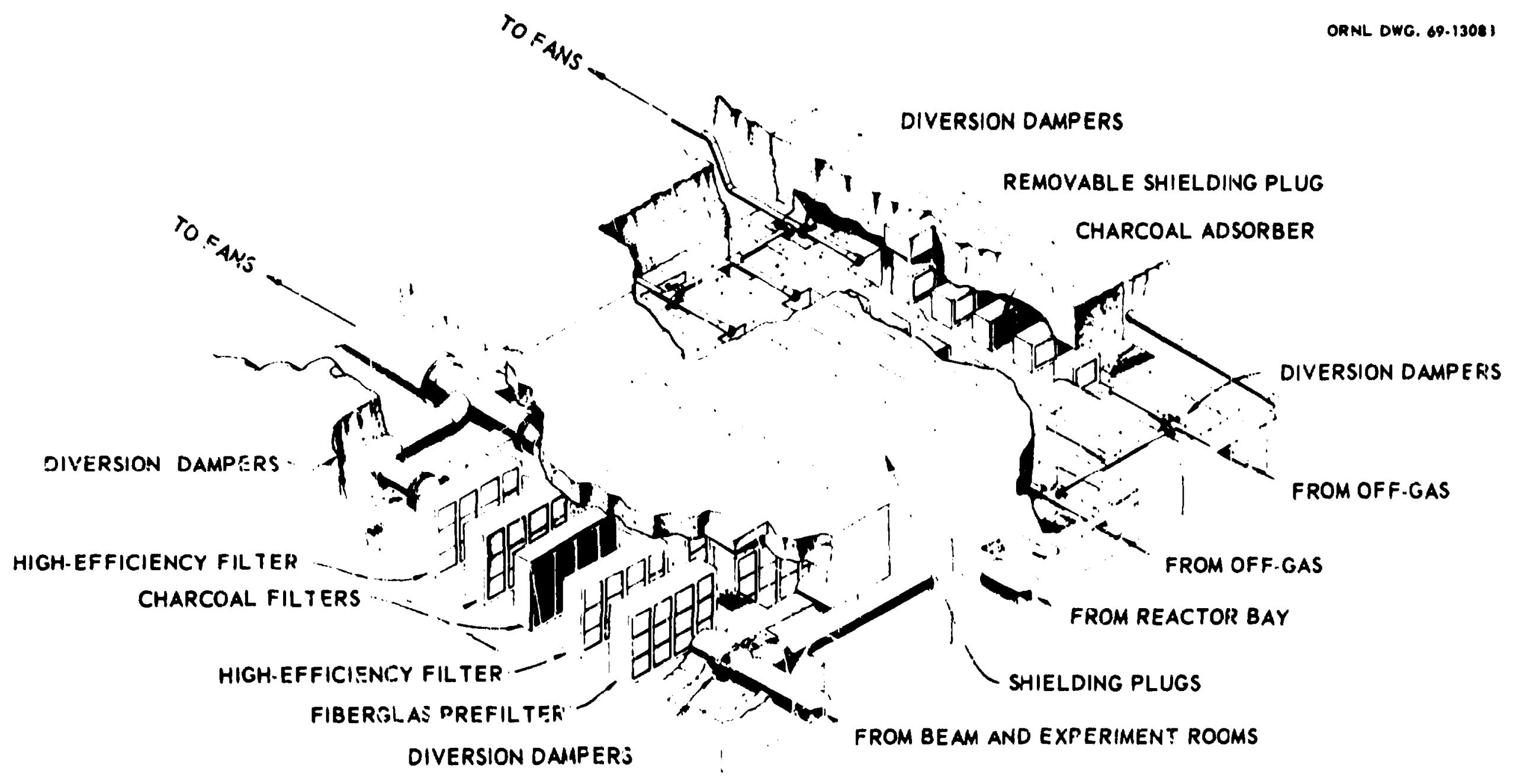

Figure 5. High Flux Isotope Reactor Filter System. 
boiling water type generally contained a standby filter system containing HEPA filter and charcoa? adsorbers and may contain a heating section for humidity contrel; these are singl:=-pass systems which exhaust to a stack. Sone power reactors of the pressurized wazer type contain recirculating fiiter systems with: $n$ the containment which include femisters, SEPA fiiter units and, in many cases, charcoal adsorbers; these systems exhaust back into containment. Containment gases are exhausted through a separate system to the siacli at some length of time after the accident.

Examples of all these systems along with construction details may be found elsewhere. 5

III. MATHEMATICAL BASIS FOR THE THERMAL ANALYSIS OF A CHARCOAL ADSORBER

In planning the development of the necessary calculational tools for making a thermal analysis of a charcoal adsorber, it was decided to start with a basic description of heat generation and heat loss founded on arcepted heat iransfer principles. The plan therefore was to define a matiematical model of the adsorber unit and then produce computer codes to facilitate the calculations. Values of physical parameters critical to the codes are to be measured in the laboratory in a concurrent effort.

The General Heat Balance Equation

The general heat balance performed on a unit volume of the charcoal mass assuming a:r flows in one direction only is

$$
\rho_{b} C_{p_{b}} \frac{\partial T_{b}}{\partial t}+\rho_{g} C_{p_{g}} v_{g} \frac{\partial T_{g}}{\partial x}=k_{b} \nabla^{2} T_{b}+q \cdots
$$

where

$T_{b}=$ temperature of the charcoal mass,

$T_{B}=$ temperature of the rooling gas,

$\rho_{b}, C_{P_{b}}=$ density and specific heat of the charcoal

$P_{g}, C_{P_{F}}=$ density and specific r.at of the cooling gas

$t=$ time 
$x=$ distance along the direction of cooling gas fiow

$v_{8}=$ velocity of cooling gas

$k_{b}=$ effective thermal conductivity of the charroal

$q^{\prime \prime \prime}=$ volumetric heat generation rate in the charcoal mass (heat per unit time per unit volwe)

and the operator

$$
\nabla^{2}=\frac{\partial^{2}}{\partial x^{2}}+\frac{\partial^{2}}{\partial y^{2}}+\frac{\partial^{2}}{\partial z^{2}}
$$

The first term on the left is the neat absorbed by the charcoai itself and the second term on the left is the heat absorbed by the cooling gas. The first term on the rigint is the heat diffused by conduction and the second term on the right is the heat source in the charcoal mass. The heat source depends on the nuclear characteristics of the isotopes adsorbed and is normaliy $a$ function of time and position along the $x$ directior: (gas flow direction). It exists only in the charcoal mass 1 tself and is

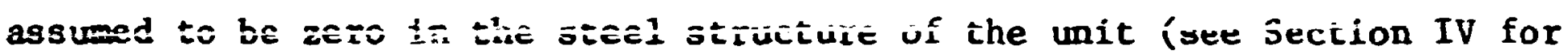
detailed expression of the heat source).

The heat alsontbed by the gas wiII depend on the capability of the charcoal particles to transfer heat to the gas flowing around theñ. The heat absorbed by the ias per unit volume of the bed can be expressed as

$$
S^{\prime \prime \prime}=h_{\text {eff }}^{\prime \prime \prime}\left(T_{b}-T_{g}\right)
$$

where

$S^{\prime \prime}=$ heat absorbed by the gas per unit volume of charcoal, Btu/min-i $\mathrm{c}^{3}$

$h=$ IIIm heat Lransfer coefficient between the surface of the charcoal particles and the gas flowing around them, Btu/min-in. ${ }^{2}{ }^{\circ} \mathrm{F}$

$A_{\text {eff }}^{\prime \prime \prime}=$ an effective surface area of the particles availabie for heat transfer for each unit volume of bed, $1 /$ in.

since $h$ and $A$ eff are characteristic to the charcoal mass and the cooling gas, we will let

$$
H=h A \text { eff }
$$

and we can write

$$
S^{\prime \prime \prime}=P_{8} C_{p_{8}} v_{g} \frac{d g}{d X}=H\left(T_{h}-T_{8}\right)
$$


where $H$ will be called the "voibmetric heat transfer coefficieat" between the charcoal mass and tìe cooling gas; its dimensions are Btu/inin-in. ${ }^{3}{ }^{\circ} F$. Substituting Eq. (4) into Eq. (1), we get

$$
\rho_{D} c_{p_{b}} \frac{\partial T_{b}}{\partial t}=k_{b} \nabla^{2} T_{b}+q^{\prime \prime}-H\left(T_{b}-T_{g}\right) \text {. }
$$

Equation (5), together with Eq. (4), is the basic equation for finding the temperature distribition in the charcoal adsorier.

The volumetric heat transfer coefficient, $H$; can be calculated approximately by using existing ccrraiations for heat transfer coefficient in packed adsorbers an evaluating the effective heat transfer area per unit volume of the adsorbent. However, the avaliable correlation for heat transfer coefficient in paciked arieurbers is not very reliable especially in the low gas flow range. Also, the free surface area of the charcoal particles actially in contact with the cooling gas cannot be evaluated with good accuracy. Therefore, experimental measurement of $F$ is usually needed. For a given charcoal adsorber the volumetric heat transfer ccefficient will be a function of the gas flow and the physical properties of both the gas and the charcoal. ( $A$ more detailed discussion on the volumetric heat transfer coefificient is given in Section IV).

\section{Simplified Machematical Models of Charcoal Adscider Unit}

In this work we considered three models of the charcoal adsorber wit, a general description for which has been given in Section II. One model considers the charcoal adsorber as an infinite one-dimensional slab of charcoal, 2 in. thick, with no heat loss to environmen: except by way of the flowing gas. This model will be referred to as the "Infinite slai". A second model considers a finite slab (the dimensions can be varied but the values used were $2 \mathrm{ft}$ by $2 \mathrm{ft}$ in cross section and $2 \mathrm{in}$. thick). Heat loss is to the flowing gas and by radiation and natural convection to the environment from the four vertical $2 \mathrm{ft}$ by $2 \mathrm{in.} \mathrm{side} \mathrm{faces} \mathrm{of} \mathrm{the}$ slab. This model will be referred to as the "3-dimensional slab." A third model represents a single tray-type charccal adsorber. It includes two charcoal masses ( $2 \mathrm{ft} \times 2 \mathrm{ft} \times 2 \mathrm{in}$. each) and the steel structure arsund them. 'leat ioss is to the flowing gas, to the environment and to the 
steal structure itself. This model will be referred to as the "jdimenstonal unit" model.

At Ira gas flows, or whan no flow is assumed, thc steel structure and heat loss to che environment both have a significant effect on the rasiirıng lemperature distribution, and therefore the "3-dimensional unit" andei should be used. Fny relatively high flows it can be assumed that the heat Inss tc the cooling gas is the dominating cooling effect and the "infinite slat" model can be used.

The temperature distritution for the "intinite slab" model was found by two separate methods, based on Eqs. (4) and (5). One method is analytical in its approach and the other is based on a general heat transfer computer code. Since for the "infi:iite slab", the gas velocities are assumed to he relatively high, the cooling gas temperature $\mathrm{T}_{\mathrm{g}}$ does not Iise much while penetrating the charcoal mass and can be considered to be constant. Letting

$$
T_{b}^{\prime}=T_{b}-T_{g}
$$

and recalling that in an infinite slab, conduction in the bed occurs only in the $X$ direction, will reduce Eq. (5) t,

$$
\hat{\sim}_{b} C_{P_{b}} \frac{\partial T_{b}^{\prime}}{\partial t}=k_{b} \frac{\partial^{2} T_{b}^{\prime}}{\partial x^{2}}+q^{\prime \prime \prime}-H T^{\prime}{ }_{h}{ }^{\prime}
$$

The boundary conditions are:

$$
\begin{aligned}
& \frac{\partial T^{\prime} b}{\partial x}=0 \text { for } x=0 \text { and any } i \\
& \frac{\partial T^{\prime}}{\partial x}=0 \text { for } x=\ell \text { and any } t \\
& T_{b}=I_{0} \text { for } c=0 \text { and any } x,
\end{aligned}
$$

where $x=0$ is the front face of the charcoal mass and $t=0$ is the time at which radioactive iodine first reaches the charcoal adsorbei. The analytical solution of tive "infinite slab" is based on Eq. (6) and is explatined in Section IV. The dtiallec solution and its computer program are given in Appendix A.

The second metincd used to calculate the temperature distribution in the "infinite slab" is based on a general heat transfer compuier code and takes into accolint the change in cooling gas temperature as it propagates 
through the charcoal mass. The basic equation to be solved is a onedimensional Form of Eq. (5) where $\mathrm{T}_{\mathbf{g}}$ is a function of temperature.

The "3-dimensional slab" and "3-dimensional unit" models must take into account the temperature changes in the cooling gas itself as well as heat transfer to the metal structure. Here, Eq. (5) must be used in its complete form coupled with $E_{\mathcal{q}}$. (4), 1.e.,

$$
\rho_{b} C_{n_{b}} \frac{\partial T_{b}}{t}=k_{b}: \frac{\partial^{2} T_{b}}{\partial x^{2}}+\frac{\partial^{2} T_{b}}{\partial y^{2}}+\frac{\partial^{2} T_{b}}{\partial z^{2}}+q^{\prime \prime}-H\left(T_{b}-T_{g}\right)
$$

where $T_{g}$ is given from Eq. (4) by

$$
\rho_{g} C_{P_{g}} v_{g} \frac{\partial T}{\partial x}=H\left(T_{b}-T_{g}\right) \text {. }
$$

The initial conditions are

$$
\begin{aligned}
& T_{g}=T_{0} \text { at } t=0 \text { and any } x, \\
& T_{b}=T_{0} \text { at } t=0 \text { and any } x
\end{aligned}
$$

The boundary condition for the cooling gas is

$$
T_{g}=T_{0} \text { for } x=0 \text { and any } t \text {. }
$$

The joundary conditions for the adsorber unit are complicated and will be best described in the illustrative case given in section V. The same general heat transfer computer code as used for the "infinite slab" is used to solve the "3-dimensional slab" model and a description of it is given in Section IV. This same code has the capability to solve the "3dimensional unit" model but that suiltion has not been performed.

\section{DEVELOPMENT OF COMPUTER CODES}

The transposition of the mathematical models, fust discussed, into computer codes is the subject of this section of the report. Relationships for the heat generation and heat transfer characteristics for charcoal masses were developed and then incorporated into the basic heat diffusion equations. Solucions were then developed and coded for the computer. 


\section{Heat Source}

Heat generation in the charcoal adsorber comes from beta and gamma activity resulting from the radicactive decay of fodine isotopes. Let $a_{i}$ and $g_{i}$ be the decay heat per thermal $M_{w}$ of reactor power produced by the ith isotope from beta and gamma activity, respectively. If the reactor power is $P(t)$ thermal 's, then the decay heat of the ith isotope will be $P(t) a_{i}$ and $P(t) g_{i} B t u / m i n$ for beta and gamma activity, respectively. Since only a certain fraction, $F$, of the radioactive material coming from the reactor is absorbed by the charcoal, the total decay heat in the charcoal bed itself will be

$F P(t)\left(a_{i}+g_{i}\right)$ Btu/uin.

The time dependent decay heat will be then

$$
\operatorname{PP}(t)\left(a_{i}+f_{g_{i}}\right) e^{-\lambda_{i}\left(t+t_{D}\right)} \text { Btu/min }
$$

where $\lambda_{i}$ is the decay constant of isotope $i, t_{D}$ is the time delay between end of fissioning and beginning of actud: adsorption, $f$ is the fraction of the gamma heat which does not escape the bed, and $t$ is time elapsed from beginning of actual adsorption. If the volume of the charcoal adsorber is $v_{b}$, then the average specific heat generation cue to radioactive decay in the bed is

$$
q_{i}^{\prime \prime \prime}(x)=\frac{F P(t)}{v_{b}}\left(a_{i}+f g_{i}\right) e^{-\lambda_{i}\left(t+t_{D}\right)} \text { Btu/min-in. }{ }^{3}
$$

However, since iodine concentration is not uniform along the depth of the charcoal mass, we will assume here an exponential distribution according to

$$
B(x)=\beta_{0} e^{-b x} \text { so that } \frac{1}{l} \int_{0}^{\ell} B(x) d x=1
$$

where $(x)$ is the ratio between local and average radioactive fodine concentration, $\beta_{0}$ is the ratio between maximum $(x=0)$ and average radioactive iodine concentration and $b$ is the attenuation factor. It 13 clear that

$$
1=\frac{1}{l} \int_{0}^{l} \beta_{0} e^{-b x} d x=\frac{\beta_{0}}{b l}\left(1-e^{-b l}\right) .
$$


Therefore

$$
\beta_{0}=b \ell /\left(1-e^{-b \ell}\right)
$$

where $\hat{x}$ is the thickness of she charceal mass.

The local radioactive iodine concentration tritn is

$$
B(x) a_{i}=R_{0} a_{i} e^{-b x}=\frac{b l a}{1-e^{-b l}} c^{-b x} .
$$

However, since $b$ is different for elemental iodine $\left(I_{2}\right)$ and methy? iodide $\left(\mathrm{CH}_{3} \mathrm{~L}\right)$, we must take their locai concentratiuns into account separately. Assuming $\beta_{1}$ and $\beta_{2}$ are the fractions of $\mathrm{I}_{2}$ and $\mathrm{CH}_{3} \mathrm{I}$, respectiveiy, we get by using Eqs. (9) and (10) that the local specific heat generation in the bed is

$$
\begin{aligned}
& q_{i}^{\prime \prime \prime}(x, t)=\frac{F P(t)}{v_{b}}\left[\left(\frac{\beta_{1} b_{1} l}{1-e^{-b_{1} \hat{l}}} e^{-b_{1} x}+\frac{\beta_{2} b f}{1-e^{-b_{2} l}} e^{-b_{2} x}\right) a_{i}\right. \\
& \left.+f g_{i}\right] e^{-\lambda_{i}\left(t+t_{D}\right)} \text { Btu/min-in. }{ }^{3} .
\end{aligned}
$$

Note that it was assumed that the gamma heating (indicated by the $\mathrm{fg}_{\mathrm{i}}$ term) is not position dependent, hence the te:n developed in Eq. (10) was not multiplied by $\mathbf{f}_{g_{i}}$ in Eq. (11). Let

$$
\begin{aligned}
& B_{1}=\frac{P(t)}{V_{b}} \frac{B_{1} b_{1} l}{1-e^{-b_{1} l}} \\
& B_{2}=\frac{P(t)}{V_{b}} \frac{\beta_{2} b_{2} l}{1-e^{-b_{2} l}} \\
& G=\frac{P(t)}{V_{b}} f
\end{aligned}
$$

and we get

$$
q_{i}^{\prime \prime \prime}(x, t)=F\left[\left(B_{1} e^{-b i_{1} x}+B_{2} e^{-b_{2} x}\right) a_{i}+G g_{i}\right] e^{-\lambda_{1}\left(t+t_{D}\right)} .
$$

Summing up the effect of a:.l the isotopes, we get

$$
\begin{aligned}
q^{\prime \prime \prime}(x, t)= & F\left[\left(B_{1} e^{-b_{1} x}+B_{2} e^{-b_{2} x}\right) \sum_{i=1}^{m} a_{i} e^{-\lambda_{1} e\left(t+t_{D}\right)}\right. \\
& \left.+G \sum_{i=1}^{m} g_{i} e^{-i_{i}\left(t+t_{D}\right)}\right] .
\end{aligned}
$$


If in addition we take into account that the loading of radioactive material onto the adsorbers is gradual as in the case $10 x$ recirculating adsorber systems accordiñ̄̃

$c=c_{0}\left(1-e^{-a R t / y}\right)$,

where

$C=$ amount of iodine on charcoal at time $t$

$C_{0}=$ initial amount of iodine in containment

$a=$ fraction of iodine removed from air as it passes through charcoal (assumed here to be 0.9 )

$\mathrm{R}=$ air flow rate, $\mathrm{ft}^{3} / \mathrm{min}$

$\mathrm{V}=$ volume of containment, $\mathrm{ft}^{3}$

$t=$ time elapsed from beginning of iodine adsorpticn by charcoal, Then

$$
\begin{aligned}
q^{\prime \prime}(x, t)= & F\left[\left(B_{1} e^{-b} 1^{x}+B_{2} e^{-b} 2^{x}\right) \sum_{i=1}^{m} a_{i} e^{-\lambda_{i}(t+t D)}\right. \\
& \left.+G \sum_{i=1}^{m} g_{i} e^{-\lambda_{i}\left(t+c_{D}\right)}\right]\left(1-e^{-(a k / V) t}\right)
\end{aligned}
$$

where

$q^{\prime \prime \prime}(x, t)=$ heat generation rate per unit volume of chazcoal bed

$x=$ distance from front face of charcoal bed in direction of gas flow

${ }^{t}=$ time delay between end of fissioning and beginning of iodine adsorption.

$\mathrm{b}_{1}=$ attenuation coefficient for elemental iodine

$\mathrm{b}_{2}=$ attenuation coefficient for methyl iodide

$F=$ fraction of total iodine adsorbed by the charcoal filter

$B_{1}, B_{2}$ and $G$ are given in Eqs. (12), (13), and (14), respecitively.

In those equaiions

$P(t)=$ reactor power in $\mathrm{Mw}(t)$

$v_{b}=$ volume of charcoal bed

$\ell=$ thickness of charcoal layer

$(1-f)=$ fraction of gamma rays escaping from charcoal mass without capture

$\beta_{1}, \beta_{2}=$ fractions of iodine and riethyl iodide, respectively.

$a_{i}, g_{i}, \lambda_{i}=$ see Table $D-3$, Appendix $D$. 
A computer program was written for the heat generation rate per unit voiume, based on Eq. (17). The progran is written in XTRAN shich is a version of Fortran IV for the time-sharing computer of Com-Share Company. A listing of this program appears in Appendix B. The program will output the mininum, (at $x=2.0$ in.), the maximum (at $x=0.0$ ), and the average heat generation rates per unit volume as well as the total heat generation rate for the adsorber as functions of time.

\section{Charcoal Characteristics}

In order to perform heat transfer calculations in packed adsorbers, one must know adsorbent characteristics like shape, porosity, sphericity and mean dianeter of the particles. The porosity in this case is not concerned with internal cavities of the charcoal particles, but only with the void space between the solid particles in packed array. Porosity is defined as volume of void space divided by the totai volume of the adsorbent container. Sphericity is defined as the surface area of a sphere having a volume equal to that of the particle divided by the surface area of the particles. Values for these and other parameters will be given in Section $V$.

\section{Volumetric Heat Transfer Coefficient}

In Section III it was shown that the cooling process in adsurbers can be visualized as a volumetric heat sink which can be expressed from Eqs. (2) and (4) as

$$
S^{\prime \prime \prime}=h A_{\text {eff }}^{\prime \prime \prime}\left(T_{b}-T_{g}\right)=H\left(T_{b}-T_{g}\right) \text {. }
$$

It was emphasized in Section III that some correlations do exist in the literature for calculating the film heat transfer coefficient $h$, but that they are not very reliable and are usually derived for high Reynolds numbers. In addition, the surface area actually available for heat transfer is not typical for all adsorbers, and it is difficult to estimate it. Experimental work was needed then to evaluate the volumetric heat transfer coefficient, $H$, for charcoal adsorbers. Such work is being accomplished and will be reported separately. In order to have some approximate values for use here, an analytical approach was used.

If $\omega$ is the percentage of adsorbent particle area which is actually available for heat transfer, the volumetris heat transfer coefficient can be expiessed as 


$$
H=h A_{\text {eff }}^{\prime i}=h \frac{A_{P}^{N i}}{V_{E}^{N I}\left(\frac{I}{1-d}\right)}=h i \cdot(1-d) \frac{A_{p}}{V_{F}}
$$

where

$h=$ film heat transfer coefficient from the particle surface to the gas, Btu/hr-ft ${ }^{2}-{ }^{\circ} \mathrm{F}$

$\omega=$ percentage of area actually available to heat transfer

$\exists=$ bed porosity

$A_{p}=$ one particle surface area, $\mathrm{ft}^{2}$

$\mathrm{v}_{\mathrm{p}}=$ one particle volume, $\mathrm{ft}^{\overline{3}}$

$\mathbb{N}=$ number of particles per unit volume of bed

$\mathrm{H}\left(\mathrm{Bt} \mathrm{u} / \min -\mathrm{in} .{ }^{3}-{ }^{\circ} \mathrm{F}\right)=9.65 \times 10^{-6} \mathrm{H}\left(\mathrm{Btu} / \mathrm{hr}-\mathrm{ft}{ }^{3}-^{\circ} \mathrm{F}\right)$.

In order to evaluate $H$ we must find the heat transfer coefficient ( $h$ ) between the particle surface and the gas. References 6-9 suggest possible correlations to be used. The one given by Coppage ${ }^{\hat{9}}$ seems to be most adaptable to our case although like the other three correlations, its applicability is for higher flows than the ones we are interested in. Nevertheless, it wall be used as an approximation for the cases discussed in this repori. The correlation for the range $6<\mathrm{G} / \mu \mathrm{A}<13,000$ i.s

$$
h={ }_{i}^{E G C} P_{\underline{r}}^{-2 / 3}(4 \hat{G} / \mu A)^{-m}
$$

where

$$
\begin{aligned}
& C_{p}=\text { specific heat, Btu/lb- }{ }^{\circ} \\
& G=W / S, 1 h / h r-f t^{2} \\
& W=\text { total flow, lb/hr } \\
& S=\text { total cross section area of the bed, } \mathrm{ft}^{2} \\
& A=\text { total particle surface per unit volume of bed } \\
& =\frac{A}{V}(1-x), 1 / f t \\
& \operatorname{Pr}=\text { Prandt } 1 \text { number of gas } \\
& L=\text { dynarte viscosity of gas, } 1 b / h r-f t \\
& E, m=\text { constarts which are functions of } d .
\end{aligned}
$$




\section{Computer Codes}

\section{ENIS Code}

The partial differential equation for the "infinite slab" model and the corresponding toundary conditions assumed are given in Eq. (6). The heat generation $\mathrm{q}^{\prime \prime}$ is given in Eq. (15). To solve ti:is Dartial differential equation a change of variables was made so that:

$$
T_{b}^{\prime}(x, t)=\dot{y}(x, t) e^{-\alpha(h / k) t}\left(=T_{b}-T_{g}\right)
$$

where $a=k_{b} / \hat{p}_{b} C_{p_{b}}$. This reduces Eq. (6) to

$$
\frac{\rho C_{p}}{a} \frac{\partial \psi(x, t)}{\partial t}=k_{b} \frac{\partial^{2} \psi(x, t)}{\partial x^{2}}+A(x, t)
$$

where

$$
A(x, t)=\left(B_{1} e^{-b_{1} x}+B_{2} e^{-b} 2^{x}\right) \sum_{i=1}^{m} a_{i} e^{-\beta_{i} t}+G \sum_{i=1}^{m} g_{i} e^{-B_{i} t}
$$

and

$$
\beta_{i}=\lambda_{i}-\alpha\left(\mathrm{H} / \mathrm{k}_{\mathrm{b}}\right)
$$

and the boundary conditions become

$$
\begin{aligned}
& \frac{\partial \psi}{\partial x}(0, t)=0 \text { at } x=0 \\
& \frac{\partial \psi}{\partial x}(\ell, t)=0 \text { at } x=\ell \\
& \psi(x, 0)=0 \text { at } t=0 .
\end{aligned}
$$

By using efther Green's theorem or Fourier cosine series expansion, an analytical solution of Eq. (22) is achieved (see Appendix A for details) in the form 


$$
\begin{aligned}
& T_{b}^{\prime}(x, t)=\left\{-\frac{a}{k_{b}}\left(\frac{B_{1}}{b_{1}}\left(1-e^{-b} 1^{\hat{\chi}}\right)+\frac{B_{2}}{b_{2}}\left(1-e^{-b_{2} \ell}\right)\right\} .\right. \\
& \sum_{i=1}^{m} \frac{a_{i}}{B_{i}}\left(e^{-\lambda_{1} t}-e^{-\alpha(x / k) t}\right)-\frac{c}{i}(G) \cdot \sum_{i=1}^{m} \frac{g_{i}^{\prime}}{B_{i}}\left(e^{-\lambda_{1} t}-e^{-(\alpha H / k) t}\right\}+
\end{aligned}
$$

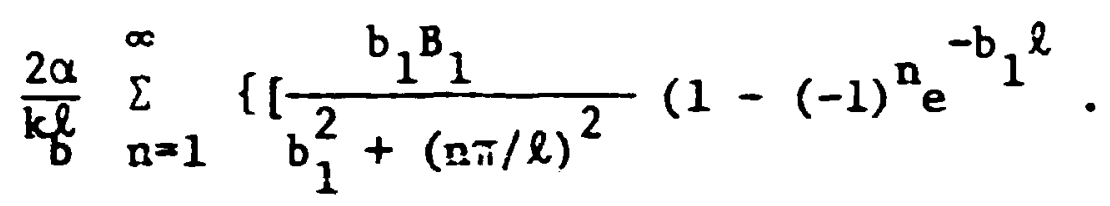$$
\left.+\frac{b_{2} B_{2}}{b_{2}^{2}+(n \pi / 2)^{2}}\left(1-(-1)^{n} e^{-b_{2} l}\right)\right] \cos (n \pi x / l) .
$$$$
\left.\sum_{i=1}^{m} a_{i}\left[\frac{e^{-\lambda i t}-e^{-\alpha(n \pi / l)^{2}}+\left[\left(H / k_{b}\right)\right] t}{a(n \pi / l)^{2}-\beta_{i}}\right]\right]
$$

Tc facilitate the use of this solution it was programmed in Fortran IV. Later the code was expanded to include the time delay parameter and also to allow the change of the volumetric heat transfer coefficient, $H$, with time. A plocting routine was also incorporated in the program.

The computer code is a numerical expression of Eq. (23) with some additional capabilities added to it. It will accept as input data the constants $B_{1}, B_{2}$, and $G$ appearing in the heat genexation term, the volumetric heat transfaz coefficient, $H$ (which can be changed five times during a singie run), the time delay between end of fission and beginning of lodine adsorption fin adsorbers, the locations for which printouts of temperature are desired, the time intervals for surh printouis and the option to get a plot of the maximum temperature versus time. The computer code, its listing, an outp!t sample and an input format tabie are given in Appendix A.

This code was used eaciy in the program to study the several variables; its applicability was limited to gas velocilies of $40 \mathrm{ft} / \mathrm{min}$ and up because of the restriction of keaping the temperature of the gas constant. This deficiency led to the development of a more exact code discussed in the next subsection. 


\section{CHART Codes}

The CHART cod's was jeveloped to solve the 3-dimenstonai rodels as discussed in sosica 3 . Tivis model is described mathematically by Eqs. (7) and (8). Such a model is too complicated to be solved analytically. A general heat transfer computer code, named HEATING-2 ${ }^{10}$, and its modified version, HEsrrvG-3 ${ }^{11}$, were found, aftar some modifications, to be most suitable for our purpose.

The HEATING heat transfer code is a general transient 3-dimensional code urftten in Firtran IV language for the IBM 360 computer system. It can accept both rectangular and cylindrical geometry. It solves the steady state problems by the "extrapolated Liebamann method" and the transient probiess by first foward time difference $t \pi$ the "explicit method". Thermal properties can be temperature dependent. It can handle as many as 8000 lattice points, 100 regions, 50 materials and 50 joundary sonditions. It can handle nonlinear boundary conditions (natural convection or radiation heat transfer) as well as linear ones (forced convection). It will handle problems with heat transfer from surface to surface (like in radiation from one slab to another). The heat generation in each region can be a fuiction of position and/or time. It also has an acceleration procedure to reduce computer time without the code becoming unstable. It has a nodal generator, which means that only region coordinates must be supplied and the program generates the required nodes with their geometrical and thermal properties. The input required is generally simple (see Ref. 10 for input procedures.)

Any general heat transfer computer code for conduction is based on solving numerically the diffusion partial differential equation in the form

$$
\alpha_{p}(\partial T / \partial t)=k \nabla^{2} T+Q^{\prime \prime \prime}
$$

with the corresponding boundary condiclons. Heat transfer by convection can be taken into account on the boundaries only. Also the heat gersation. term $Q^{\prime \prime \prime}$ can normally be taken into account as a function of position and time. In the case of HEATING3 this dependerce had the form of

$$
q^{\prime \prime \prime}(X, Y, Z, t)=F_{1}(X) F_{2}(Y) F_{3}(Z) F_{4}(t)
$$

where $F_{1}(X), F_{2}(Y)$, and $F_{3}(Z)$ are each a position dependent function of one coordinate and $F_{4}(t)$ is a time dependent function defined by a set of points (a table). 
If we compare Eq. (24) to Eq. (7) which is the one we wart to solve, we see that

$$
Q^{\prime \prime \prime}=q^{\prime \prime \prime}-H\left(T-T_{8}\right)
$$

where $q^{\prime \prime \prime}$ is given by Eq. (17) and $T_{g}$ must be solved from Eq. (8). It can be seen that (a) the heat generation term $Q^{\prime \prime \prime}$ is a function of temperature as well as of position and time and (b) the heat generation term has a very complicated form which cannot be expressed in the form of Eq. (25).

In order to inciude those capabilities a number of subroutines in HEATING3 have beer. modified and the final version has been called "CHART". Subroutine THRMPR has been modified so that it will call the heat generation subrcutine GENFN not more than twice for each node, will do it for every time step and wil? include in its calling arguments list the current time and temperature. Having that capability, the heat generation subroutine GENFN was rewritten so that the heat generation term can be expressed by any analytical function of position, time, and temperature. Currently Eq. (17) is used for the heat generation cerm. The subroutine also calculates the cooling gas temperature as function of temperature along the flow direction (based on Eq. 8) and feeds the result into the heat generation term (Eq. 26). Through the use of this technique it is possible to handle adsorber problems which are combined conduction and convection problems, using a basically heat conduction computer code. Inserting Eqs. (17) and (8) Into the HEATING3 code changed the criteria which must be met in order to prevent instabilities. The largest tiwe step allowed for stabflity became somewhat smaller and in addition an upper limit exists for the element size in the cooling gas flow direction.

Subroutines "CALQLT" and "HGNFN" of HEATING3 were modified to include those new criteria for stability; the criteria are described in Appendix $C$. Additional modifications have been made to accept and print the appropriate input data in the "MAIN" program.

In addition to the regular capabilities of HEATING 23 described in Reference 11 the CHART code can handle the following variables:

1. The power constants $B_{1}, B_{2}$ and $G$ and atceruation coefficients $b_{1}$ and $b_{2}$ appearing in Eq. (17). 
2. The fraction of total iodine adscrbed by the charcoal filters.

3. The inlet temperature of the cocling gas and its physical properties.

4. The location of the charcoal slab as related to the overall coordinates of the syste=.

5. The loading rate of the lodine on the adsorbers. A large value will impose an "instantaneous loading".

6. The time delay between end of fissioning (shutdown) and beginning of actual iodine adsorption.

7. The velocity of the cooling gas at the beginning of lodine adsorption and at the time when $95 \%$ of the lodine has been absorbed. This gives the flexibility of having normal conditions all the time, accidental conditions (blower slowdown) right from the beginning, or accidental conditions only after $95 \%$ of the iodine is already loaded on the adsorbers.

8. The isotopes constants $a_{i}, g_{1}$, and ' $i$ appearing in Eq. (17). The CHARI code can be used in three ways:

CHART A - Used to compare results with output from ENIS code for the "Infinite Slab" model. By inserting an arbitrary large value (like $10^{5}$ ) for the heat capacity of the cooling gas the code will not allow the temperature of the gas $T_{8}$ to change.

CHART B - Ised for calculations with the "Infinite Slab" and the "3-dimensional slab" models. True heat capacity for the cooling gas must be used.

CHART C - ised with the "3-dimensional unit" model. The code will define the charcial $s 1 a b$ and the metal structure around it. Accual cooling gas temperature will then be taken inte account. A trial run has been run for the "3-dimensional unit" model and it seems to be vorking well. However, jecause of the large number of nodes and their small size, the tirse increment required for stability becomes very small (about $3.0 \times 10^{-3} \mathrm{~min}$ ), and the computer-time to actual-time ratio became very large (about 26). Even by use of the acceleration capabilities of the modifled method 
wethod (see Ref. 10) a complete run of this case requires an inordinate amoust of time. Some modifications are needed to reduce the iength $=f$ such a calculation.

\section{APPLICATION OE COMPUTER CODES}

To illustrate the application of the codes one must first place values on such critical parameciers as heat generation, heat transfer coefficients, and charcoal characteristics and then define typical reactor systems for scudy. Examples will be given to illustrate the appiicability of the codes to recirculating adsorber systems similar to those utilized with power reactors of the pressurized-water type and alsc to once-through adsorber systems of the type utilized by power reactors of the boilingwater types and by AEC reactors using the negative pressure containment concept.

\section{Heat Generation by Decay of Radioiodine}

The equilibrium quantities of the various isotopes of lodine contained in the fuel of a power reactor are substantial. When significant quantities of these isotopes are assumed to be adsorbed on the charcoal surfaces then the heating load is considerable. This heat is senerated as a result of the absorption by the charcoal cf the kinetic energy of the products of radioactive decay: the beta particles and the sauma photons. The amount of heat produced w:1l, of course, be a function of the quantity of fodine isotopes which have been adsorbed and this quantity wi11 depend upon the quantity avaiiable in the fuel for release at the time of the accident.

Isotopes of lodine are formed as a result of fission of ${ }^{235} \mathrm{U}$ as well as through the decay of isctopes of teilurium; depending upon the specific application both modes of production may have to be considered. Both lodine and tellurium are released from molten fuel to about the same extent $^{12}$ bi:t the tellurium may subsequently be adsorbed or react in such a way as will preclude 311 of the lodine produced by its decay from reaching the charcoal. Consequently, when considering the heat geveration in charcoal 
adsorbers a decision must be made as to what fraction of the iodine (mainly ${ }^{134} \mathrm{I}$ ) produced by decay of tellurium (after reactor shutdown) should be included as part of the heating source. An example of the magnitude of this effect is included in the example subsection which follows.

Equilibrium quantities of the isotopes of iodine at time of reactor shutdown and at various times of decay thereafter were calculated and the results appear in Table 1 ; in this listing the amounts of iodine produced by decay of tellurium isotopes after reactor shutdown were included. However, in the examples which follow we did not consider the "growing-in" of iodine after shutdown and assumed that the amounts of radioiodine isctūpes present at reactor shutdown represent the maximum quantity of heat producing material available for deposit on the charcoal adsorbers. The fission product loading is reduced by limited release of iodine from the fuel, by plateout, and by radiodecay as the isotopes travel from the fuel to the adsorbers; a significant amount of time and plateout could to involved in this travel.

It is most difficult to define the exact quantity of radioiodine that will be released from the fuel in an accident situation and the fraction of that amount which will plateout on surfaces; therefore it is the custom to assume, for a safety analysis, that $25 \%$ of the fuel inventory of the iodine will appear in the containiment for adsorption onto the charcoal and further, that the isotcpes travel from the fuel without decay. Decay neating is allowed to start when the isotope is adsorbed on the charcoal surface.

The assumption concerning decay time places a large burden on the adsorbers since the iodine inventory is reduced very rapidly over the first few mirutes following shutdown. Various estimates ranging from tenss of minutes to several hours can be made of the length of time from shutjown until arrival of lodine at the adsorber. In the examples that follox, some allowances will te made for decay prior to adsorption on the charcoal. The effect of decay on the iodine quantity values is also illustrated in: Table 1 where decay up to 200 minutes is considered.

In Table 2, the curies of fodine at shutdown have been converted into watts of decay power per $M(t)$ of reactor power; values are contained 
Table 1. Radioactive Iodines Produced In a neactor, Curies/Mw(t) of Reactor Power Nuclide Radioactivity, Curies/Mw(t) of Reactor Power

\begin{tabular}{|c|c|c|c|c|c|c|}
\hline Isotope & Shutdowra & $20 \mathrm{~min}$ & $40 \mathrm{~min}$ & $60 \mathrm{~min}$ & $80 \mathrm{~m} n$ & $100 \mathrm{~m} 1 \mathrm{n}$ \\
\hline $\begin{array}{l}I-128 \\
I-129 \\
I-130 \mathrm{~m} \\
I-130 \\
I-131 \\
I-132 \\
I-133 \\
I-134 \\
I-135 \\
I-136 \\
I-137 \\
I-138 \\
I-139\end{array}$ & 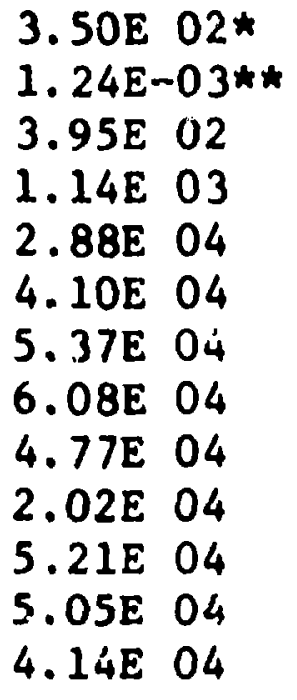 & 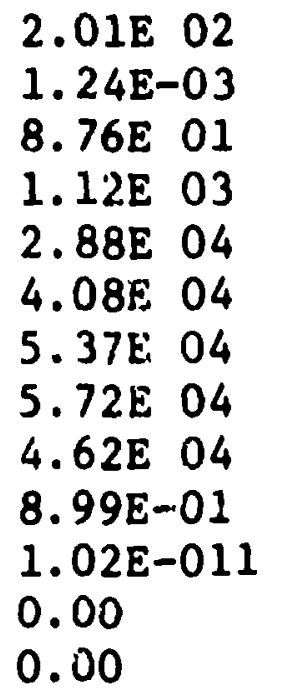 & $\begin{array}{ll}1.15 E & 02 \\
1.24 E & 03 \\
1.94 E & 01 \\
1.10 E & 03 \\
2.88 E & 04 \\
4.07 E & 04 \\
5.37 E & 04 \\
5.16 E & 04 \\
4.46 E & 04 \\
3.99 E-05 \\
0.00 \\
0.00 \\
0.00\end{array}$ & $\begin{array}{ll}6.62 \mathrm{E} & 01 \\
1.24 \mathrm{E}-03 \\
4.30 \mathrm{E} & 00 \\
1.08 \mathrm{E} & 03 \\
2.88 \mathrm{E} & 04 \\
4.06 \mathrm{E} & 04 \\
5.31 \mathrm{E} & 04 \\
4.5 \mathrm{IE} & 04 \\
4.31 \mathrm{E} & 04 \\
1.77 \mathrm{E}-09 \\
0.00 \\
0.00 \\
0.00\end{array}$ & $\begin{array}{ll}3.80 \mathrm{E} & 01 \\
1.24 \mathrm{E} & -03 \\
9.53 \mathrm{E} & -01 \\
1.06 \mathrm{E} & 03 \\
2.88 \mathrm{E} & 04 \\
4.05 \mathrm{E} & 04 \\
5.27 \mathrm{E} & 04 \\
3.85 \mathrm{E} & 04 \\
4.16 \mathrm{E} & 04 \\
7.89 \mathrm{E}-14 \\
0.00 \\
0.00 \\
0.00\end{array}$ & $\begin{array}{ll}2.18 E & 01 \\
1.24 E & 03 \\
2.11 E-01 \\
1.04 E & 03 \\
2.88 E & 04 \\
4.04 E & 04 \\
5.23 E & 04 \\
3.24 E & 04 \\
4.02 E & 04 \\
0.00 & \\
0.00 & \\
0.00 & \\
0.00 & \end{array}$ \\
\hline Total & $3.98 \mathrm{E} \quad 05$ & $2.28 E \quad 05$ & $2.20 \mathrm{E} 05$ & $2.12 E \quad 05$ & $2.03 E 05$ & $1.95 \mathrm{E} 05$ \\
\hline
\end{tabular}

* In all tables this shocthand method of density powers of ten will be used; this ualue ls read as $3.5 \times 10^{2}$ or 350 .

* This value 18 read as $1.24 \times 10^{-3}$ or 0.00124 . 
Table 1, Continued

\begin{tabular}{|c|c|c|c|c|c|c|}
\hline Isotope & Shut down & $120 \mathrm{~min}$ & $140 \mathrm{mIn}$ & $160 \mathrm{~min}$ & $180 \mathrm{~m} 1 \mathrm{n}$ & $200 \mathrm{~m} 1 \mathrm{n}$ \\
\hline$I-128$ & $3.50 E$ O2. & $1.24 \mathrm{E} 01$ & $7.20 E 00$ & $4.14 \mathrm{E} 00$ & $2.38 E 00$ & $1.36 \mathrm{E} 00$ \\
\hline$I-129$ & 1. $24 \mathrm{E}-03 * t$ & $1.24 E-03$ & $1.24 E-02$ & $1.24 E-03$ & $1.24 E-03$ & $1.2 .4 \mathrm{E}-03$ \\
\hline$I-130 m$ & $3.95 \mathrm{E} 02$ & $4.68 \mathrm{E}-0 . ?$ & $1.00 F .03$ & $2.30 \mathrm{E}-03$ & $5.09 E-04$ & $1.23 E-04$ \\
\hline$I-130$ & $1.14 E_{03} 03$ & $1.02 \mathrm{E} 03$ & 1.0450 .3 & $9.83 E \quad 02$ & $9.65 E \quad 02$ & $9.47 \mathrm{E} 02$ \\
\hline$I-131$ & $2.88 \mathrm{E} \quad 04$ & $2.87 E 04$ & $2.87 E 0.4$ & $2.87 E 04$ & $2.87 E \quad 04$ & $2.86 \mathrm{E} \quad 04$ \\
\hline$I-132$ & $4.10 E 04$ & $4.03 \mathrm{E} \quad 04$ & $4.01 E 04$ & $4.00 \mathrm{E} 04$ & $3.99 E 04$ & $3.98 \mathrm{E} \quad 04$ \\
\hline$\therefore-133$ & $5.37 E 04$ & $5.18 \mathrm{E} 04$ & $5.14 \mathrm{E}, 04$ & $5.09 \mathrm{E} \quad 04$ & $5.04 E 014$ & $4.98 \mathrm{E} \quad 04$ \\
\hline $1-134$ & $6.08 \mathrm{E} \quad 04$ & $2.70 E 04$ & $2.25: 04$ & $1.81 E 04$ & $1.47 E 04$ & $1.18 \mathrm{E} 04$ \\
\hline$I-135$ & $4.77 \mathrm{E} \quad 04$ & $3.89 \mathrm{E} \quad 04$ & 3.765 .04 & $3.63 \mathrm{E} \quad 04$ & $3.51 \mathrm{E} 04$ & $3.39 E 04$ \\
\hline$I-136$ & $2.02 \mathrm{E} 04$ & 0.00 & 0.00 & 0.00 & 0.00 & 0.00 \\
\hline $1-137$ & $5.21 E 04$ & 0.00 & 0.00 & 0.00 & 0.00 & 0.00 \\
\hline$I-138$ & $5.05 \% 04$ & 0.00 & 0.00 & 0.00 & 0.00 & 0.00 \\
\hline$I-\llcorner 39$ & $4.14 E 04$ & 0.00 & 0.00 & 0.00 & 0.00 & 0.00 \\
\hline Tol al & $3.98 E \quad 05$ & $1.88 \mathrm{E} 05$ & $1.81 \mathrm{E} 05$ & $1.75 E \quad 0.5$ & $1.75 E \cap 5$ & $1.65 \mathrm{E} 05$ \\
\hline
\end{tabular}


Table 2. Constants for Iodine Isotopes Produced in a Reactor

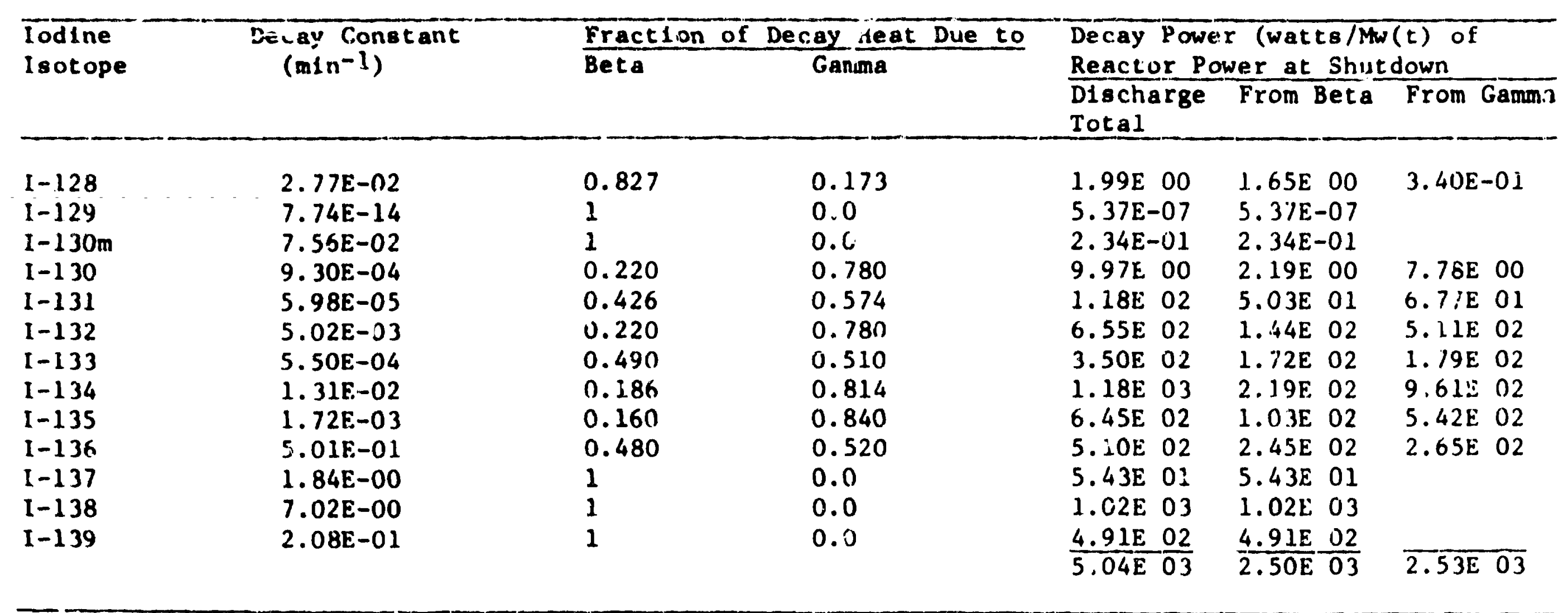


which represent contributions from both beta and gamma enissions; the ertire beta and gamma energy is assumed to be converted into heat. The effect of decay time on decay heating is 1llustrated in Fig. 6 which includes iodine produced by decay of tellurium.

\section{Charcoal Parameters}

As noted in Section IV values for certain charcoal parameters or characteristics are needed to perform heat transfer calculations in adsorber units. One must know values for châacteristics such as shape, porosity, sphericity and mean diameter of the particles. The porosity in this case is not concerned with internal cavities of the charcoal, only with the void space between the particles when in packed array; porosity is defined as volume of void space divided by the total volume of the container. Sphericity is defined as the surface area of a sphere having a volume equal to that of the particle divided by the surface area of the particle. The bed porosity for $8 \times 1 \mathrm{l}$ mesh (U.S.) charcosl particles will be somewhere between 0.38 and 0.45 while the sphericity will be between 0.70 and 0.80 .

on examination of a sample batch of charcoal, the particles seem to be prisnatic in form with a.a.2a as a falrly representative shape. This shape has a sphericity of 0.767 . This particular sample has a porosity estimated to be acout 0.43 . This figure will probably yaxy no more than $10 \%$ from batch to bat cin.

One cubic centimeter was found to contain 278 particles. With a vold fraction of porosity of 0.43 this resuits in a particls voiume of $0.002050 \mathrm{~cm}^{3}$ or $0.0001251 \mathrm{in.}^{3}$. One particie plus the vold or interstitial space occupies $0.0002195 \mathrm{in}^{3}$. The mean diarseter, which is the dianeter of a sphere having same volume as an average particle, is equal then to $0.06205 \mathrm{in.}$, which compares favorably with a screen analysis, indicating an average particle diameter of $0.0504 \mathrm{in}$. If the particle has a prisiatic shape of a.a.2a as previously assumed, tine volume is $2 a^{3}$ and $a=0.03970$ in. The total area of this representative particle is $10 \mathrm{a}^{2}$ or $0.01576 \mathrm{in}^{2}$. The effective heat transfer area in the bed will be of course 1 ess than this. The above characteristics will be used in any calculation made in this report. 


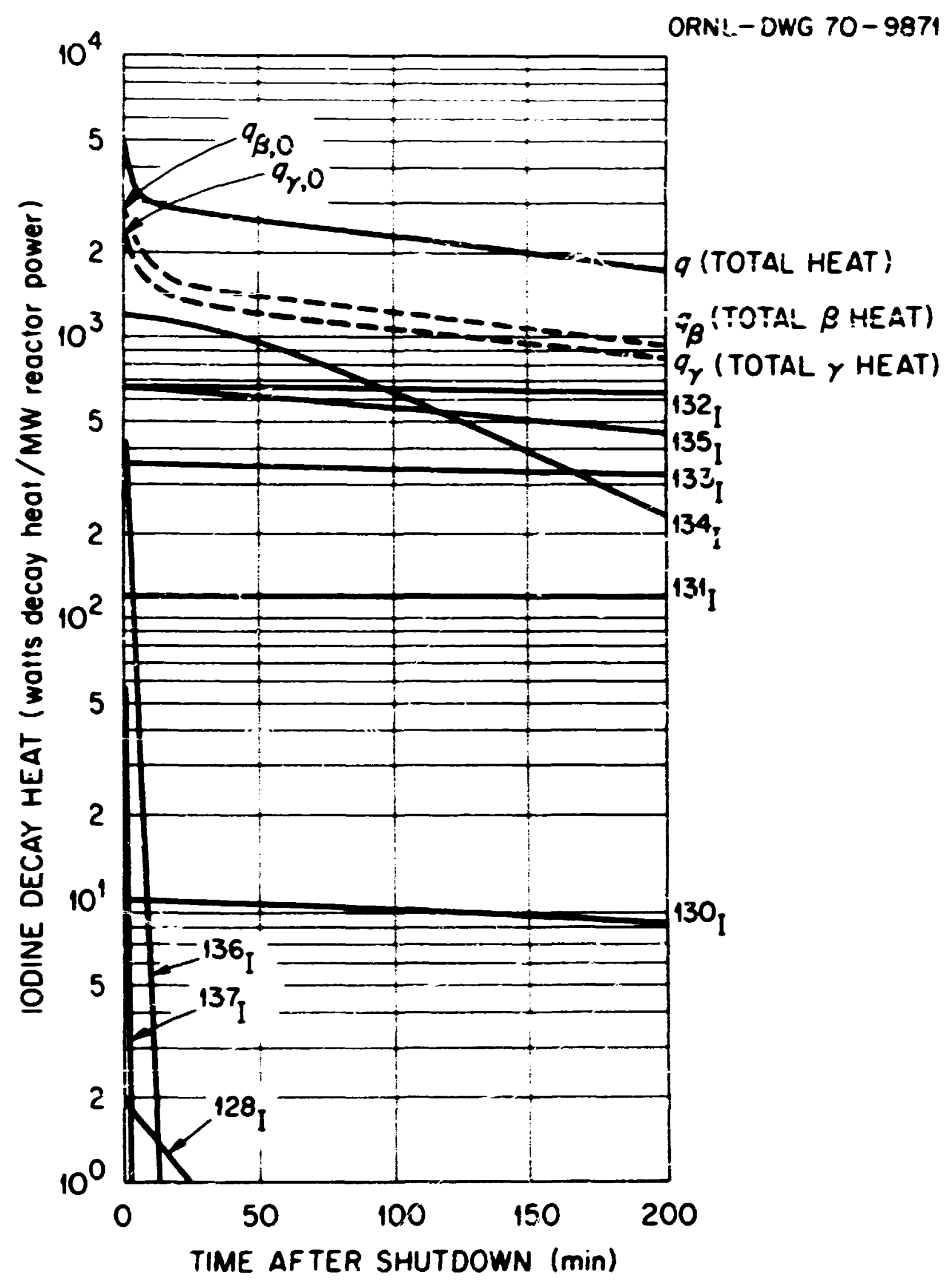

P1gure 6. Fission Product Iodine Decay Heat as a Function of Tine After Shutdown. 
The physicil properties of a charcoal bed are by no means a constant value. Each property depends on several factors. The apparent density of a charcoal bed is affected by the amount of moisture adsorbed and the method used in packing the bed. The thermal conductivity of charcoal beds is also subject to variations. It is a function of the temperature of the gas which fills the void between tite grains and probably also of grain size. The greatest variation in a property is exhiofted when neasuring the heat capacity $(C D)$ of a charcoal bed over a range of temperatures. As moisture and other adsorbed gases are desorbed they act as a heat sink and thus cause a large increase in the hest capacity while this is taking place. Heat capacity and thermal conductivity have been studiei in the labura:sry and will ve reported in a separate report.

In the examples which follow, the following values have been assumed: Heat capacicy $=C_{p}=0.2 \mathrm{Btu} / 1 \mathrm{~b}-{ }^{\circ} \mathrm{F}$ Density $=0=35 \mathrm{lb} / \mathrm{ft}^{3}=2.0235 \times 10^{-2} \mathrm{lb} / \mathrm{ia} .^{3}$ Conducivity $\mathrm{k}=0.12 \mathrm{Btu} / \mathrm{hr}-\mathrm{ft}-{ }^{\circ} \mathrm{F}=1.6667 \times 10^{-4} \mathrm{Btu} / \mathrm{in} .-\mathrm{nd}-{ }^{\circ} \mathrm{F}$.

Volumetric Heat Transfer Coefficient

Equat:ion (19) was given previously to relate $H$ (the volubetric heat transfer ccefficient) with $h$ (the film heat transfer coefficient from the charcoal particle to the flowing gas) and Eq. (20) was given to aid in est!mating values of $h$; the needed values of parameters have now been specified and $a$ value for $H$ can be estimated.

lising the characteristics given in the above subsection and assuming that about $80 \%$ of the charcoal surface area is available for heat transfer we get Srom Eq. (19):

$$
\begin{aligned}
& H=(0.8)(1-0.43)\left(\frac{0.01576}{0.0001251}\right)(12) \mathrm{h} \\
& H=689.4 \mathrm{~h} \mathrm{Btu} / \mathrm{hr}-\mathrm{ft} \mathrm{t}^{3}-{ }^{\circ} \mathrm{F}
\end{aligned}
$$

from the reported correlation ${ }^{9}$ we get values c, 0.272 and 0.341 for $E$ and as assuring $d=0.43$; then expressir.g $G$ as $60 \rho V_{8}$ where $V_{8}$ is in $\mathrm{ft} / \mathrm{min}$ and $1 \mathrm{sing}$ the properties of the adsorber unit and gas we get,

$$
h=1.0887 v_{8}^{0.66} B t u / h r-f t^{2}-s q
$$


Substituting into Eq. (27) we get

or

$$
\mathrm{B}=; 50.55 \mathrm{v}_{\mathrm{g}}^{\mathrm{j} .66} \mathrm{Btu} / \mathrm{hr}-\mathrm{ft}{ }^{3}{ }^{\circ} \mathrm{F}
$$

$H=0.00724 \mathrm{~V}_{\mathrm{g}}^{\mathrm{C} .66} \mathrm{Btu} / \mathrm{min-in},{ }^{3}-^{\circ} \mathrm{F}$.

Equation (29) was directly incorporated into the computer code for obtaining the volumetric heat transfer coefficient for each specified gas velocity.

\section{Examples of Code Applications}

As noted earlfer, in order to illustrate the apolication of the codes one must first define a typical reactor systeii and then place numerical values on the various input parameters. The following exanifles are offered.

The folluwing reactor system was defined for the express purpose of illustrating the applicability of the computer code. While the assumed jysteim fs sfimlā to curzent pressurized-ugter reactore no effort was nade to define a particular reactor: reactor power, $3077 \mathrm{Mw}(t)$; volume of containment, $1.14 \times 10^{6} \mathrm{ft}^{3}$; face area of charcoal adsorier, $2800 \mathrm{ft}^{2}$; charcoal thickness, 2 inches; superficial air velocity through charcoal, as specified.

Example 1 - As discussed earlier, much of the early work was accomplished with the ENIS code which did not allow the tenperature of the flowing air to change; the CHART series of codes was developed to handle a temperature rise in the flowing gas. CHART-A was so defined as to compare with the limitations of ENIS to allow a comparison to be made and to validate the assumptions made in the CHART series. Table 3 compares the output for ENIS, CHART-A, and CHART-B for an identical adsorber system. It is assumed that $25 \%$ of the lodine inventory is passed from the reactor core io the charcoai ddscrber with 10 minutes decay and then instantly dispersed over the charcoal before additionai decaj is allowed; the sequence is referred to as "instant loading." The time values in the table refer to time after the lodine has been loaded onto the cisarcoal and not time frim reactor shutdown. It is noted that icmperature rise in the fiowing air is an important consideration especially at the low flow races. All of the following exauples were done with the CHART-B code. 
Table 3. Corparison of Temperature R1se es Calculated for Charcoal Adsorber by Three Computer rodes

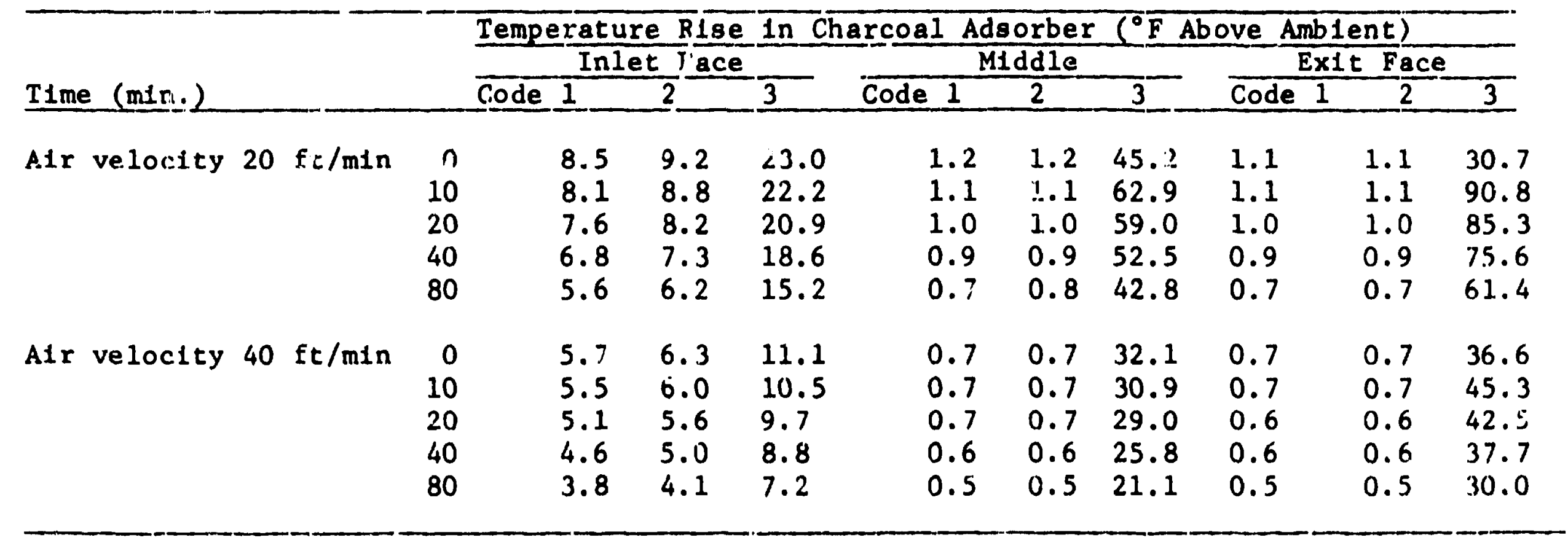

Code 1: ENIS code, which 10 an analytical solution of Eq. (23); temperature of flowing al $r, t_{g}$, constant.

Code 2: CHART \&: comparas with ENIS; $t_{8}$ constant.

Code 3: CHART B: allows $t_{g}$ to vary. 
Example 2 - It is assumed that $25 \%$ of the iodine irventory is passed from the core to the charcoal adsorber with 10 minutes $a: s c a y$ and then instantly dispersed over the charcoal tefore additional decay is aliowed; this sequence is referred to as "instant loading." Figure 7 shows the maximum charcoal temperature as a function of time as computed by the CHART-B code for two air velocities through the charcoal mass. The time values on this grapit refer to time after the lodine has been loaded onto the charcoal and not time from shutdown; the temperature values refar to temperature rise above the assumed starting temperature of the charcoal. At an air velocity of $4 \mathrm{ft} / \mathrm{min}$ the maximum temperature rise was approximately $380^{\circ} \mathrm{F}$ above the starting temperature, and this occurred at about 36 minutes after iodine loading; at a velocity of $20 \mathrm{ft} / \mathrm{min}$ the heat transfer is much greater and the maximum tomperature jisc minutes. It may be noted that the air flow through charcual is normally about $40 \mathrm{ft} / \mathrm{min}$ or greater and further that the ignition point of charcoals normally in use exceed $600^{\circ} \mathrm{F}$.

Example 3 - In recirculating adsorber systems the iodine loading will De more graduai tnan assumed in Exampie 1. Using Eq. (16), the loading characteristics for various air flows were computed and are illustrated in Fig. 8. This sequence is referred to as "gradual loading." As the air flow rate increases two effects ar? noted. First the factor in the computer code which controls the loading rate, allows the heat generation rate to increase because iodine is being removed from the containment volume and defnsited on the charccal with less decay. At the same time, the greater air $\mathrm{fl}$ increases the heat removal rate and tends to limit the temperature rise. In Fig. 9 the maximum tzuperature in the charcoal adsorber is plotted against time for air velocities of $2,4,10$, and $20 \mathrm{ft} / \mathrm{min}$.

Comparison of the effects of "instant" vs "gradual iodine loading" for air velocities of 4 and $20 \mathrm{ft} / \mathrm{min}$ may be made with the aid of Fig. 10 . Gradual loading lowers the maximum temperature rise by $210^{\circ} \mathrm{F}$ at $4 \mathrm{ft} / \mathrm{min}$ air velocity.

Example 4 - The first two examples demonstrate that air velocity and the schedule of iodine loading are very important parameters. This infers that the most hazardous situation might be one in which the loading 


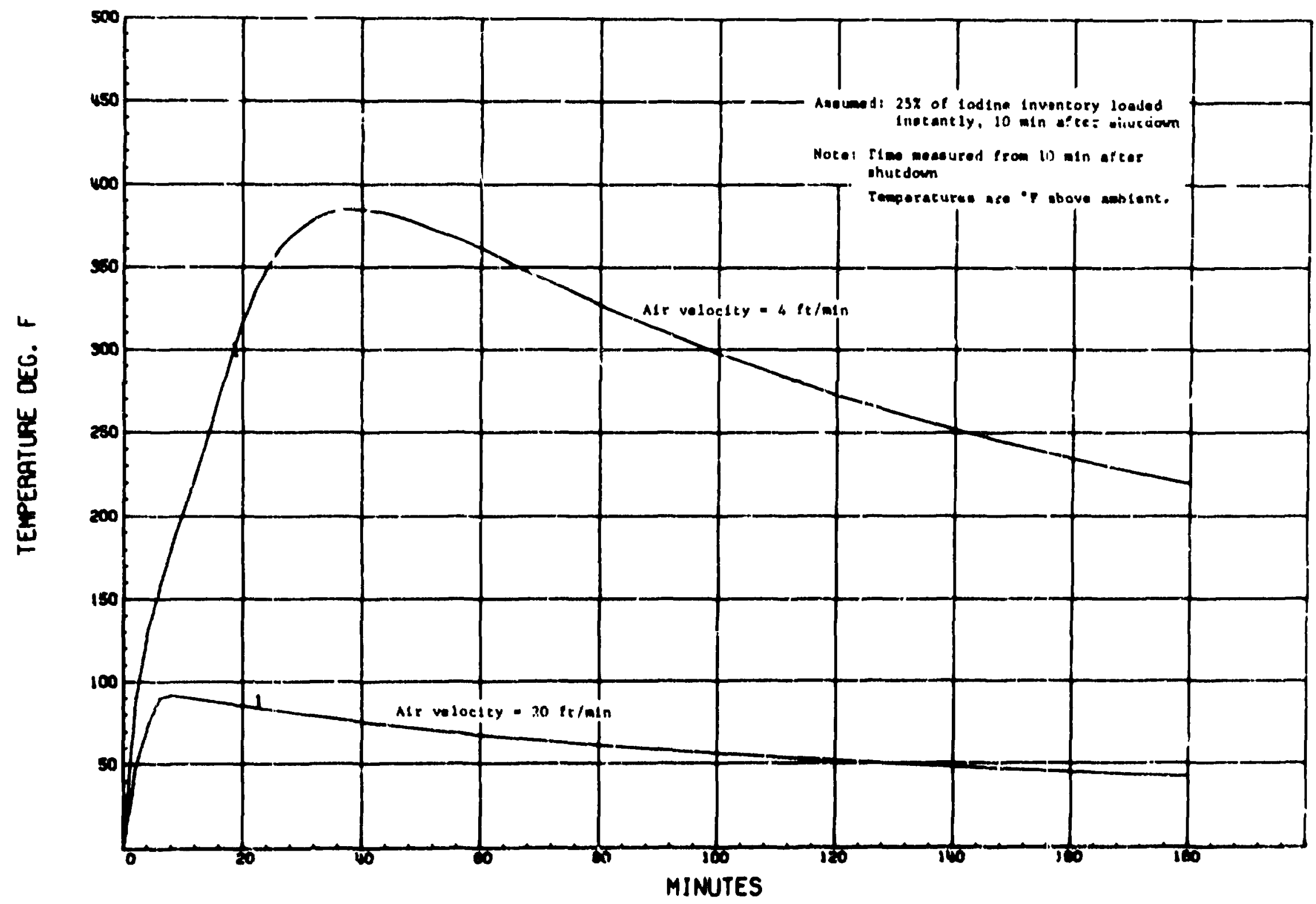

F1gure 7. Maximum Charcoal Temperature va TIme for Instant Loading 10 Minutes after Shutdown. 
ONML-OWG 70-10024

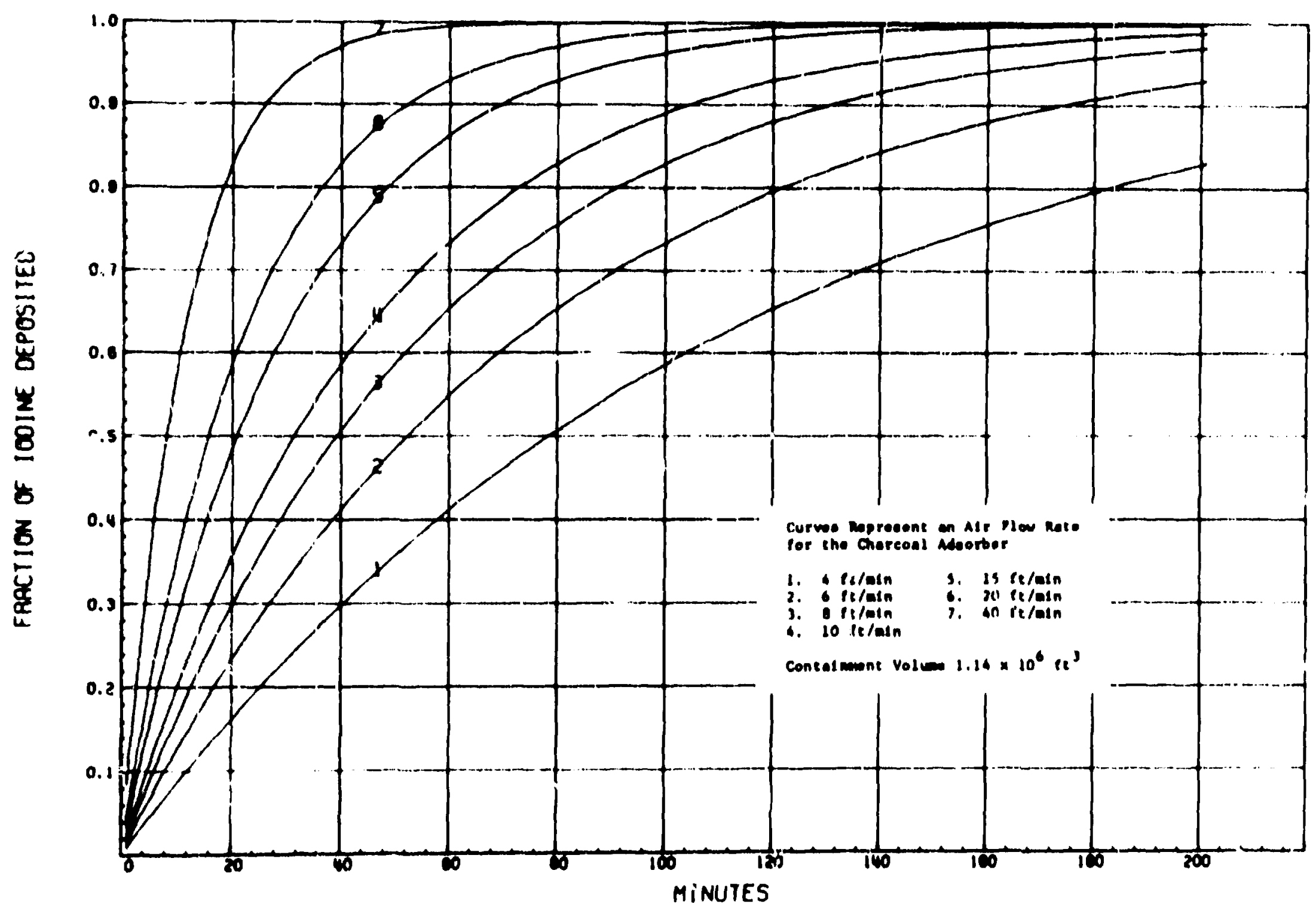

F1gure 8. Frastion of Contalnment Iodine Deposited on Charcoal ve Time. 


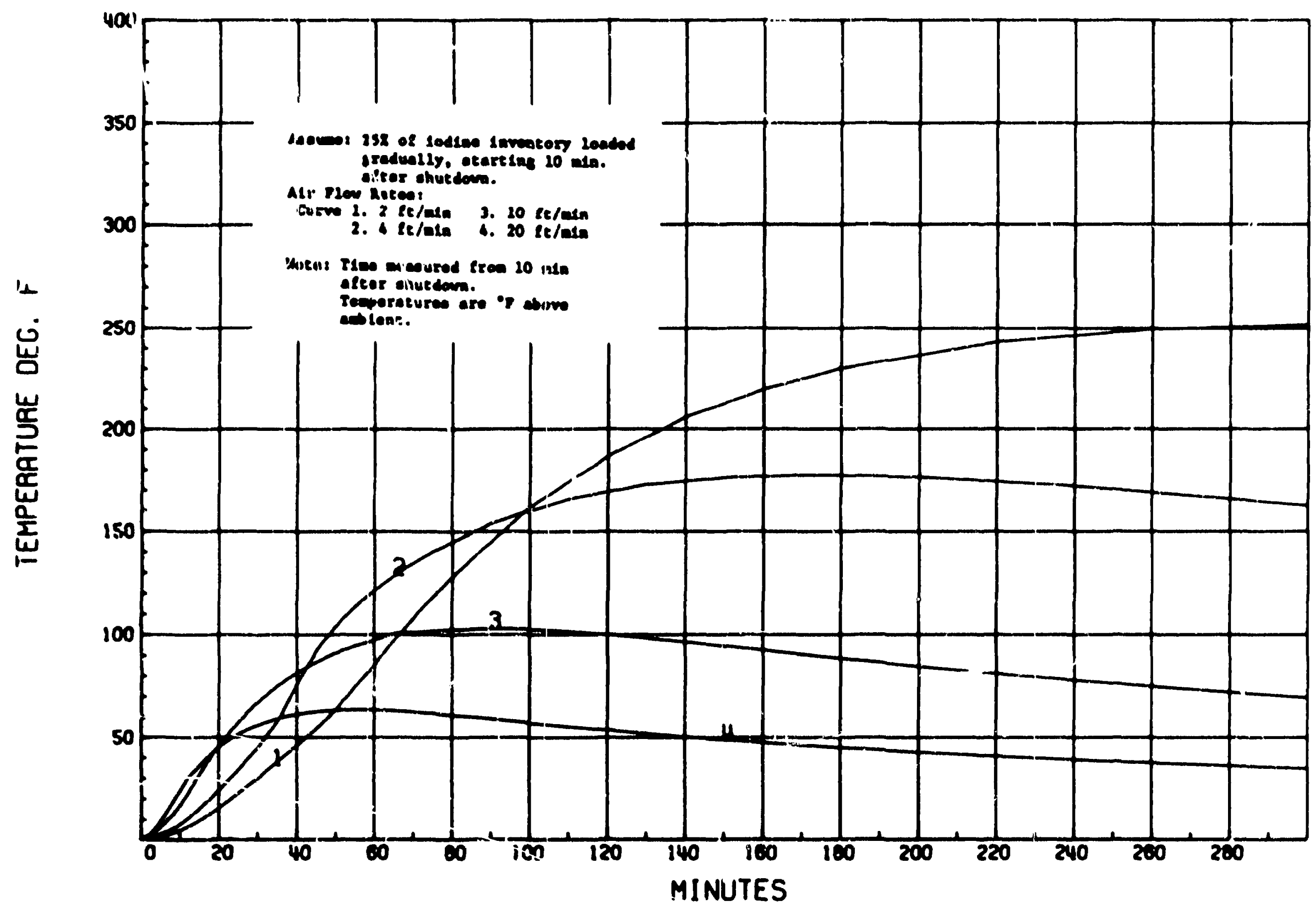

F1gure 9. Maximum Charcoal Temperature ve Time for Gradual Loading. 


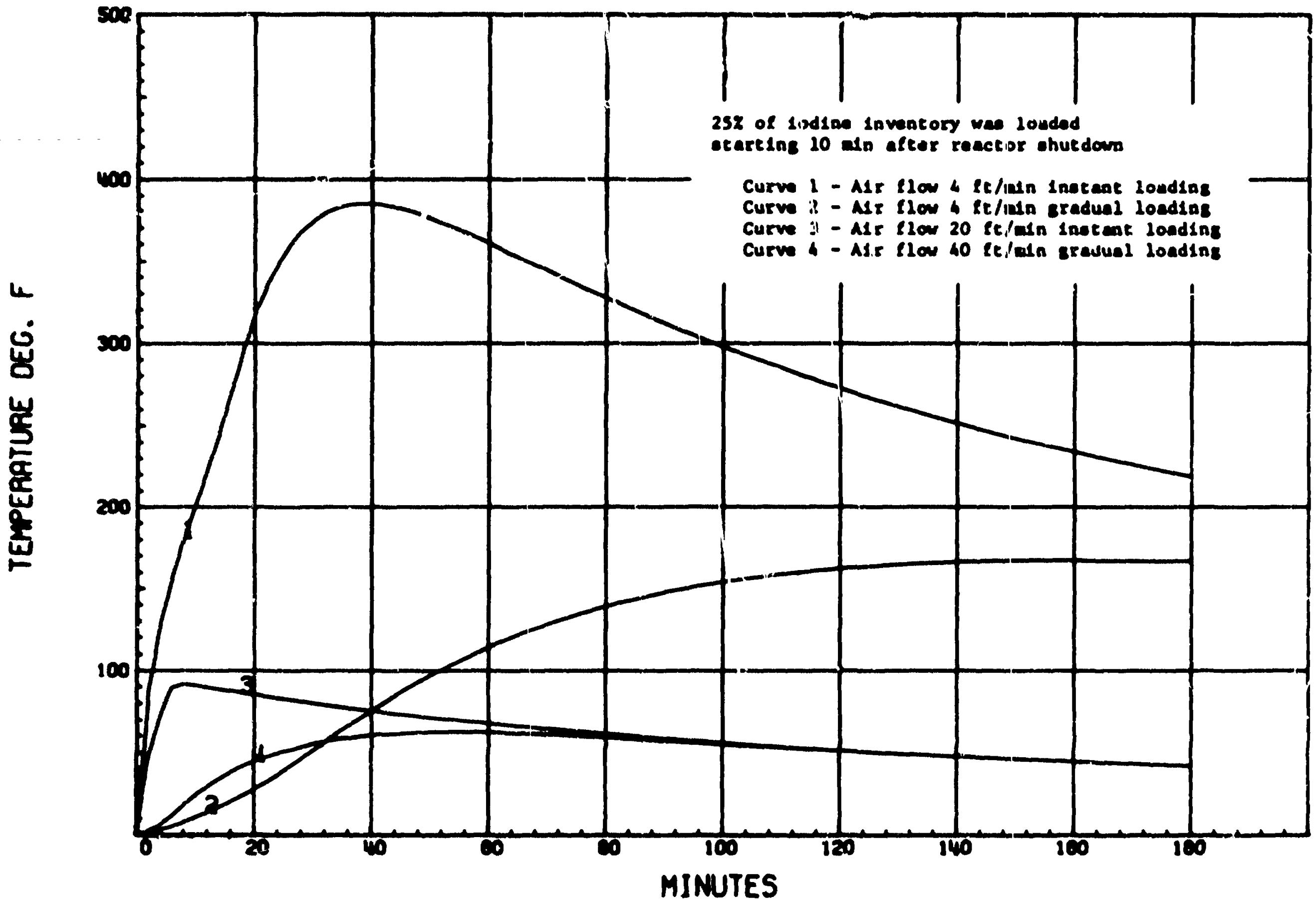

Figure 10. Temperature (max) of Charcoal va Time - Instant and Gradual Loading. 
of iodine sccurred quickly and in which a low flow condition developed as a result of partial blower failure after iodine loading. Figure 11 indicates how the maximum teaperature might change in that situation. Specifically the temperatures listed were calculated assuming a normai flow ( $40 \mathrm{ft} / \mathrm{min}$ ) for long enough to load $95 \%$ of the iodine which would eventually be loaded and then assuming a reduction tc a flow of $4 \mathrm{fc} / \mathrm{min}$ after that. As can be seen, the maxinum temperature rise was not extreme.

Example 5 - The volumetric heat transfer coefficient (H) is calculated Eor each air flow rate entered in the computer code and the result is applied to determine the transfer of heat from the charcoal to the air. The computer code was used to compare the temperature distribution in the charcoal, using the $(H)$ value calclilated by the equations considered to be most representative in lieu of measured values, and using an (H) value reduced by a factor of 10 . These two values of $(H)$ were used for 2,4 , and $10 \mathrm{ft} / \mathrm{min}$. Figure 12 is a plot of the maximum temperature vs =ime under these conditions. As expecied there is practically no difference in the two cases for low air flow because the capacity of the air for heat is quickly reached and the air temperature becomes the controlling factor. At increased air velocities the effect of $(H)$ becomes more apparent. is noted earlier in this report, values of $(H)$ were measured in the lab and wiil be reported in a future report.

Example 6 - The previous examples have utilized the maximum te-uperature irrespective of the location within the charcoal mass. If the charcoal slab is subdivided as in Fig. 13 then temperature can be calculated at desired locations by use of CHART-B. Figure 13 illustrates maximum temperature at the center and the corner of a charcoal slab.

Example 7 - This calculation illustrates the surface temperature profile of a charcoal slab along the lines 1, 2, 3, 4, and 5, as illustratec in Fig. 14. It is noted that temperature profiles are comparable to within 3 inches of edge if charcoal slab.

Example 8 - In this calculation we apply CHART-B to a once-through charcoal adsoliber syster. For purposes of this illustration a hypotheticai ractor and adsorber system was defined as: power level, 350 tw $(t)$; iodinc relesse, $25 \%$ of inventory with $90 \%$ as $\mathrm{I}_{2}$ and $10 \%$ as $\mathrm{CH}_{3} \mathrm{I}$; transit tire jetween core and cilarcoal, 10 minutes; size of adsorber system, 
Cent.anc 70.1030 ?

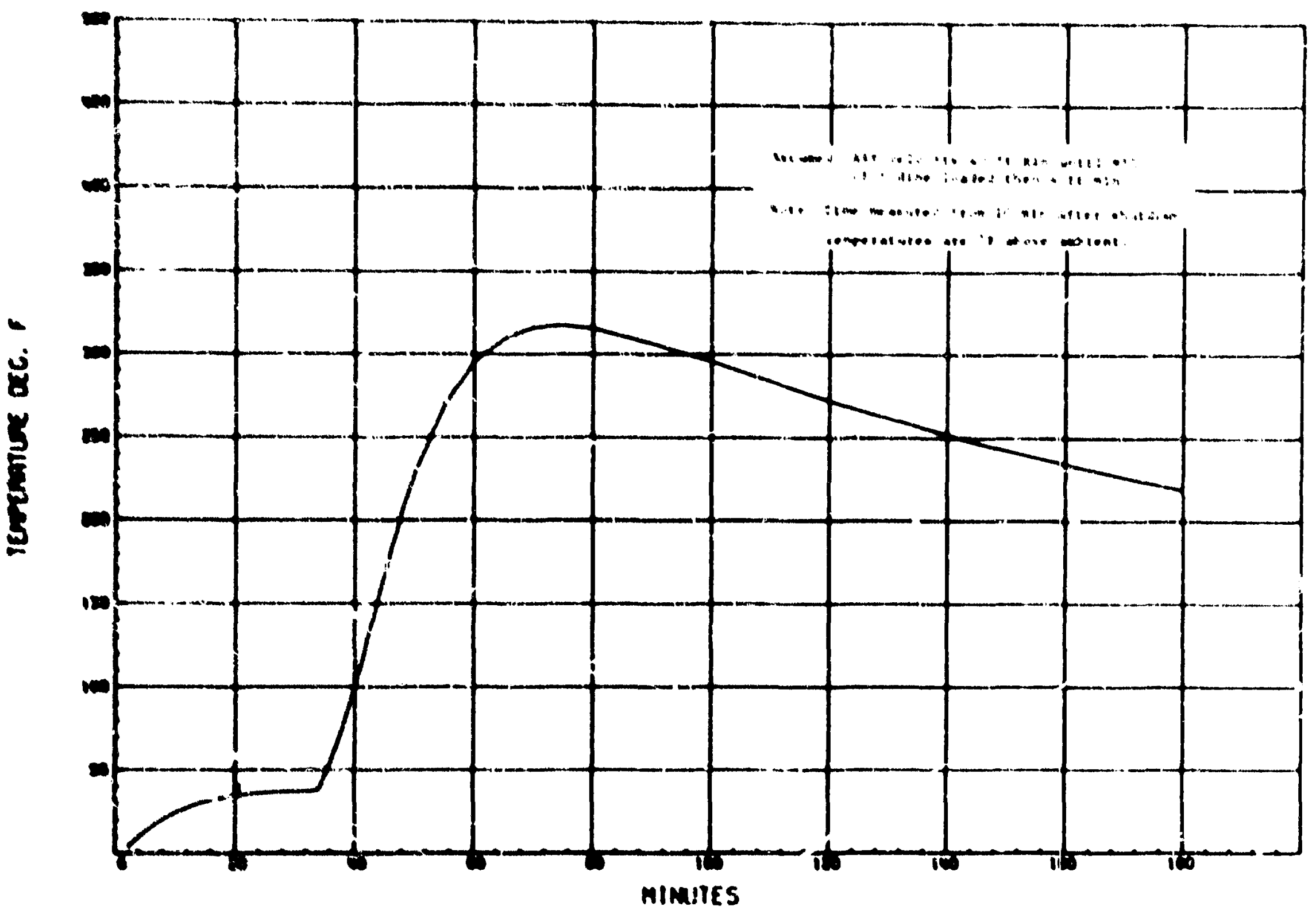

Figure 11. Maximum charcoal Temperazure ve Ilme for High Alr Fluw followed by Low Alr Flow. 


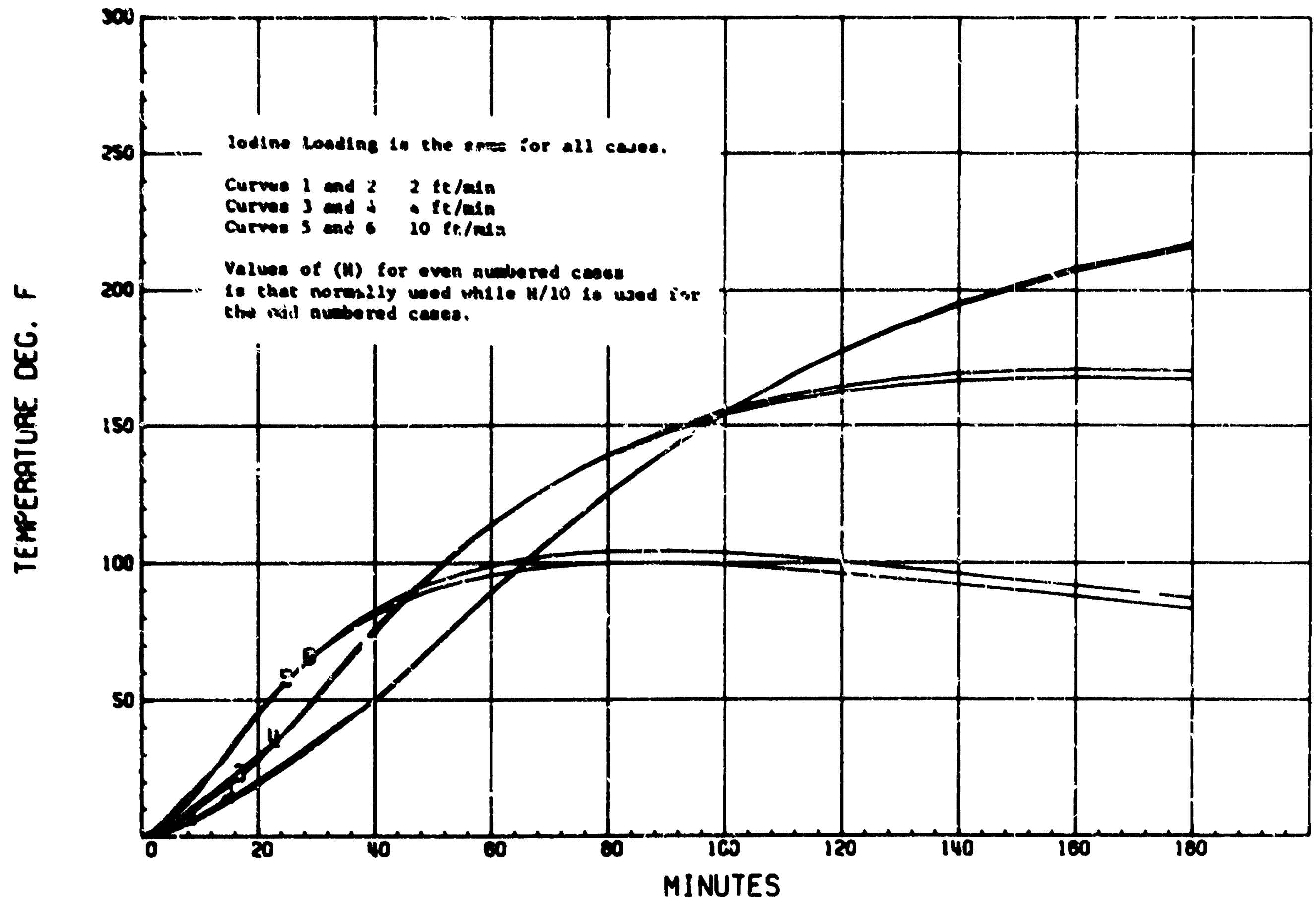

P1gure 12. Temperature (Max.) of Charcoal ve TIme-Effact of. Chanje (H). 


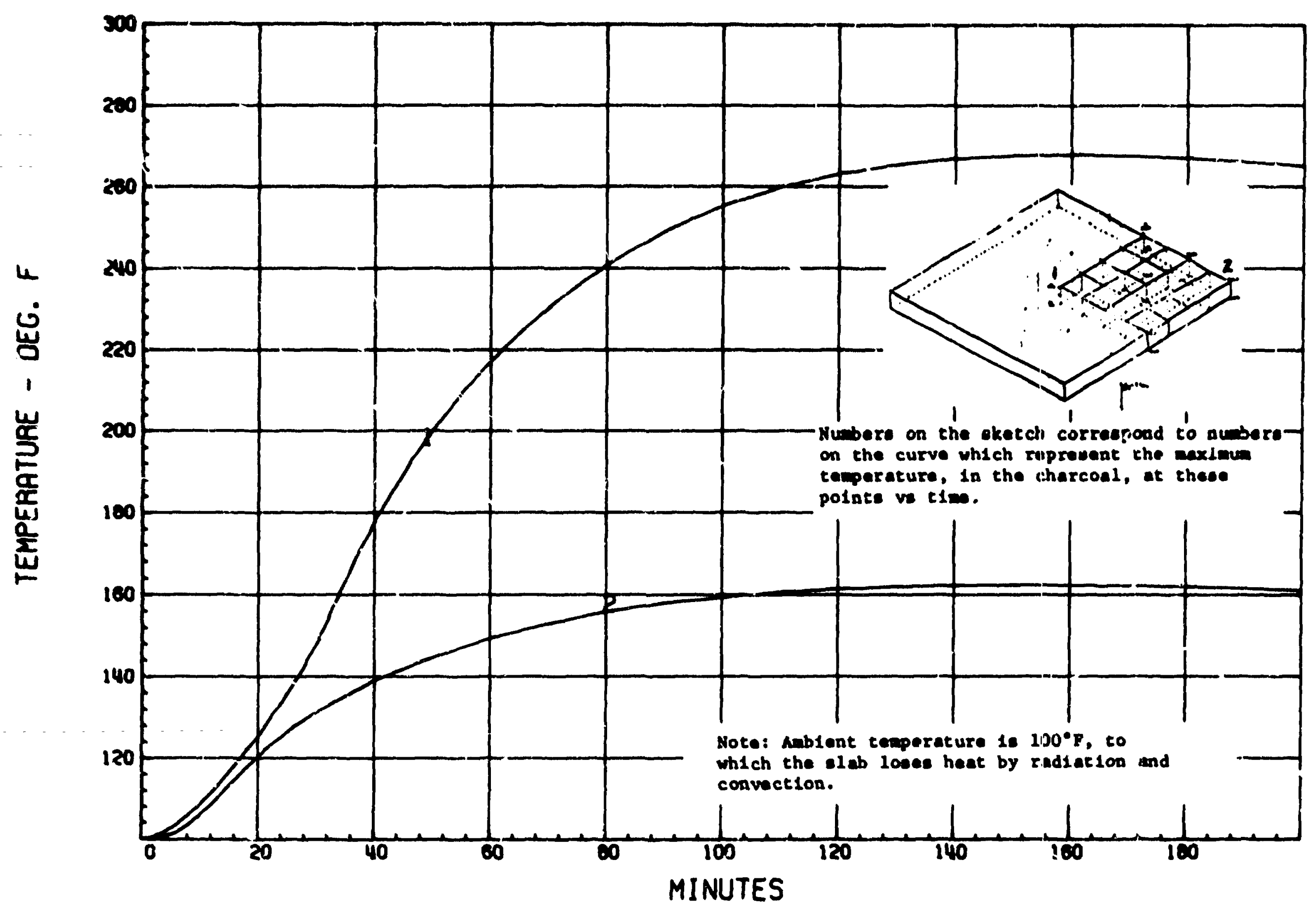

Figure 13. 3-Dimensional Slab Calculation, Maximum Temperatic vo Time. 


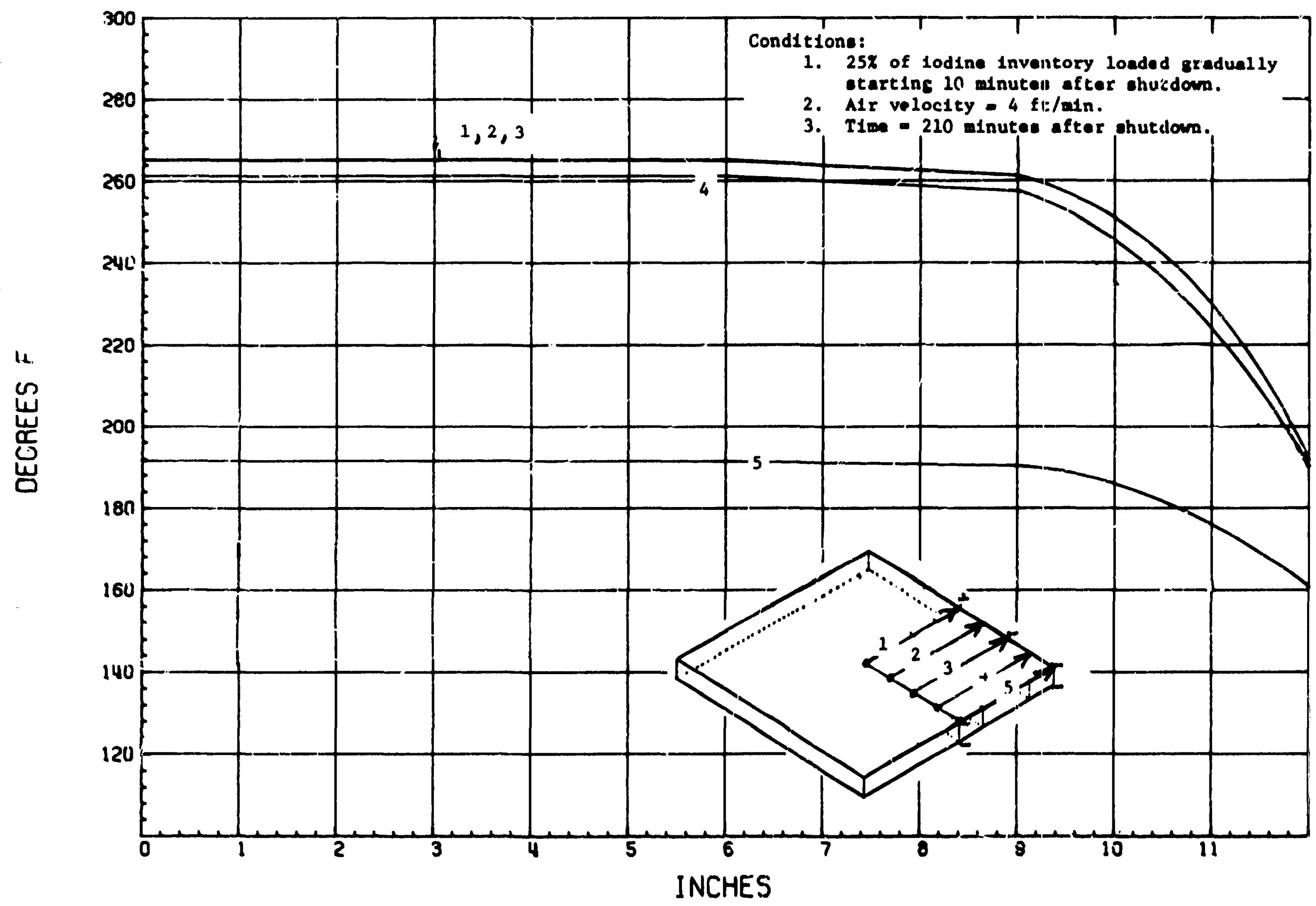

Figure 14. Surface Temperature of Charcoal Slab. 
$600 \mathrm{ft}^{2}$ face area by 2 inches depth; normal linear velocity of air, $40 \mathrm{ft} / \mathrm{min}$; abnormal linear velocities of 20 and $4 \mathrm{ft} / \mathrm{min}$; efficiancy of charcoal, 99\%. The temperature response of the charcoal under instant loading conditions is given in Fig. 15. The manner in which these calculations were made is detailed in Appendix $D$.

Example 9 - Calculations of the quantities of isiac avalsble wore made assuming (1) only the iodine released directly from the fuel reaches the charcoal or (2) all the lodine, including that produced by decay of tellurium after reactor shutdown, reaches the charcoal; this was accomplished through use of a computer code called ORIGEN ${ }^{13}$. Other assumptions include: (1) $25 \%$ of iodine inventory in a $3000 \mathrm{Nw}(t)$ reactor reaches containment 10 minutes after shutdown, (2) lodine is defosited on $2800 \mathrm{ft}^{2}$ of charcoal adsorber (with a 2 inch depth of charcoal) at a rate such that $95 \%$ of the total iodine eventually deposited is deposited in abs:t 100 minutes. The results are contained in Fig. 16. By including that iodine produced by decay of tellurium (after shutdown) the heating load at its maximum is increased by about $19 \%$.

\section{COOLING THE CHARCOAL ADSORBER BY NATURAI AIR CONVECTION}

A model reactor complex has been descrited earlfer in this report and used for the development of computer codes to calculate the temperature distribution caused by the decay heat of the radioactive lodines adsorbed on the charcoal adsorbers. These calculations show that air flow rates as low as $4 \mathrm{ft} / \mathrm{min}$ can effectively remove the decay heat from charcoal. adsorbers. The very important question that rerains is the consequences of no forced air flow through the charcoal adsorbers. Can the natural means of heat transfer dissipate the decay heat through the air exit duct and the walls of the adsorber? To answer this question some piceliminary calculations were made to deternine the rate that heat can be dissipated from a model adsorber when the charcoal is at a temperature of $475^{\circ} \mathrm{F}$. A further consideration is giver to enhancing the natural fiow of air through the charcsal by adding a stack near the exit of the charcoal adsorber.

In order to check the possibility of corling the charcoal adsorbers by naturai convection some rough calculations have been made for steady state conditions. 


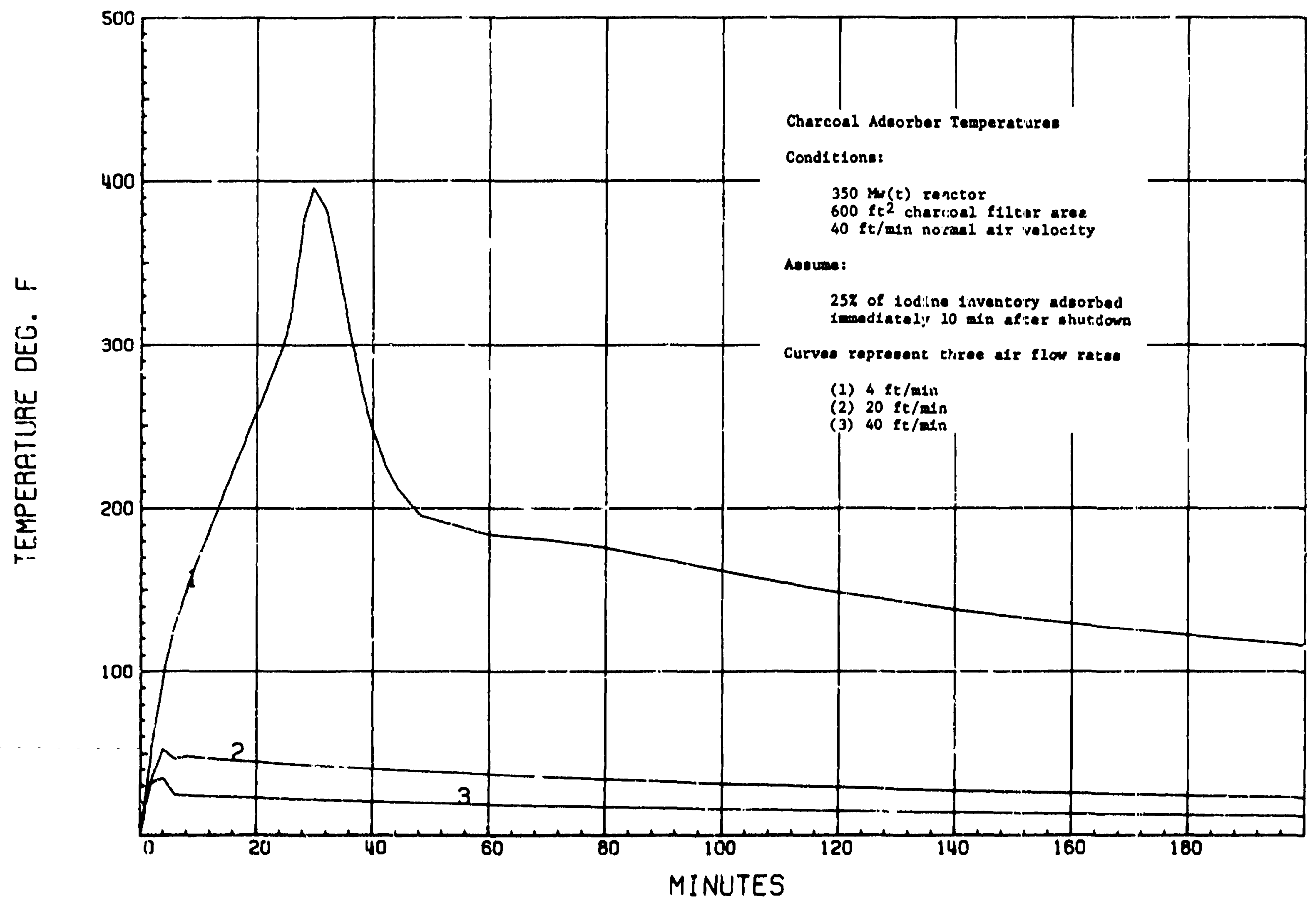

figure 15. Maximum Temperature vo Time. 


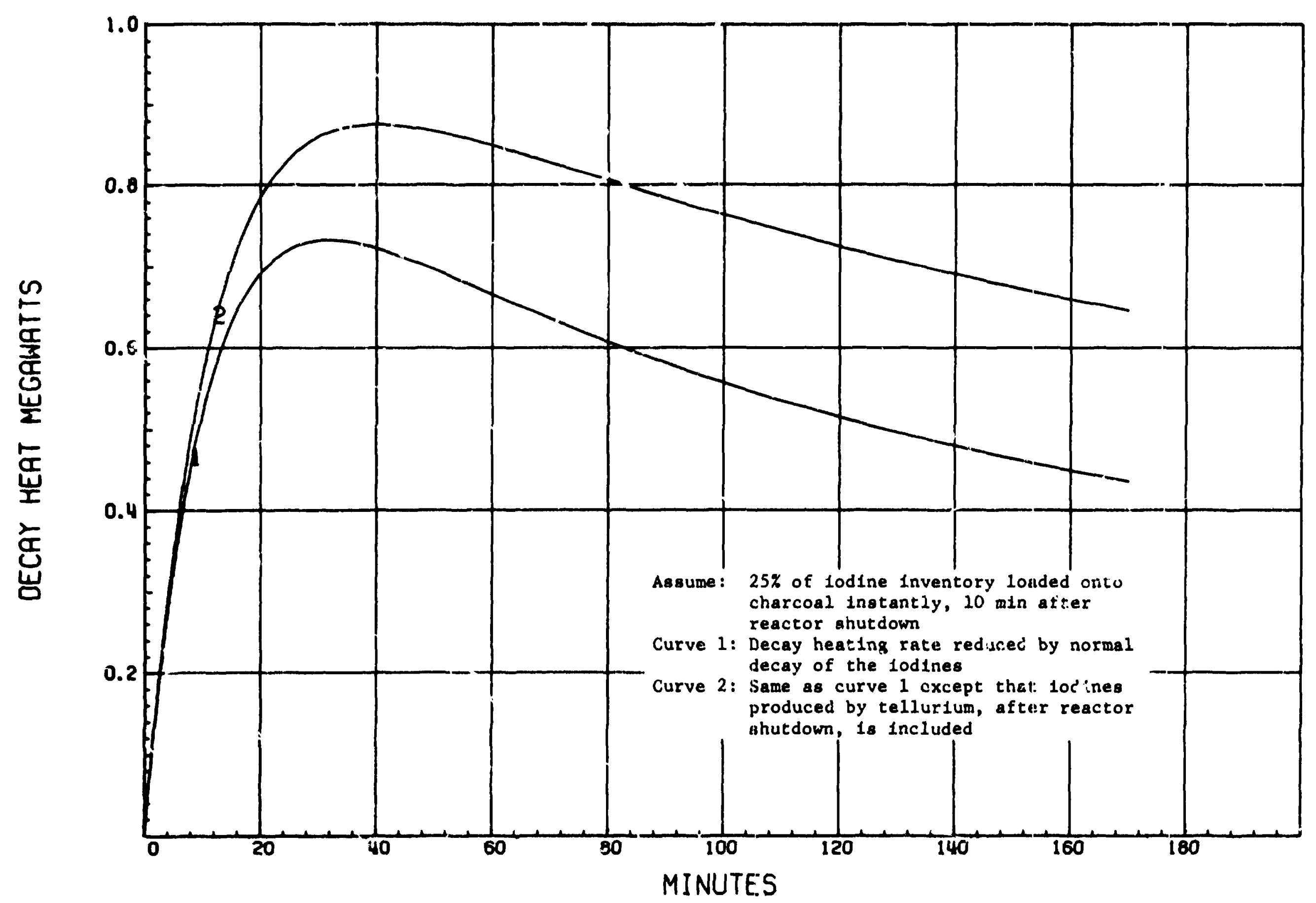

Figure 16. Decay Power of Fisston Product Iodine vs Time from 3000 Mw( $t$ ) Reactor. 
The driving force by laturis convection is

$$
\Delta P=Z\left(\rho_{c}-\rho_{h}\right)
$$

where

$\Delta \mathrm{P}=$ driuing Físsure in $1 \mathrm{~b}_{\mathrm{f}} / \mathrm{ft}^{\hat{L}}$

$Z$ = elevation of unit

$\rho_{c}=$ density of air at cold side (bottom of unit)

$\rho_{h}=$ density of air at hot side (top of unit).

The driving pressure required on the pressure resistance through the bed can be calculated by

$$
\Delta P=2.8508 \times 10^{-5}\left(\frac{L \mu V_{g} F_{E}}{g_{e} D_{P}^{2} F_{R e}} ; .\right.
$$

The correct gas velocity will be achieved by balancing the driving force with the pressure drop required. Equating Eq3. (30) and (31), we get then

$$
v_{g}=\frac{g_{c} D_{P}^{2} F e^{Z\left(C_{c}-\rho_{h} !\right.}}{2.8508 \times 10^{-5} L F_{F}}
$$

where

$Z=$ distance separating the cold air and hot air $-6.75 \mathrm{ft}$

$\rho_{c}=$ density of air at $100^{\circ} \mathrm{F}=0.07087 \mathrm{~b} / \mathrm{ft}^{3}$

$\rho_{h}=$ density of air at exit conditions of $475^{\circ} \mathrm{F}=0.0 .420 \mathrm{ib} / \mathrm{ft}^{3}$

$\mathrm{B}_{\mathrm{c}}=32.17 \mathrm{ft} / \mathrm{sec}^{2}$

$D_{p}=0.00517^{2}=0.00002673 \mathrm{ft}^{2}$

$F_{\operatorname{Re}}=48.0$

$\mathrm{L}=$ total bed thickness $=18 \times(2 / 12)=3.0 \mathrm{ft}$

$\mu=0.04594 \mathrm{lb} / \mathrm{ft}-\mathrm{hr}$

$F_{f}=1500.0$

Substituting the above values in Eq. (32) gives for the naiural gas velocity

$$
v_{8}=0.2626 \mathrm{f}+/ \mathrm{min}=15.76 \mathrm{ft} / \mathrm{hr} \text {. }
$$

The heat transferred to the cooling air can be calculated by

$$
q_{g}=W C_{p}\left(T_{h}-T_{c}\right)=V_{8} \rho A_{b} C_{p}\left(T_{h}-T_{c}\right) \text {. }
$$

To this, one can add the heat $100 \mathrm{t}$ from the duct surface to the ambient atmosphere by natural convection and radiation as 


$$
q_{w}=C A_{w}\left(T_{w}-T_{c}\right)^{1.33}+\varepsilon_{A_{w}} \sigma\left(T_{w}^{4}-T_{c}^{4}\right)
$$

Where

$$
\begin{aligned}
& W=\text { rate of flow of air in } 1 \mathrm{~b} / \mathrm{min} \\
& C_{p}=\text { specific heat of air }=0.245 \mathrm{Btu} / 1 \mathrm{~b}-{ }^{\circ} \mathrm{F} \\
& A_{w}=\text { exterial surface of the duct around the adsorber }=40 \mathrm{ft}^{2} \\
& T_{h}=\text { hot exit temperature of cooling air }=475^{\circ} \mathrm{F} \\
& T_{c}=\text { cold or ambient temperature }=560^{\circ} \mathrm{R}\left(100^{\circ} \mathrm{F}\right) \\
& T_{u}=\text { average temperature of the wall }=747^{\circ} \mathrm{R}\left(287^{\circ} \mathrm{F}\right) \\
& \varepsilon=\text { emissivity of wall surface }=0.5 \\
& C=\text { empirical constant for natural corvection }=0.221 \\
& \sigma=\text { Steffan-Boltzmann constant }=0.173 \times 10^{-8} \mathrm{Btc} / \mathrm{hr}-\mathrm{ft}-{ }^{\circ} \mathrm{R}^{4} \text {. }
\end{aligned}
$$

It was assumed here that the ambient temperature is $100^{\circ} \mathrm{F}$ (which is an optimistic value) and that the exit temperature of the cooling air at the top is allowed to reach the temperature linit of $475^{\circ} \mathrm{F}$. The adsorber container itself is assumed to contain three columns of adsorber units with 18 charcoal slabs in each column. The size of the duct around the adsorber is taken to be $31-1 / 2$ in. high, 83-i/2 in. wide and $28: \mathrm{n}$. deep. Tis gives abcut $40 \mathrm{ft}^{2}$ of external surface area around the duct and $12 \mathrm{ft}^{2}$ flow area of the gas in vertical direction. Based on the above assumptions, we can have an estimate of the arount of cooling that can be expected by naturai means and without using a stack.

The heat transferred to the alr using Eq. (33) is then

$$
q=W C_{p} \Delta T=V_{g} \rho A C_{p} \Delta T=15.76(0.0564<)(12)(0.245)(375)=980 \mathrm{Btu} / \mathrm{hr}
$$
and the heat transferred to ambient air using Eq. (34) will be

$$
\begin{aligned}
q_{\mathrm{h}^{*}} & =0.221 \times 40 \times 182^{1.333}+0.5 \times 40 \times 0.173 \times 10^{-8}\left(742^{4}-560^{4}\right) \\
& =9101+7085=16,186 \mathrm{Btu} / \mathrm{hr} .
\end{aligned}
$$

So the total heat loss by natural means will be

$$
I_{1}=q_{8}+q_{w}=980+16,186=17,166 \mathrm{Btu} / \mathrm{hr}=5.03 \mathrm{Kw} \text {. }
$$

The total maximum heat gereration in the model adsorber for 27 charcoal trays was computed to be $5 f_{5} \bar{K} \mathrm{~K}$ using the assumed reactor system. This means that even with optimistic assumptions the heat nominally assumed to be generated in the charcoal bed cannor be removed by normal air convection around the adsorber container. 
Since only a small fraction of the total heat can be rewoved from the adsorber by natural convection, it might be desirable to increase the thermal buoyancy by adding an emergency stack to the system. The piessure loss through the system is the sum $0:$ the pressure drop through the ductwork, the bed and stack. If the emergency stack can be located close enough to the bed and an opening provided to the outside air, then the pressure drop in the ductwork can be ignored and the total $\Delta P$ will then be equal to the sum of the frictional iesistances in the stack and in the bed plus $i-1 / 2$ velicity heads based on the bed velocit; plus $1-1 / 2$ velocity heads based on the stack velocity.

A program was written in X-Tran for the Com-Share Computer called STACK which calculates tise fraction of the maximum heat generated from the peak reat generation rate on a steady state basis for any given ambient temperature, stack height, and diameter. A listing of this program appears in Appendix F. Calculations are sased on Eqs. (35) and (36). The results of this program are shown in Fig. 17 for ambient temperature of $100^{\circ} \mathrm{F}$ stack heights from 0 to $100 \mathrm{ft}$ and stack diameters from 1.0 to $4.0 \mathrm{ft}$ where the total maximum heat generation for the total adsorber is $732 \mathrm{Kw}$. Figure 18 gives the same data for ambient temperacure of $240^{\circ} \mathrm{F}$.

Kestilts indicate that a stack 3 feet in diameter and 35 fett in height would control the heat generation under ai: assumed ambiert temperature of $100^{\circ} \mathrm{F}$; for an ambient temperature of $240^{\circ} \mathrm{F}$ the dimensions would be 4 feet in diameter and 70 feet in height.

\section{SUMMARY}

In this report two major objectives have been pursued. Une, to suggest a method which might be applied to do a thermal analysis of a charcoal adsorber and two, to provide calculational means to apply the analysis. Specifically, the noints itemized below have betn presented.

1. A description of an assumed reactor complex with the necessary details to place the charcoal acisorber cf the systen in context so it will be seen as part of the whole system while considering the likelihood of its becoming heated by the decay heat of the lodine. 


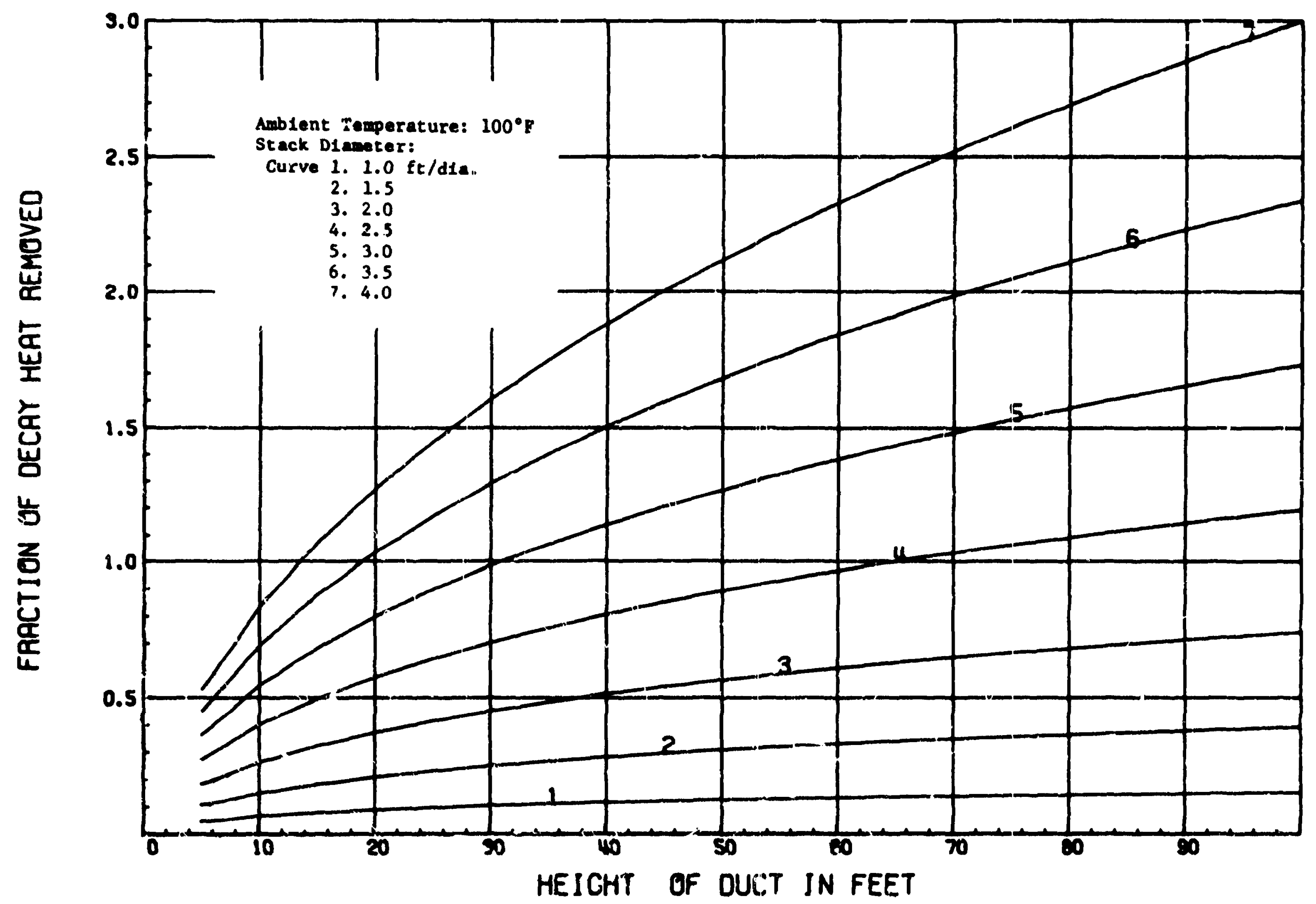

F1gure 17. Fraction of Heat Removad ve Height of Stack. 


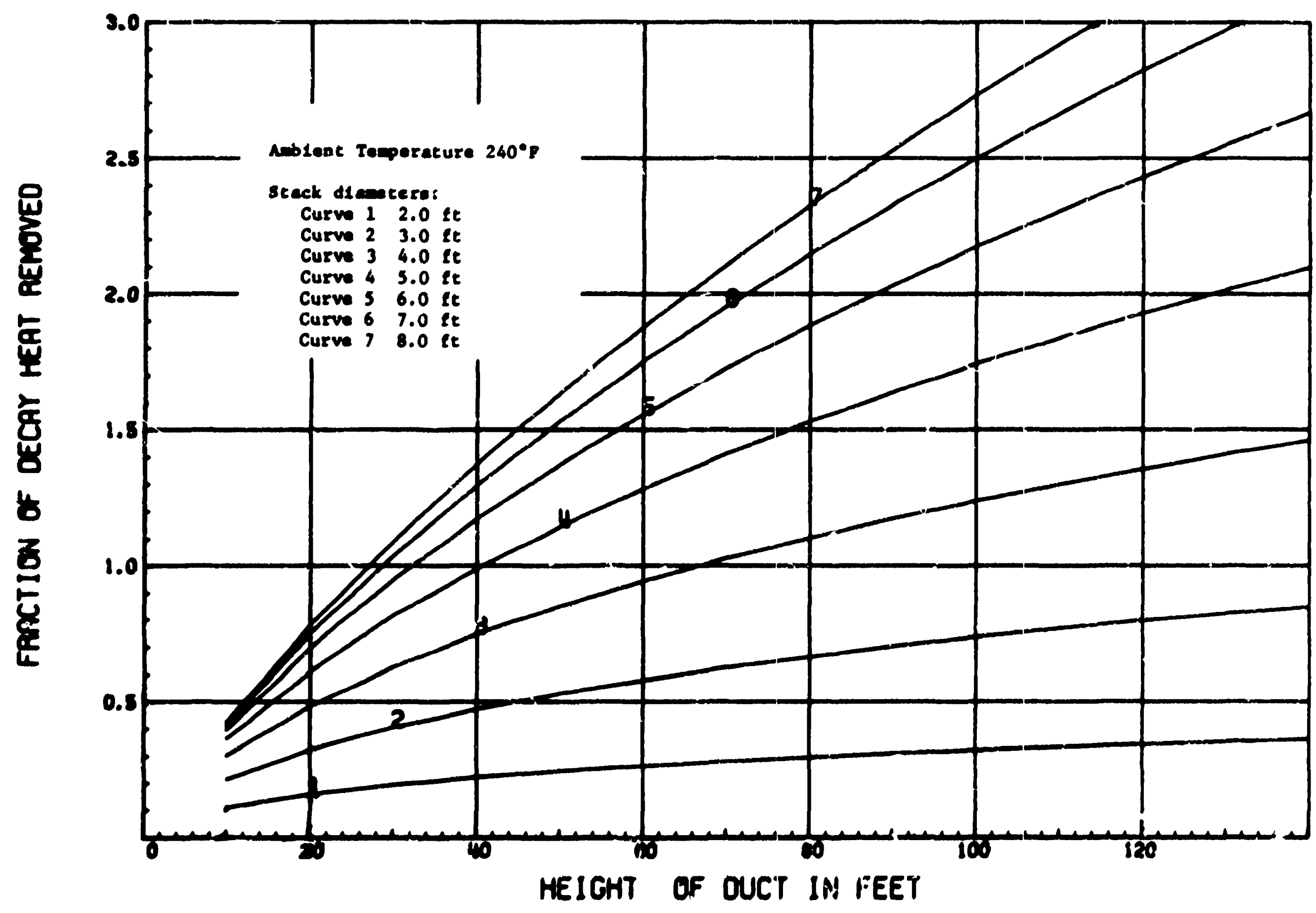

Plgure 18, Fraction of Heat Removed ve lledght of Stack. 
2. The all important consideration of the quantity of iodines which will be adsorbed on the charcoal. In this connection it is emphasized strongly that any statement as to the amount of iodine available for adsorption must be presented as a function of time.

The source of the iodine activity is defined, in the main, as the iodine present in the reactor at the time of the postulated accident but the radioactive decay of tellurium provides a source which continues to produce lodine after the reactor is shutdown. The extent to which the daughters of the tellurium isotcpes should be included was not pursued but a calculatior. was made to illustrate the contribution of this mode of ioline production to the entire iodine inventory.

3. Advantage has been taken of the time intervals which are inherent in the span or time from reactor shutdown to the time when the charcoal adsorbers have adsorbed that quantity of iodice which can be a threat to the charcoal. Salce in the early minutes after reactor shutdown the iodine isotopes decay very rapidly, the heat generating power is also derreasing at a rapid rate and so reduces the maximum heat load that can accumulate on the charcoal.

4. Calculational procedures have been developed for use in estimating the temperature distribution in charcoai adsorbers. Three di : crent mathematical models have been taken to analyze the problen. Computer codes were developed for the study and are briefly described.

\section{EN:IS Code}

An analytical solution of the differential equation was accomplished by assuming that the temperature of air moving rapidly through the bed would not isicrease significantly. This cocis is not useful for low flows which are of most interest. It is useful, however, to make any studies of interest at high air flow rates and in this work provides a check on the numerical method. 


\section{CHART Code}

A numerical method, employing a general heat program for the computer, was used to solve the heat distribution problem resulting from iodine decay heat in a three-dimerisional slab of charcoal. This code was used in three ways:

CHART A: Used to compare results with output from ENIS code; does not allow temperature of gas, $T_{g}$, to change.

CHART B: Used for calculations with "Infinite Slab" and "3dimensional S'ab" models; true heat capacicy of gas must be used as $\mathrm{T}_{\mathrm{g}}$ changes.

CHART $C$ : Used with the "3-Limensional Unit" mojel; this was not fully operational at present time.

5. A calculational procedure has been developed for estimating the maximum heat which the charcoal adsorber san lose by natuial means when no air is flowing through the sysiem.

6. It was found that a vertical air duct (chimney) made a part of the adsorber exit and excending well up into the containment can create a natural air flow which will remove the maximum heat generated in the adsorber. The matheratical calculation for this consideration is presented along with a computer program (STACK) for solving the problem.

7. Details for the mathematical developments have been included as appendices.

\section{AGKNOWLEDGEMENTS}

The assistance of J. P. Sanders, Reactor Division, and C. W. Entemann, formerly of the Computer Technology Center, GRGDP, in the formulation and solution of the original heat transfer concepts.

The authors also wisi to acknowledge the contributions of $\mathrm{W}$. $\mathrm{P}$. Turner, of the Computer Technology Center, ORGDP, to tne divelopment or the CHART code and the asisstance of G. H. Llewellyn, General Engineering Division, with various calculations. 
A.PPENDICES 


\section{$110+3+2 x$}

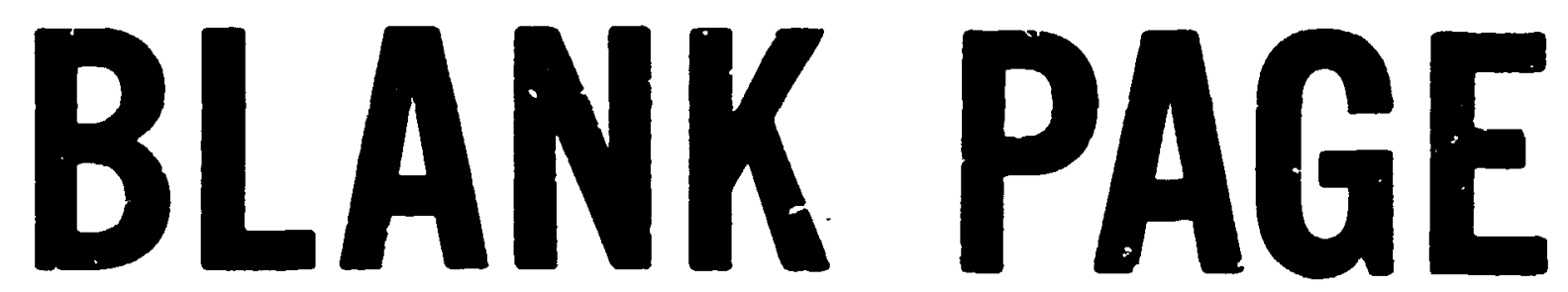


Appendix A. Analytical Solution of the Diffusion Equation for the Infinite Slab Model (Eerivation of Equation 23)

I. Solution by Green's Theorem

The diffusion equation and its boundary conditions for the infirite slab model (Eq. 22) are given as

$$
\begin{aligned}
& \rho_{b} C_{p_{b}} \frac{1}{\alpha} \frac{\partial \psi}{\partial t}=k_{b} \frac{\partial^{2} \psi}{\partial x^{2}}+q^{\prime \prime \prime}(x, t) \\
& \text { Iniriai condition: } \psi^{\prime}(x, 0)=0 \\
& \text { Boundary condition } 1: \frac{\partial \psi}{\partial x}(l, t)=0 \\
& \text { Boundary condition2: } \frac{\partial \psi}{\partial x}(l, t ;=0
\end{aligned}
$$

where

$$
q^{\prime \prime \prime}(x, t)=+B e^{-b x} \sum_{i=1}^{m} a_{i} e^{-\beta} i^{t}+G \sum_{i=1}^{m} g_{i} e^{-\beta} i_{i} .
$$

(For simplicity the double exponential $B_{1} e^{-b_{1} x}+B_{2} e^{-b_{2} x}$ was replaced by $B e^{-b x}$ since the procedure of solution is the same.)

Here the one-dimensional Green theorem for conduction* can be used where instead of initial temperature $f(x, t)$ we have heat generatio. $A(x, t)$ per unit time, per unit volume. We get then:

$$
\psi(x, t)=\int_{0}^{t} \int_{0}^{\ell} u\left(x, x^{\prime}, t-\tau\right) \frac{q^{\prime \prime}\left(x^{\prime}, \tau\right)}{\rho_{b} C_{p_{b}}} d x^{\prime} d \tau
$$

where $u(x, t-\tau)$ is the corresponding Green function for instantaneous plare source of unit strength at $t=0$ and at $x^{\prime}$, for a slab $0 \leq x \leq \ell$ with no heat flow over the boundaries $x= \pm l$.

The required Green function is:

$$
u(x, t-\tau)=\frac{1}{\ell}\left[1+2 \sum_{n=1}^{c o} e^{-\frac{\alpha n^{2} \pi^{2}}{\ell^{2}}(t-\tau)} \cos \frac{n \pi x}{\ell} \cos \frac{n \pi x^{\prime}}{\ell}\right] .
$$

Substituting this equation into Eq. (A-2) we get

\footnotetext{
*Carslaw, H. W. and Jaege-, J. C., "Conduction of Heat in Solids," Oxford University Presia, 1959, Paragráph 14.3III(7).
} 


$$
\begin{aligned}
& \psi(x, t)=\int_{0}^{t} \int_{0}^{\ell} \frac{q^{\prime \prime}\left(x^{\prime}, \tau\right)}{l \rho_{b} \delta p_{b}}\left[1+2 \sum_{n=1}^{a} e^{\left.-a_{n}^{2} \pi^{2}:=-\tau\right) / l^{2}} \cos \frac{n^{\pi x}}{\ell} \cos \frac{n x^{\prime}}{l}\right] d x^{\prime} d \tau \\
& =\frac{1}{\rho_{b} C_{P_{b} l} l} \int_{0}^{t} \int_{0}^{\ell} q^{\prime \prime \prime}\left(x^{\prime}, \tau\right) d x^{\prime} d_{\tau}+\frac{2}{\rho_{b} C_{p_{b}} l} \sum_{n=1}^{\infty}
\end{aligned}
$$

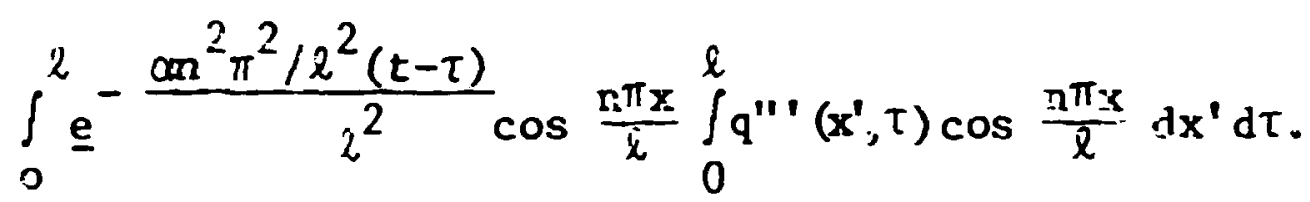

Using Eq. $(A-1)$, we get:

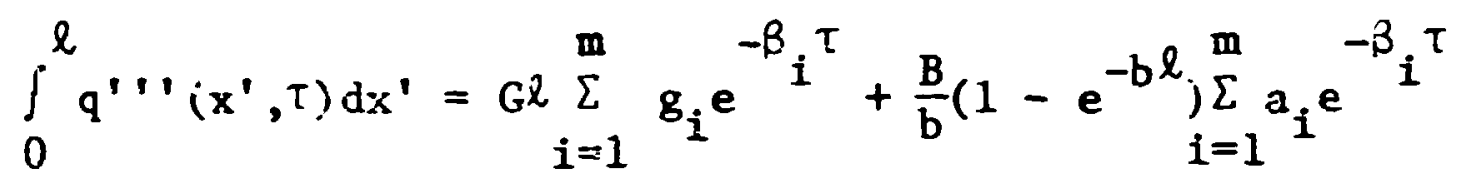

and

$$
\begin{aligned}
& \int_{0}^{\ell} q^{\prime} \cdots\left(x^{\prime}, \tau\right) \cos \frac{n \pi x^{\prime}}{\ell} d x^{\prime}=G \sum_{i=1}^{m} g_{i} e^{-\beta} i^{\tau}\left[\sin \frac{n^{\pi} x^{\prime}}{\ell}\right]_{0}^{\ell} \frac{\ell}{n^{\top}} \\
& +B\left(\sum_{i=1}^{m} a_{i} e^{-\beta} i^{\tau}\right) \int_{0}^{\ell} e^{-b x} \cos \frac{n \pi}{l} x^{\prime} d x^{\prime} \\
& =B\left(\sum_{i=1}^{\pi} a_{i} e^{-\beta} e^{\tau}\right)\left[\frac{e^{-b x^{\prime}}}{b^{2}+\left(\frac{n \pi}{l}\right)^{2}}\left(-b \cos \frac{n \pi x^{\prime}}{\Gamma^{\prime}}+\frac{n \pi}{l} \sin \frac{a \pi}{l} x^{\prime}\right)\right]_{0}^{l} \\
& =B\left(\sum_{i=1}^{\mathbb{a}} a_{i} e^{-\beta_{i} T}\right)\left[\frac{-b(-1)^{n} e^{-b l}+b}{b^{2}+\left(\frac{n \pi}{l}\right)^{2}}\right] \\
& =b B\left(\sum_{i=1}^{m} a_{i} e^{-B} i^{\tau}\right)\left[\frac{1-(-1)^{n} e^{-b l}}{b^{2}+\left(\frac{n \pi}{l}\right)^{2}}\right] \text {. }
\end{aligned}
$$

Substituting Eq. $(A-4)$ and $(A-5)$ into Eq. (A-3), se get: 


$$
\begin{aligned}
& \psi(x, t)=\int_{0}^{\tau}\left[\frac{G}{\rho_{b} C_{p_{b}}} \sum_{i=1}^{m} g_{1} e^{-\beta i \tau}+\frac{B}{\ell \rho_{b} C_{p_{t}}{ }^{3}}\left(i-e^{-b l}\right) \sum_{i=1}^{m} a_{i} e^{-3} i^{\tau}\right.
\end{aligned}
$$

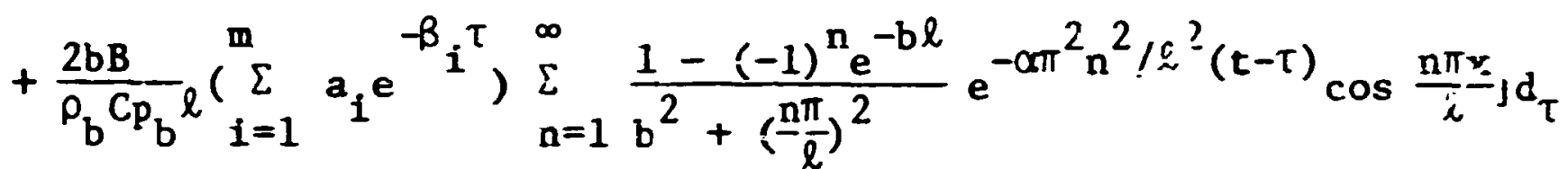

$$
\begin{aligned}
& \psi(x, t)=\frac{G}{\rho_{b} C p l} \sum_{i=1}^{a} g_{i} \int_{a}^{t} e^{-B} e^{\tau} \tau_{\tau}+\frac{B\left(1-e^{-b l}\right) m}{\rho_{b} C_{p_{b}} b l} \sum_{i=1}^{m} a_{i} \int_{0}^{t} e^{-\beta_{i} \tau} d_{\tau} \\
& +\frac{2 B b}{\rho_{b} C p_{b} l_{n=1}^{\infty}} \frac{\left(1-(-1)^{u} e^{-b l}\right)}{b^{2}+\left(\frac{n \pi}{l}\right)^{2}} \cos \frac{n \pi x}{l} \sum_{i=1}^{m} a_{i} \int_{0}^{t} e^{-\beta} e^{\tau-\frac{\operatorname{con}^{2} \pi^{2}}{l^{2}}(t-\tau) d \tau} \\
& \int_{0}^{t} e^{-B_{i} \tau} d_{\tau}=\left[-\frac{1}{\beta_{i}} e^{-\beta_{i} \tau}\right]_{0}^{t}=\frac{1}{\beta_{i}}\left(1-e^{-B_{i} \tau}\right)
\end{aligned}
$$

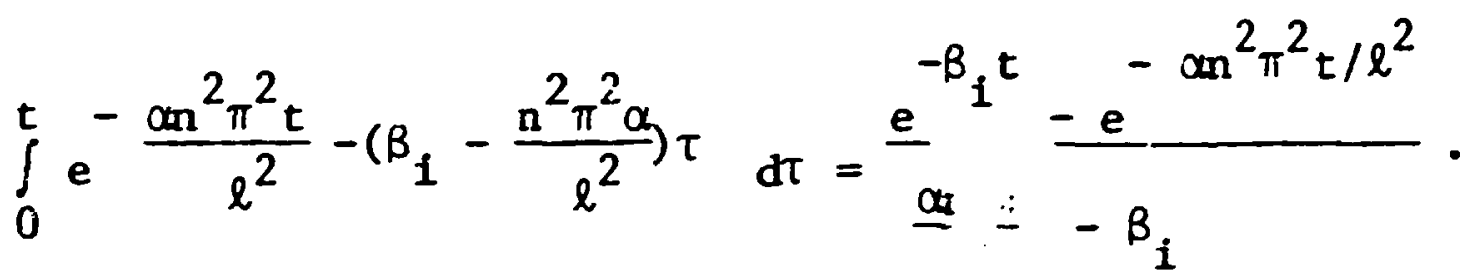

Substituting back into Eq. (A-6), we get:

$$
\begin{aligned}
& \psi(x, t)=\frac{G}{\rho_{b} c_{p_{b}}}-\sum_{i=1}^{m} \frac{g_{i}}{\beta_{i}}\left(1-e^{-\beta_{i} t}\right)+\frac{B(1}{\left.\rho_{b} c_{p_{b}}-e^{-b l}\right)} \sum_{i=1}^{m} \frac{a_{1}}{\beta_{1}}\left(1-e^{-\beta_{i} t}\right) \\
& +\frac{2 B b}{\rho_{b} c_{p_{b}}}-\sum_{n=1}^{\infty} \frac{\left[1-(-1)^{n} e^{-b l}\right]}{b^{2}+\left(\frac{n \pi}{l}\right)^{2}} \cos \frac{n \pi x}{\ell} \sum_{i=1}^{m} \frac{a_{i}\left(e^{-\beta_{i} t}-e^{-\alpha n^{2} \pi^{2} t / l^{2}}\right)}{\frac{\alpha n^{2} \pi^{2}}{l^{2}}-\beta_{1}}
\end{aligned}
$$

Remembering from Eq. (21) that

$$
T_{b}^{\prime}(x, t)=T_{b}(x, t)-T_{g}=\psi(x, t) e^{-\alpha(H / k) t}
$$

and from Eq. (22a) that

$$
\beta_{i}=\lambda_{i}-\alpha(H / k)
$$

we can get the solution for $T_{b}^{\prime}$ as given in Eq. (23) in the report. 
II. Sclution by Fourier Consine Series Expansion Again the diftusion equation is given by:

$$
\frac{\partial^{2} \psi(x, i)}{\partial x^{2}}-\frac{1}{a} \frac{\partial \psi(x, t)}{\partial t}=\frac{p}{k} e^{-b x} \sum_{i=1}^{c} a_{i} e^{-B_{i} t}-\frac{G}{k} \sum_{i=1}^{m} g_{i} e^{-B_{i} t} .
$$

The bcundary conditions are:
(a) $\psi(x, c)=0$
(b) $\frac{\partial \psi_{i}}{\partial x_{i}=0}=0$

We expand the solution (if any) in a Fourier cosine series.

$$
\dot{\psi}(x, t) \sim \sum_{n=0}^{\infty} c_{n}(t) \cos \frac{n \pi x}{\ell}
$$

where

$$
c_{n}(t)=\frac{2}{\ell} \int_{0}^{l} \|(x, t) \cos \frac{n \pi x}{l} d x .
$$

The set of all $c_{n}(t)$ uniquely determines $\psi(x, t)$ and is called the finite cosine transform of $\psi(x, t)$. We assume $\partial^{2} \psi(x, r) / \partial x^{2}$ is continuous and get:

$$
\begin{aligned}
& \frac{2}{l} \int_{0}^{l} \frac{\partial^{2} \psi(x, t)}{\partial x^{2}} \cos \frac{n \pi x}{l} d x=\frac{2}{\ell}\left[\frac{\partial \psi(x, t)}{\partial x} \cos \frac{n \pi x}{l}\right]_{0}^{l} \\
& +\frac{2}{\ell}\left[\frac{n \pi}{\ell} \int_{i}^{l} \frac{\partial \psi^{\prime}(x, t)}{\partial x} \sin \frac{n \pi x}{l} d x\right] .
\end{aligned}
$$

The first term is zero since $\frac{\partial \psi}{\partial x_{r x=0}}=0$.

$$
x=\ell
$$

$$
\frac{n \pi}{l} \int_{0}^{l} \frac{\partial \psi(x, t)}{\partial x} \sin \frac{n \pi x}{l} d x=\frac{n \pi}{l}\left[\psi(x, t) \sin \frac{n \pi x}{l}\right]_{0}^{l}-\frac{n^{2} \pi^{2}}{l^{2}} \int_{0}^{l} \psi(x, t) \cos \frac{n \pi x}{l} d x .
$$

Therefore: 


$$
\frac{2}{\ell} \int_{0}^{\ell} \frac{\partial^{2}-\psi(x, t)}{\partial x^{2}} \cos \frac{n \pi x}{l} d x=-\frac{\underline{n}^{2} \pi^{2}}{l^{2}}\left[\frac{2}{\ell} \int_{0}^{\ell} \psi(x, t) \cos \frac{n \pi x}{l} d x\right]
$$

Therefore the cosine transform of

$$
\begin{aligned}
& \frac{\partial^{2} \cdot \dot{\psi}(x, t)}{\partial x^{2}}=-(n \pi / \ell)^{2} c_{n}(t) . \\
& \frac{2}{\ell} \int_{0}^{l} \frac{\partial \psi(x, t)}{\partial t} \cos \frac{n \pi x}{\ell} d x=\frac{\partial}{\partial t}\left[\frac{2}{\ell} \int_{0}^{l} \psi(x, t) \cos \frac{n \pi x}{\ell} d x\right]=\frac{d c_{n}(t)}{\partial t} .
\end{aligned}
$$

Therefore the equation to be solved to find the cosiue transform is:

$$
-(n \pi / \chi)^{2} c_{n}(t)-\frac{1}{\alpha} \frac{d c_{n}(t)}{d t}=A_{n}(t) .
$$

where

$$
A_{n}(t)=\frac{2}{\ell} \cdot \int_{0}^{\ell}\left[-\frac{B}{K} e^{-b x} \sum_{i=1}^{m} a_{i} e^{-\beta} e_{i}^{t}-\frac{G}{k} \sum_{i=1}^{m} g_{i} e^{-\beta} e^{t}\right] \cos \frac{n \pi x}{x} d x .
$$

Rewrite (A-9) to get:

$$
\frac{d c_{n}(t)}{d t}+\alpha(n \pi / \hat{x})^{2} c_{n}(t)=-x A_{n}(t)
$$

then:

$$
e^{(n \pi / l)^{2} t} \frac{d c_{n}(t)}{d t}+\alpha\left(\frac{n \pi}{\ell}\right)^{2} c_{n}(t) e^{\alpha(n \pi / l)^{2} t=-\alpha A_{n}(t) e^{\alpha(n \pi / l)^{2} t} \cdot(A-10)}
$$

Note that:

$$
\begin{aligned}
& \frac{d}{d t} {\left[e^{\alpha(n \pi / l)^{2}} t_{c_{n}}(t)\right]=e^{\alpha(n \pi / l)^{2} t \frac{d}{d t} c_{n}(t)} } \\
&+\alpha\left(\frac{n \pi}{l}\right)^{2} c_{n}(t) e^{\alpha(n \pi / l)^{2} t}
\end{aligned}
$$

Then Eq. $(A-10)$ can be written, using $t=\tau$,

$$
\frac{d}{d \tau}\left[e^{\alpha(n \pi / l)^{2} \tau} c_{n}(\tau)\right]=-\alpha A_{n}(\tau) e^{\alpha(n \pi / l)^{2} \tau}
$$

Integrating from $n+t$ gives: 


$$
\begin{aligned}
& e^{\alpha(n \pi / \hat{x})^{2} t} c_{n}(t)-c_{n}(0)=\int_{0}^{t}-\alpha A_{n}(\tau) e^{\alpha(n \pi / \ell)^{2}} d \tau \\
& c_{n}(t)=-e^{-\alpha(n \pi / \ell)^{2} t} \int_{0}^{t} A_{n}(\tau) e^{\alpha(n \pi / l)^{2} \tau} d_{\tau}
\end{aligned}
$$

(The condition $\psi(x, 0)=C$ requires that $c_{n}(0)=0$. For $n=0$ Eq. $(A-9)$ becomes:

$$
\frac{d c_{0}(t)}{d t}=-x A_{0}(t)
$$

or

$$
c_{0}(t)-c_{0}(0)=-\alpha \int_{0}^{t} A_{0}(\tau) d_{\tau}
$$

which is in agreement with Eq. $(A-11)$. To evaluate the integral in $(A-11)$ we first find $A_{n}(t)$.

$$
A_{n}(t)=\frac{-2 B}{l k} \sum_{i=1}^{m} a_{i} e^{-R_{i} t} \int_{0}^{l} e^{-b x} \cos \frac{n \pi x}{l} d x-\frac{2 G}{k^{l}} \sum_{i=1}^{m} g_{i} e^{-R_{i} t} \int_{0}^{l} \cos \frac{n \pi x}{l} d x
$$

For $n \neq 0$ :

$$
\begin{aligned}
& \int_{0}^{l} e^{-b x} \cos \frac{n \pi x}{l} d x=\left[\frac{e^{-b x}}{b^{2}+\left(\frac{n \pi}{l}\right)^{2}}\left(-b \cos \frac{n \pi x}{l}+\frac{n \pi}{\ell} \sin \frac{n \pi x}{l}\right)\right]_{0}^{l} \\
& =\frac{b}{i^{2}+\left(\frac{n \pi}{i^{2}}\right)^{2}}\left(1-(-1)^{n} e^{-b \ell}\right]
\end{aligned}
$$

and

For $\mathbf{n}^{0}=0$ :

$\int_{0}^{\ell} \cos (n \pi x / \ell) d x=0$.

$\int_{0}^{\ell} e^{-b x} \cos (n \pi x / \ell) d x=\int_{0}^{\ell} e^{-b x} d x=(1 / b)\left(1-e^{-b \ell}\right)$

and

$$
\int_{0}^{\ell} \cos (n \pi x / \ell) d x=\ell
$$

For $\mathbf{n} \neq 0$ : 


$$
\begin{aligned}
& \int_{0}^{t} A_{n}(\tau) e^{l(n \pi / \alpha)^{2} \tau} d \tau=\frac{-2 B b}{l k} \frac{1-(-1)^{n} e^{-b l}}{b^{2}+\left(\frac{n \pi}{l}\right)^{2}} \sum_{i=1}^{m} a_{i} \int_{0}^{t} e^{\left[\alpha(n \pi / l)^{2}-B_{1}\right] \tau} d \tau \\
& =\frac{-2 B b}{l k} \frac{1-(-1)^{n} e^{-b l}}{v^{2}+\left(\frac{n \pi}{l}\right)^{2}} \sum_{i=1}^{m} a_{i}\left[\frac{\left.e^{\alpha(n \pi / l)^{2}}-B_{i}\right] t}{\alpha\left(\frac{n \pi}{l}\right)^{2}}-B_{i}\right]
\end{aligned}
$$

For $\mathrm{n}=0$ :

$$
\begin{aligned}
& \int_{0}^{t} A_{0}(\tau) d \tau=\frac{-B}{l k b}\left(1-e^{-b l}\right) \sum_{i=1}^{m} a_{i} \int_{0}^{t} e^{-B_{i} \tau} d \tau \\
& -\frac{G}{k} \sum_{i=1}^{m} 8_{i} \int_{0}^{t} e^{-\beta_{1} \tau} d \tau
\end{aligned}
$$

From $(A-11)$ we have:

$$
c_{n}(t)=-\alpha e^{-\alpha\left(\frac{n \pi}{\ell}\right)^{2} t} \delta^{t} A_{n}(\tau) e^{\alpha(n \pi / \ell)^{2} \tau} d \tau
$$

Therefore

Therefore:

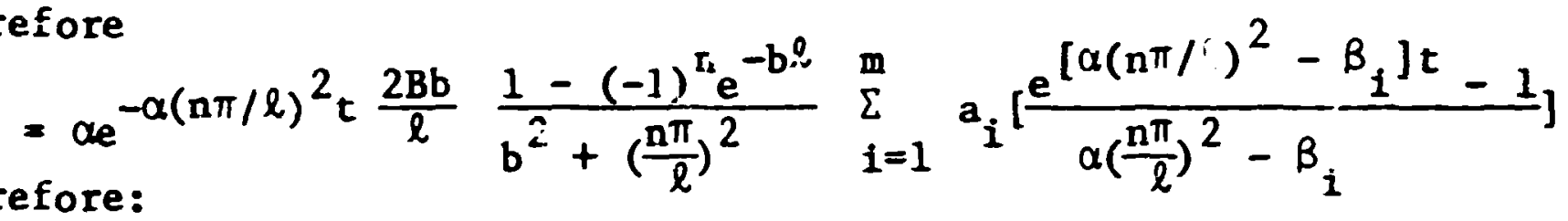

$$
c_{n}(t)=\frac{2 \alpha B b}{l k} \frac{1-(-1)^{n} e^{-b l} m}{b^{2}+\left(\frac{n \pi}{l}\right)^{2}} \sum_{i=1}^{m} a_{i}\left[\frac{e^{-\beta_{i} t}-e^{-\alpha(\pi n / l)^{2} t}}{\alpha\left(\frac{n \pi}{l}\right)^{2}-\beta_{i}}\right]
$$

$$
\begin{aligned}
& c_{0}(t)=-a \int_{0}^{t} A_{0}(\tau) d_{\tau}=-\frac{B \alpha}{\ell k b}\left(1-e^{-b l}\right) \sum_{i=1}^{m} \frac{a_{i}}{\beta_{i}}\left(e^{-B_{i} t}-1\right) \\
& -\frac{c \alpha}{k} \sum_{i=1}^{m} \frac{g_{i}}{\beta_{i}}\left(e^{-\beta_{i} t}-1\right) .
\end{aligned}
$$

For $t=0$ both of these quantities are 0 so the boundary condition $(x, 0)=0$ is satisfied. Finally we get then: 


$$
\begin{aligned}
& \psi(x, t)=\frac{-B}{b \rho_{b} C p_{b} \ell}\left(i-e^{-b l}\right) \sum_{i=1}^{m} \frac{a}{B}_{i}\left(e^{-\beta_{i} t}-1\right) \\
& -\frac{G}{\rho_{b}} \overline{C P}_{b}^{m} \sum_{i=1}^{m} \frac{8_{i}}{B_{i}}\left(e^{-B_{i} t}-1\right)+\frac{2 B b}{\rho_{b} C_{b} t} \sum_{n=1}^{\infty} \\
& {\left[\frac{1-(-1)^{n} e^{-b l}}{h^{2}+\left(\frac{n \pi}{l}\right)^{2}} \cos \frac{n \pi x}{l} \sum_{i=1}^{m} a_{i}\left[\frac{e^{-\beta} i^{t}-e^{-\alpha(n \pi / l)^{2} t}}{\alpha\left(\frac{n \pi}{l}\right)^{2}-\beta_{i}}\right]\right.}
\end{aligned}
$$

Equation $(A-12)$ is the same as Eq. $(A-7)$ and here too we can suistitute

$$
T_{b}(x, t)-T_{B}=Q(x, t)=\psi(x, t) e^{-\alpha(H / k) t}
$$

and

$$
\beta_{i}=\lambda_{i}-\alpha(H / k)
$$

to get the solutioa appearing in Eq. (31) in the zeport.

Note: Boch Eqs. $(A-i)$ and $(A-11)$ are solutions for the sirgle exponential $\mathrm{Be}^{-\mathrm{bx}}$. The solution for doutie exponential $\mathrm{B}_{1} \mathrm{e}^{-3_{1}{ }^{\mathrm{X}}+}$ $B_{2} e^{-b} 2^{x}$ is reacined the same way. 


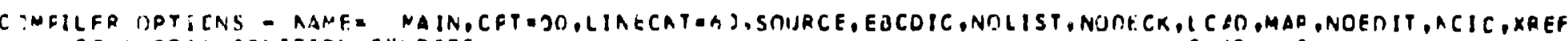

ISN RON2

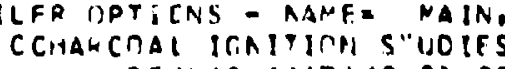

$9(: 1,1.7832: C ?, 1,7 t 4671$

CHAR

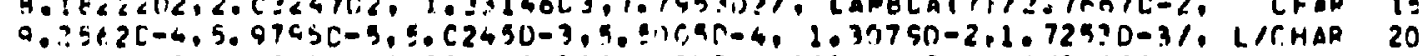

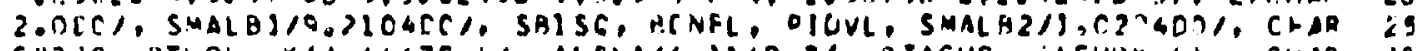

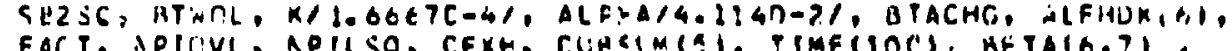

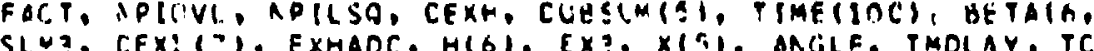

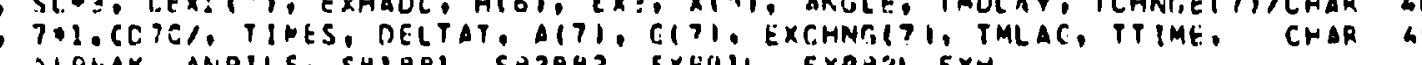

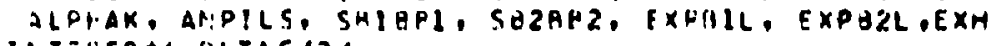

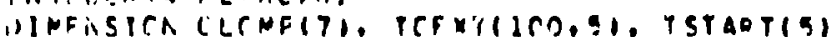

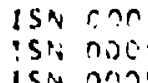

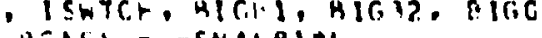

iTHDL: STMLH?DL

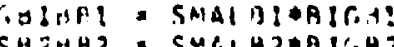

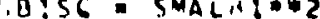

SHZSC. SMALHZOE

EXERIL: DEXPIPCNEL

ICVi:3.14:55205\%14

If (ISHTCH) $=0,40,20$

isrich ismich is

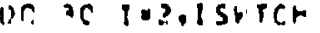

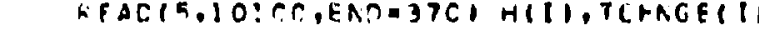
Craplaut

in ALFHAK DALPHAIK

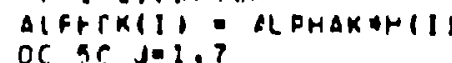

39$$
\text { aETALI, Ji }
$$

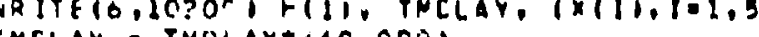

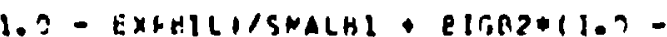
cCast? - acthjogigrick

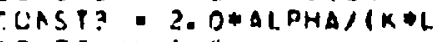

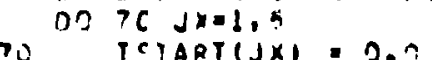

is is nom:

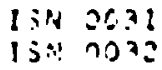

$\sin 003$

isN 2074

isN 5030

is 2 ist

ISN 2010

is
is
is
is

isn COSt

SN 206

iSN 0747

if limclar-b. De-ei aceecico alis: AAII'

ar continur

o.e $10: 20$

$$
\text { ic: } 20
$$

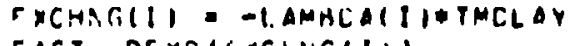

FACT= OF XPIFXC+NGIII

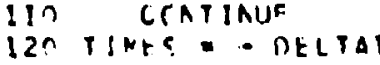

Chitie $=1$

ICPCTE = 


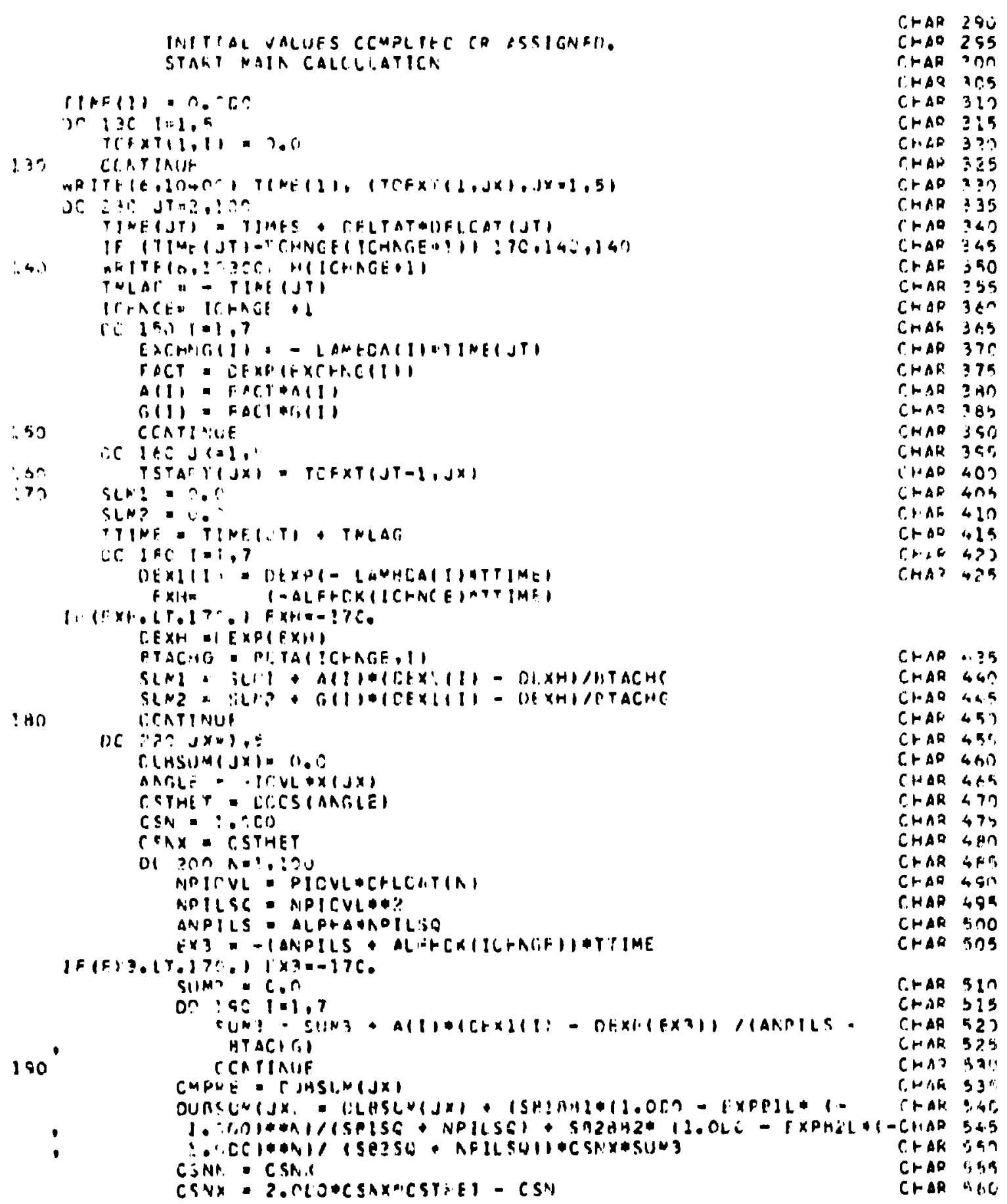




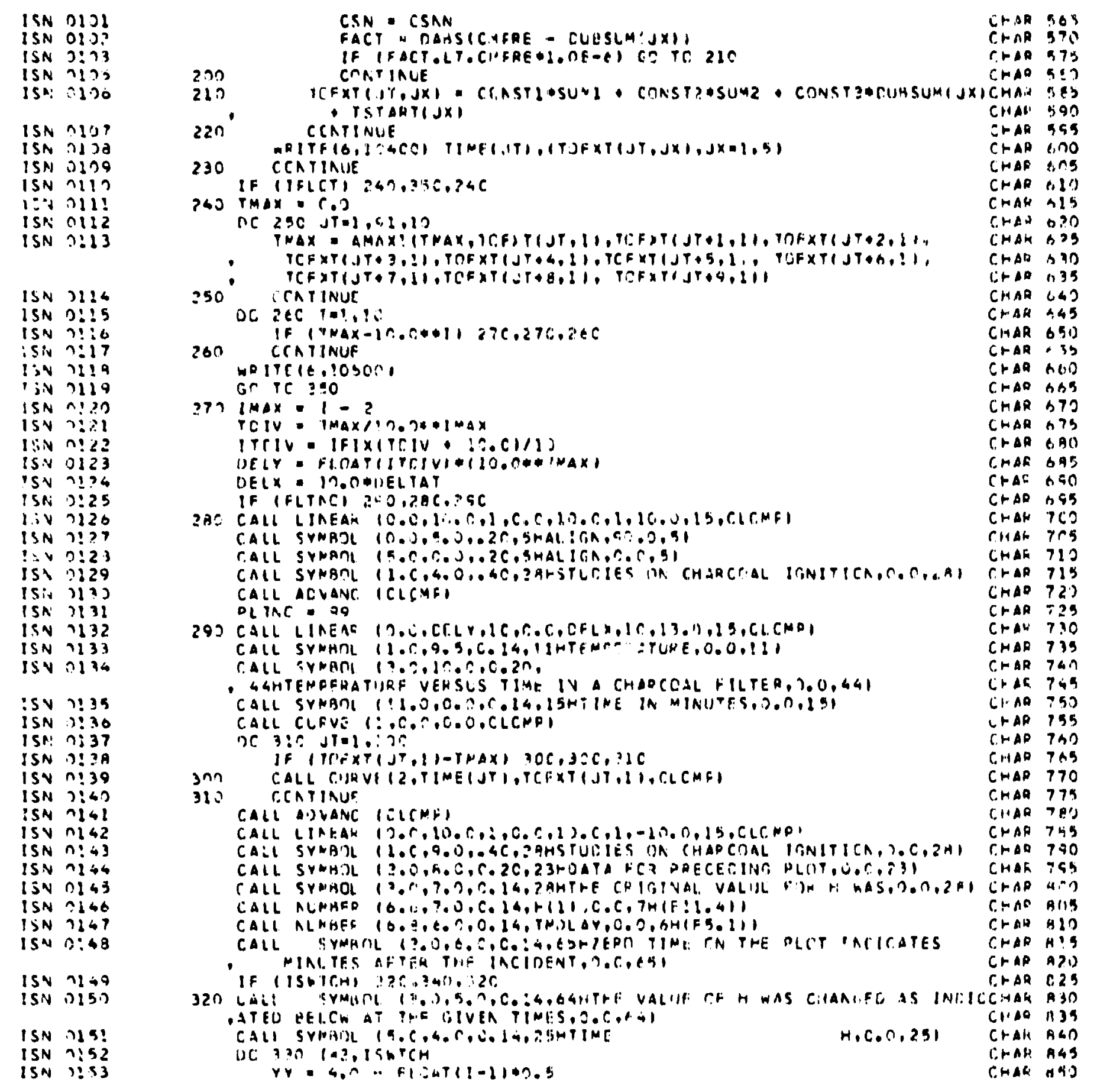




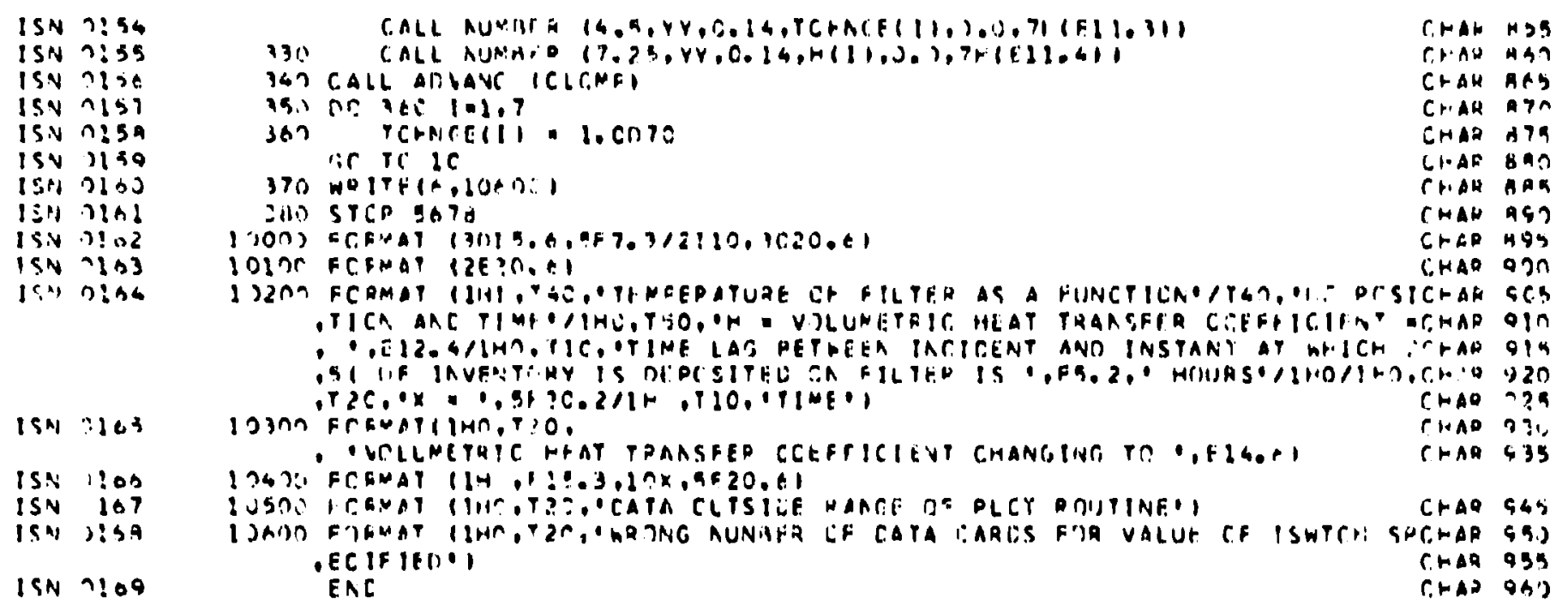


Table A-1. Input Data Required for ENIS Code

\begin{tabular}{|c|c|c|c|c|}
\hline Colunn & Formac & Varlable Name & Varlable MeanIng & Units \\
\hline \multicolumn{5}{|c|}{ Card No. 1} \\
\hline $1-15$ & $\begin{array}{l}0 . x \times x x x x D \pm x x \\
(D .15 .6)\end{array}$ & $H(1)$ & $\begin{array}{l}\text { First value of the volumetric } \\
\text { heat transfer coeffictent }\end{array}$ & Btu/min-1n. ${ }^{3}-{ }^{\circ} F$ \\
\hline $16-30$ & & DELTAT & $\begin{array}{l}\text { Time increment to be used for } \\
\text { a given run }\end{array}$ & Minute \\
\hline $31-45$ & \multirow{3}{*}{$\begin{array}{l}\mathrm{XXX} . \mathrm{XxX} \\
\mathrm{F} 6.3\end{array}$} & TMDLAY & \multirow{3}{*}{ 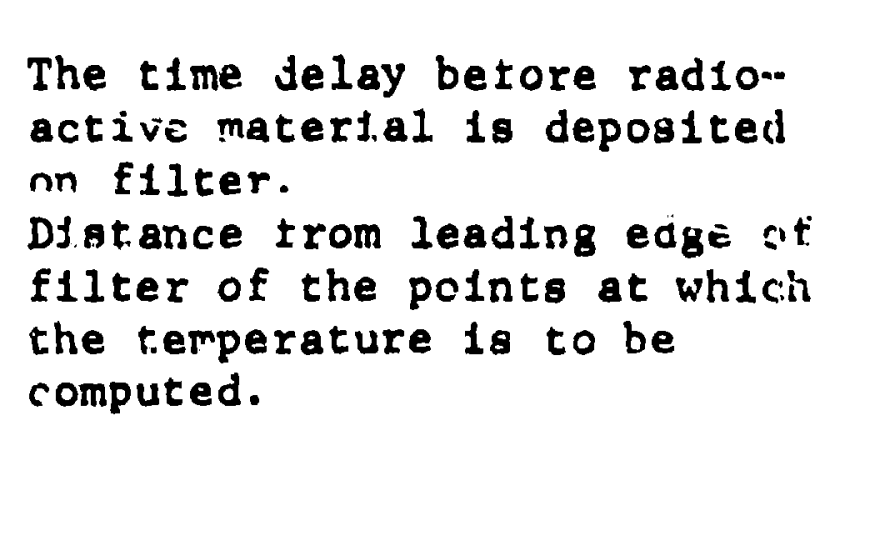 } & Hours \\
\hline & & & & Inch \\
\hline $\begin{array}{l}5 i-59 \\
60-66 \\
67-73 \\
74-80\end{array}$ & & $\begin{array}{l}X(2) \\
X(3) \\
X(4) \\
X(5)\end{array}$ & & \\
\hline \multicolumn{5}{|c|}{ Card No. 2} \\
\hline $1-10$ & $\begin{array}{l}x \times x x \times x x x x x \\
\text { I10 }\end{array}$ & 1PLOT & $\begin{array}{l}\text { Leave blank if no plcts are } \\
\text { desired. Any non-zero integer } \\
\text { in col. } 10 \text { w111 cause plots } \\
\text { to be generated. }\end{array}$ & Dimenstonless \\
\hline $11-20$ & \multirow{4}{*}{$\begin{array}{l}0 . \operatorname{xxxxxxD+xx} \\
(D 20.6)\end{array}$} & ICHNGE & $\begin{array}{l}\text { Leave blank if volumetrlc heat } \\
\text { transfer coetficient remalns } \\
\text { constant througholdt a glveit case. } \\
\text { contains the number of changes, }\end{array}$ & \multirow{3}{*}{$\frac{\text { tonis of } U}{\text { In. }^{3}{ }_{\text {" of bed }}}$} \\
\hline $21-40$ & & BIGB I & $\begin{array}{l}\text { up to } 5, \text { in col. } 20 \text { otherwise. } \\
\text { nenotss p"power" of I for the } \\
\text { reactu: under consideration. }\end{array}$ & \\
\hline $41-60$ & & BIGB2 & Same as BIGBi hut for $\mathrm{CH}_{3} \mathrm{I}$. & \\
\hline $61-80$ & & BIGG & $\begin{array}{l}\text { Denotes } \gamma^{\prime \prime p o w e r " ~ f o r ~ t h e ~} \\
\text { reactor under cons } 1 \text { deration. }\end{array}$ & $"$ \\
\hline
\end{tabular}




\begin{tabular}{|c|c|c|c|c|}
\hline Column & Format & Varlable Name & Vyrlable Meanlng & $\operatorname{lin} 1 t 8$ \\
\hline \multicolumn{5}{|c|}{ Cards 3-7 } \\
\hline $0-20$ & $\begin{array}{l}0 . X X X X X X \mathrm{XX}+X X \\
\mathrm{E} 20.6\end{array}$ & $H(I)$ & $\begin{array}{l}\text { "New" values of the } \\
\text { volumetric heat tranefer } \\
\text { coefflcient }\end{array}$ & Btu/min-1n. \\
\hline $21-40$ & & $\operatorname{TCHNGE}(I)$ & $\begin{array}{l}\text { Time at which cliange to } H(I) \\
\text { takee effect. }\end{array}$ & Minute \\
\hline
\end{tabular}




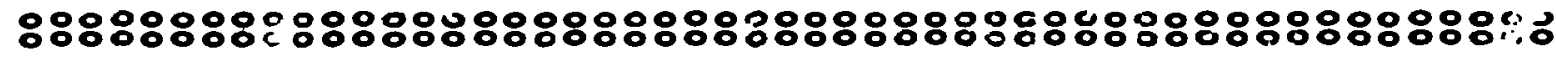

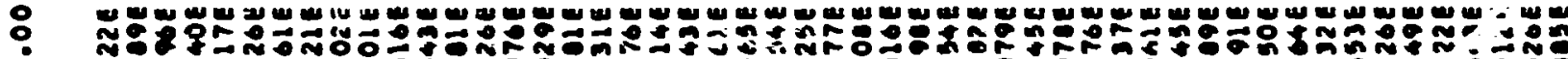

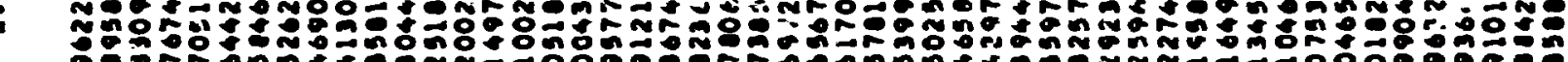

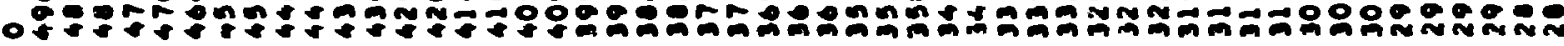

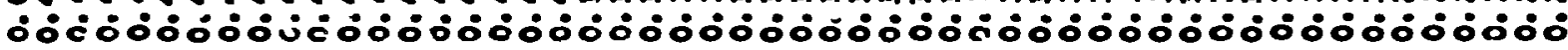

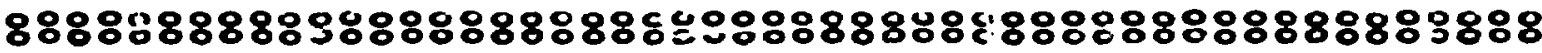

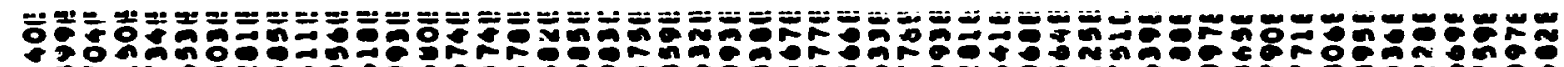

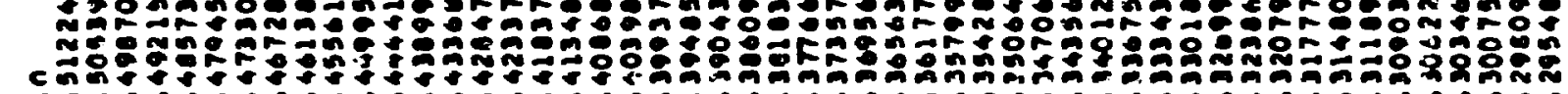

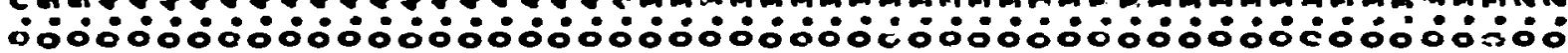$$
\text { ๑ัต }
$$

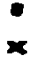

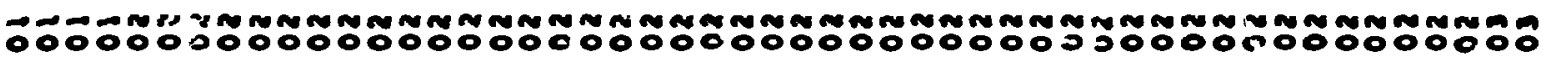

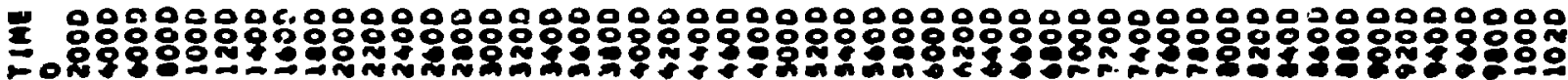

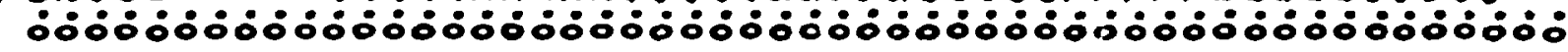


:88:88:8:8:88:8:8:8:8:8:8:8:8:8:8:

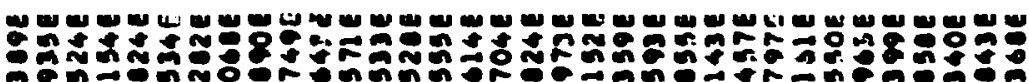

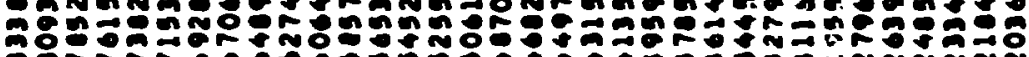

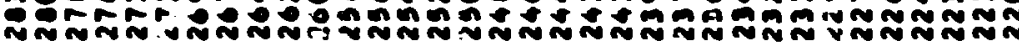

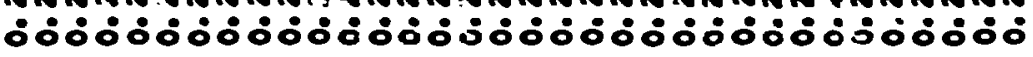

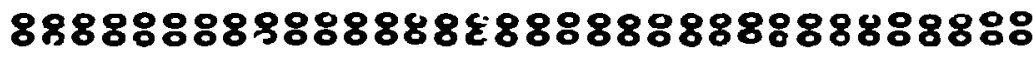

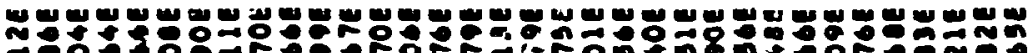

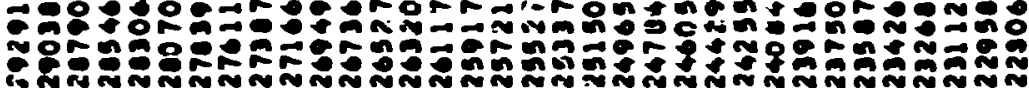

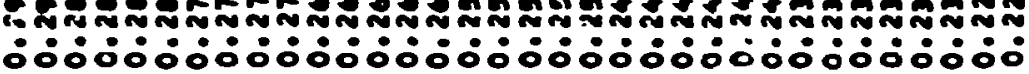

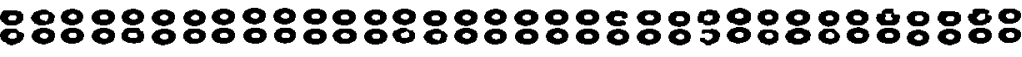

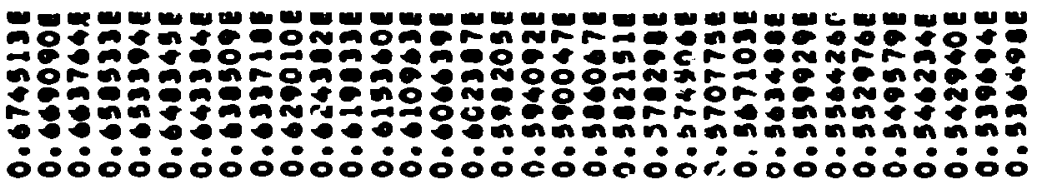

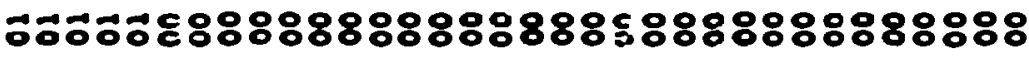

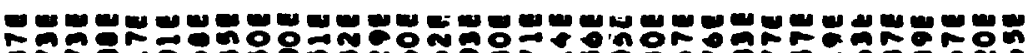

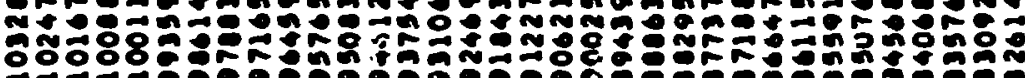

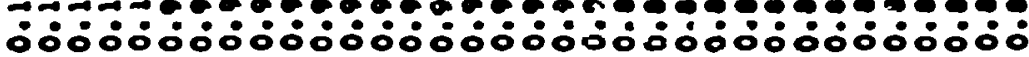

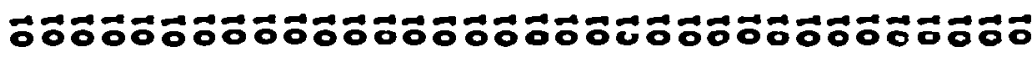

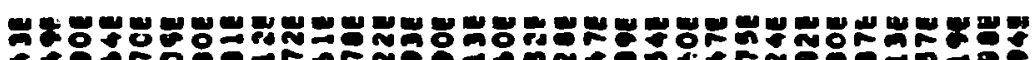

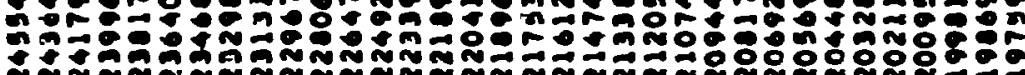

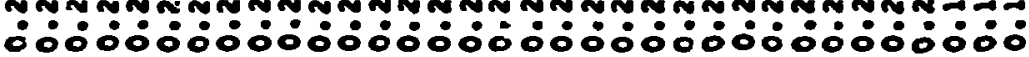

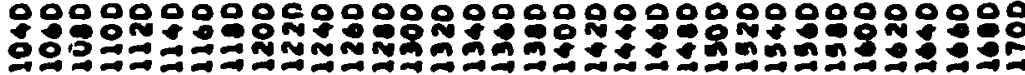

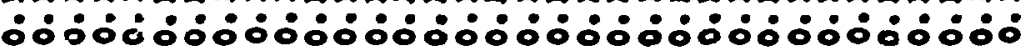


Appendix B. A Computer Program for Calculating Heat Generation, in a Charcoal Adsorber, Due to Iodine Decay

This program, listed on the following page, is in XTRAN, a version of Fortran IV for the time-sharing computer of the Con-Share Company. The heat generation rate due to the decay of lodine on the charcoal adsorber of the reactor syst 2 described on page 28 of the text is calculated for various times after reactor shutdown. Table B-1 is a listing of the output as it umes from the computer. 
Listing of Code for Heat Developed in the Charcoal Bed ( $Q^{\prime \prime}$ )

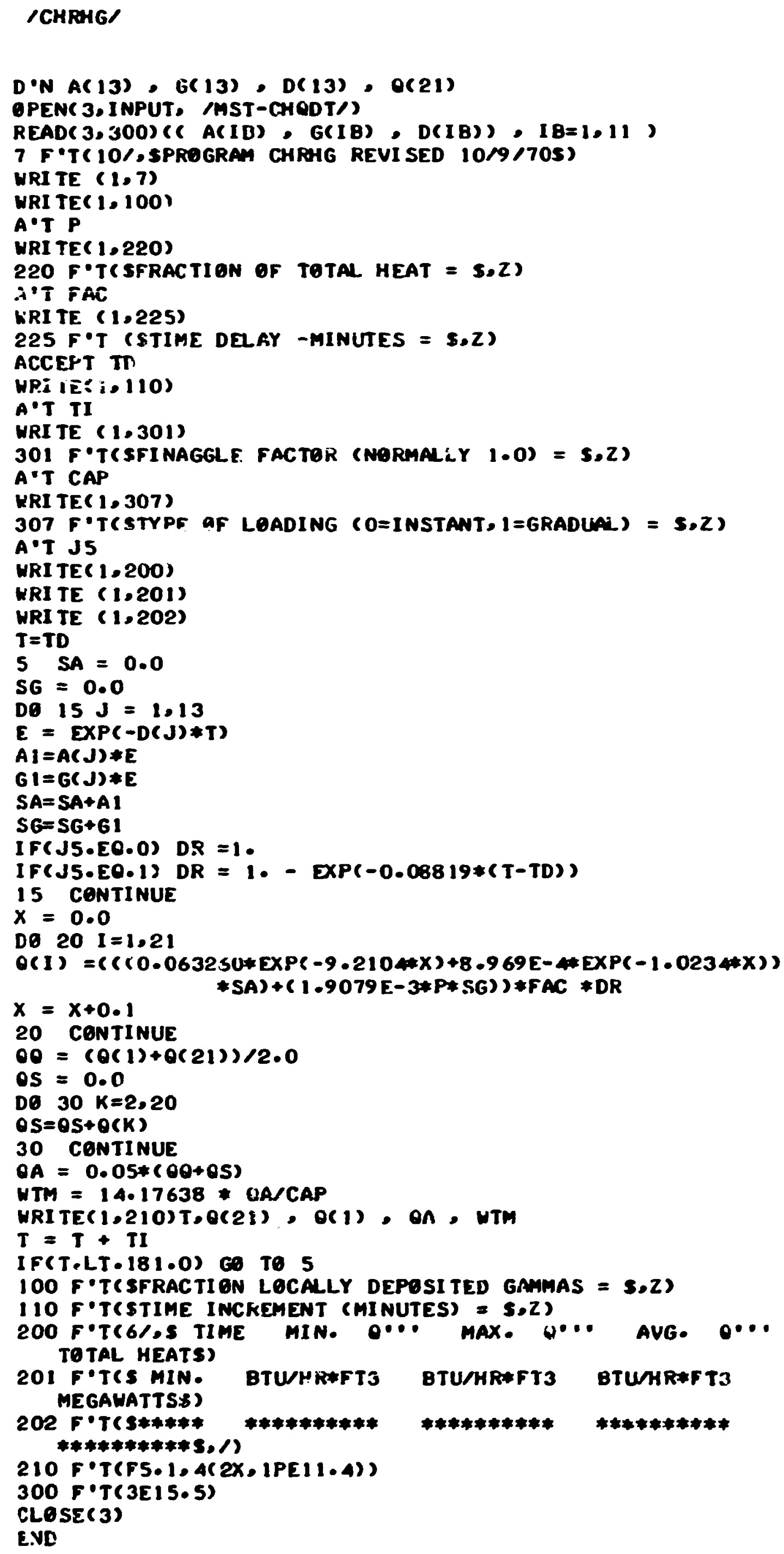


Table B-1. Output of the XIRAN Program for Comparing Heat Generation Rate from Iodine Decay Heat on Charcoal

PROGRAM CHRHG REVI SED 10/9/70

FRACTION LOCALLY DEPOSITED GAMMAS $=.5$

FRACTION OF TOTAL HEAT $=.25$

TIME DELAY - MINUTES = 10

TIME INCREMENT (MINUTES) $=2$

FINAGGLE FACTOR (NOKMALL) 1.0: $=1$

TYPE OF LOADING ( $0=1$ NSTANT, $1=$ GRADUAL $)=1$

\begin{tabular}{|c|c|c|c|c|}
\hline $\begin{array}{l}\text { TIME } \\
\text { MIN. } \\
* * * * *\end{array}$ & $\begin{array}{l}\operatorname{MIN}, \quad Q \cdots \cdot \\
\text { BTU/HR*FT3 } \\
* * * * * * * * * *\end{array}$ & $\begin{array}{l}\operatorname{MAX} \quad 6 \cdots 1 \\
\text { BTL/KR*FT3 } \\
* * * * * * * * * *\end{array}$ & $\begin{array}{l}\text { AVG } \quad 0 \cdots 1 \\
\text { 3TU/HR*FT3 } \\
* * * * * * * * * *\end{array}$ & $\begin{array}{l}\text { TO TAL HEAT } \\
\text { MEGAWATTS } \\
* * * * * * * * * *\end{array}$ \\
\hline $\begin{array}{l}10 \cdot 0 \\
12 \cdot 0 \\
14 \cdot 0 \\
16 \cdot 0 \\
18 \cdot 0 \\
20 \cdot 0 \\
22 \cdot 0 \\
24 \cdot 0 \\
26 \cdot 0 \\
28 \cdot 0 \\
30 \cdot 0 \\
32 \cdot 0 \\
34 \cdot 0 \\
35 \cdot 0 \\
38 \cdot 0 \\
40 \cdot 0 \\
42 \cdot 0 \\
44 \cdot 0 \\
46 \cdot 0 \\
48 \cdot 0 \\
50 \cdot 0 \\
52 \cdot 0 \\
54 \cdot 0 \\
56 \cdot 0 \\
58 \cdot 0 \\
60 \cdot 0 \\
62 \cdot 0 \\
64 \cdot 0 \\
66 \cdot 0 \\
68 \cdot 0 \\
70 \cdot 0 \\
72 \cdot 0\end{array}$ & $\begin{array}{l}0.0000 E+00 \\
4 \cdot 8761 E-03 \\
8 \cdot 8441 E-03 \\
1 \cdot 2063 E-02 \\
1 \cdot 4664 E-02 \\
1 \cdot 6757 E-02 \\
1 \cdot 8429 E-02 \\
1 \cdot 9756 E-02 \\
2 \cdot 0799 E-02 \\
2 \cdot 1608 E-02 \\
2 \cdot 2224 E-02 \\
2 \cdot 2682 E-02 \\
2 \cdot 3011 E-02 \\
2 \cdot 3233 E-02 \\
2 \cdot 3368 E-02 \\
2 \cdot 3423 E-02 \\
2 \cdot 3440 E-02 \\
2 \cdot 3400 E-02 \\
2 \cdot 3322 E-02 \\
2 \cdot 3214 E-02 \\
2 \cdot 3082 E-02 \\
2 \cdot 2930 E-02 \\
2 \cdot 2763 E-02 \\
2 \cdot 2584 E-02 \\
2 \cdot 2397 E-02 \\
2 \cdot 2202 E-02 \\
2 \cdot 2003 E-02 \\
2 \cdot 1801 E-02 \\
2 \cdot 1597 E-02 \\
2 \cdot 1392 E-02 \\
2 \cdot 1187 E-02 \\
2 \cdot 0982 E-02\end{array}$ & 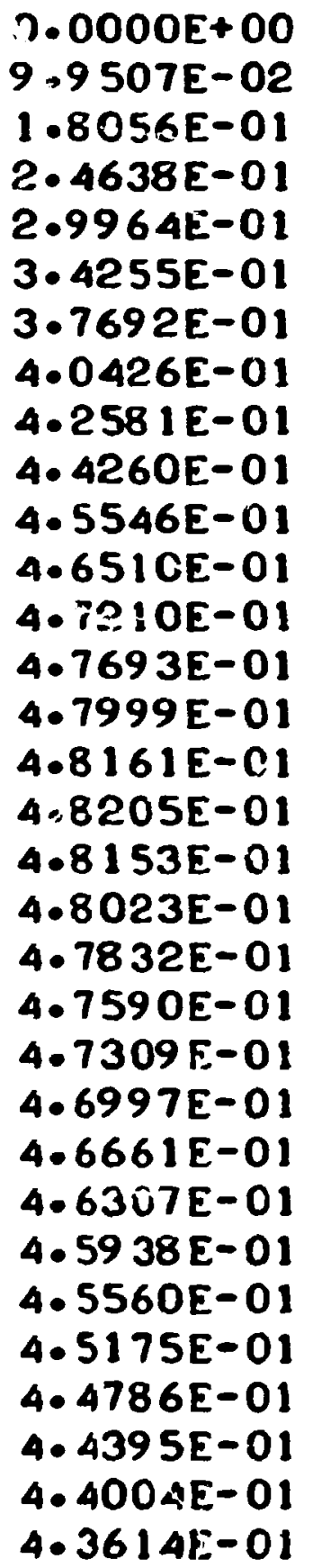 & 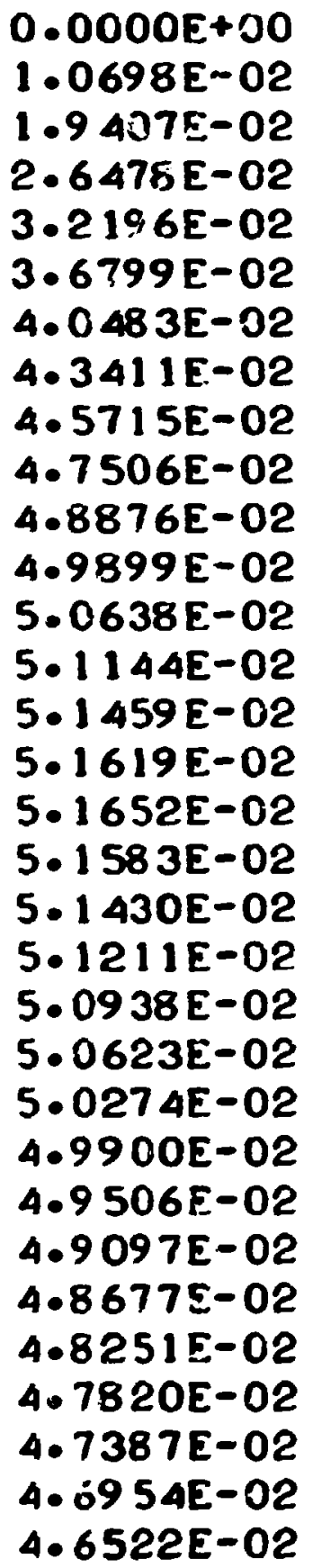 & $\begin{array}{l}C \cdot 000 C E+00 \\
1 \cdot 5165 E-01 \\
2 \cdot 7513 E-01 \\
3 \cdot 7536 E-01 \\
4 \cdot 5642 E-01 \\
5 \cdot 2167 E-01 \\
5 \cdot 7390 E-01 \\
6 \cdot 1540 E-01 \\
6 \cdot 4807 E-01 \\
6 \cdot 7346 E-01 \\
6 \cdot 9288 E-01 \\
7 \cdot 0738 E-01 \\
7 \cdot 1786 E-01 \\
7 \cdot 2503 E-01 \\
7 \cdot 2950 E-01 \\
7 \cdot 3177 E-01 \\
7 \cdot 3224 E-01 \\
7 \cdot 3126 E-01 \\
7 \cdot 2910 E-01 \\
7 \cdot 2599 E-01 \\
7 \cdot 2212 E-01 \\
7 \cdot 1765 E-01 \\
7 \cdot 1271 E-01 \\
7 \cdot 0740 E-0 ! \\
7 \cdot 0181 E-01 \\
6 \cdot 9601 E-01 \\
6 \cdot 9007 E-01 \\
6 \cdot 8402 E-01 \\
6 \cdot 7791 E-01 \\
6 \cdot 7178 E-01 \\
6 \cdot 6563 E-01 \\
6 \cdot 5951 E-01\end{array}$ \\
\hline
\end{tabular}




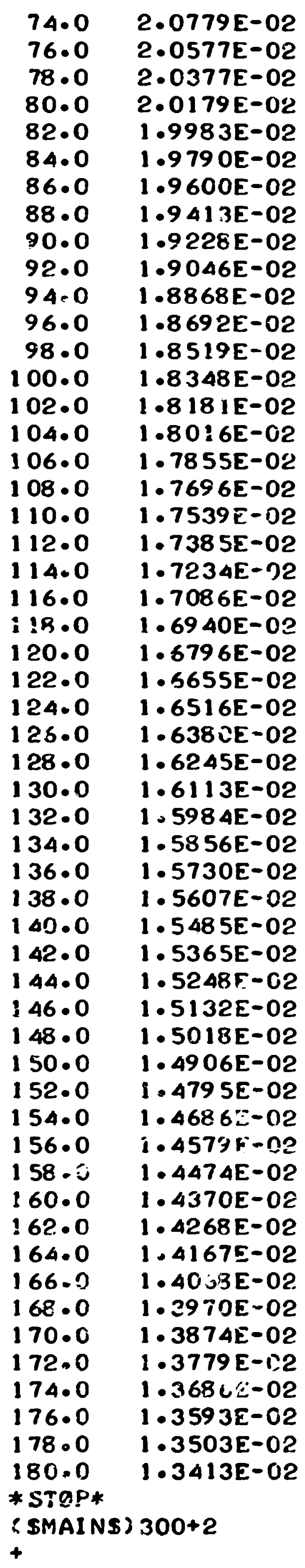

4. 3226E-01

$4.284: E-01$

$4.2459 \mathrm{E}-01$

$4.2083 E-01$

4.17105-01

4. $1343 E-01$

4. 0982E-01

4. 0626E-01

4. 0275E-C1

3.9931E-01

3.9592E- 01

$3.9259 E-01$

3.8931E-01

3.861 OE- 01

$3.8294 E-01$

3.7983E-01

3.7679E-01

$7379 E-01$

j. $7085 E-01$

3.679 7E-01

3.6513E-01

3.6235E-01

3. $5961 E-01$

3. $5693 \mathrm{E}-01$

3. 5429E-01

3. 5170E-01

3. $4916 E-01$

3. $4666 E-01$

3. $4421 E-01$

3. 4179 E- 01

$3.39425-01$

3.3709E-01

3. $3481 E-01$

3. $3256 E-01$

3. 3035E-C1

3. $2817 E-01$

3. $2604 E-01$

$3.2394 E-01$

3.2187E-01

3. 198 AE-O1

3. $1785 E-0$ !

3. $1588 \mathrm{E}-01$

3. $1395 E-01$

3. 1205E-01

3. $1018 E-U 1$

$3.0834 E-01$

3.0653E-01

3.0475E-01

3.0300E-01

3.0127E-01

2.9957E-01

2.979 0E-01

2.9626E-01

$2.9463 E-01$
4. $6092 E-02$.

$A=5665 E-02$

$4.5243 E-62$

4. $4826 E-02$

$4.4413 E-02$

4. 4007E-02

4. 3606E-02

$4.3211 E-02$

$4.2822 E-02$

$4.2439 E-02$

4.2063E-02

4. $1693 \mathrm{E}-02$

4. 1329 E-02

$4.0971 E-0 ?$

$4.0620 E-02$

$4.0275 E-02$

3.9935E-02

3.9602E-02

3.927 4E-02

3.89 52E-02

3.8636E-02

3.8326E-02

3.8020E-02

3.7720E-02

3.7 426E-02

$3.7136 E-02$

3.68 52E-02

3.6572E-02

$3.6297 E-0$ ?

3.6027E-02

3.5761E-02

3.5500E-02

3.5243E-02

$3.4991 E-02$

3. $4742 E-02$

S. $\triangle 498 E-02$

$3.4258 E-02$

3. 4022E-02

3.379 UE-02

$3.3561 E-02$

2.3336E-02

3.3115E-02

3.28? ?E-02

3.268 3E- -02

3.2472E-02

3.2264E-02

3.2060E-02

$3.1858 E-02$

3.1660E-02

3.1 $1465 E-02$

3. $1273 E-02$

3. $1084 E-02$

3.0897E-02

$3.0713 E-02$
$6.5342 E-01$

6. $4737 E-01$

$6.4139 E-01$

6. $3547 E-C 1$

$6 \cdot 2962 E-01$

$6 \cdot 2385 E-01$

6. $1817 E-01$

6. $1257 E-01$

6.0706E-01

$6.0163 E-01$

5.9630E-01

5. 91 CSE-01

$5.8589 E-01$

5.8083E-01

5. $7584 E-01$

5.7095E-01

5. $6614 E-01$

5. $6141 E-01$

5. 5677E-01

5. 5220E-01

5. $4772 E-01$

5. $4332 E-O$.

5. 3899E-01

5. 3474E-01

5. 3056E-01

5.2646E-0!

$5 \cdot 2242 E-01$

5. $1846 E-01$

5. $1456 E-01$

5. 1073E-01

5.0696E-01

5. 0326E-01

$4.9962 E-01$

$4.9604 E-01$

$4.9252 E-01$

$4.8906 E-01$

$4.8566 E-01$

$4.8231 E-01$

4.7901E-01

4.7577E- 01

4. $7258 E-01$

$4.6945 E-01$

$4.6636 E-01$

$4 \cdot 6332 E-01$

4. 6033E- 01

4. $5739 \mathrm{E}-01$

4. $5449 E-01$

4. 5! క4E-0 ]

$4.4883 E-\Omega i$

$4.4606 E-01$

4. $4334 E-01$

4. $4065 E-01$

4. 3801E-01

4. 3540E-01 


\section{Appendix C. CHART Code}

\section{A. Stability Criteria for "CHART"}

HEATING3, like any other heat transfer code which uses the exp.licit method for Its transient calculations has 2 limit on the size of time step used if stability is to be guaranteed. The basic heat conduction equation ured in ifATING3 is (see Eq. 2-22, Ref. 10):

$$
T_{J}(t+\Delta t)=I_{g}(t)+\frac{\Delta_{t}}{C_{g}}\left[\sum_{i=1}^{i} J \mathbb{R}_{i}\left(T_{i}(0)-T_{g}(0)\right)+\theta_{J}(t)\right.
$$

and the stability criteria for this equation is (Eq. 2-23 in Ref. 10):

$$
\Delta t_{\max } \leq\left(\frac{C_{J}}{\sum_{i=1} J_{i}}\right) \text { min for all J }
$$

The stability criteria given in Eq. C-2 does not inciude the heat generation term ? $?^{\cdot}$ This is correct assuming that $\theta_{J}$ is not itself a function of temperature. However, in cur case (see Eqs. 17 and 26):

$$
Q_{J}=q^{\prime \prime}-H\left(T-T_{g}\right) \text {. }
$$

The mathematical stability for $\mathrm{Bq} .(\mathrm{C}-1)$ if $\mathrm{QJ}_{\mathrm{J}}$ is itself a function of temperature s'ould include the coefficient of the temperature. In gentral any vectorial equation is the form

$$
\alpha_{1} \vec{v}_{1}+\alpha_{2} \vec{v}_{2}+\cdots \cdot \alpha_{u} \vec{v}_{n}=0
$$

There $\alpha_{1}, \alpha_{2}$.. $\alpha_{n}$ are scalar coefficients of the vectors $\vec{v}_{1}, \vec{v}_{2} .$. $v_{n}$ in order to be stable must satisfy the condition that

$$
\alpha_{1}+\alpha_{2}+\ldots \cdot \alpha_{n} \geq 0
$$

In the case of the heat conduction equation the system of vectors becomes,

$$
-\sum_{I=1}^{\mathrm{J}} \mathrm{K}_{1, J}\left(\mathrm{~T}_{I}-\mathrm{T}_{J}\right)+\frac{\mathrm{C}_{J}}{\mathrm{Lt}}\left(\mathrm{T}_{I}^{\prime}-\mathrm{T}_{J}\right)=\mathrm{C}
$$

and therefore the stability criteria becomes like in $\mathrm{Eq} .(\mathrm{C}-2)$

In our case the system of vectors becones

$$
-\sum_{I=1}^{m} i_{J}\left(T_{1}-T_{J}\right)+V_{J} H\left(T_{J}-T_{g}\right)+\frac{C_{J}}{\Delta t}\left(t_{J}^{\prime}-T_{J}\right)=0
$$

and therefore the stability criteria is 


$$
(\Delta t)_{\max } \leq\left(\frac{C_{J}}{\sum_{i=1} J_{i}+v_{J}^{H}}\right) \text { win for all }
$$

where $V_{J}$ is the volume of the node element and $H$ is our volunetric heat transfer coefficient. This criteria is incorporated now in charr. The modified method included in HEATING3 (see Ref. 11) was changed here to include the correct criteria for stability as given in Eq. (C-4).

Inserting Eq. (8) for calculating the cooling gas temperature for every increment along its flow created an additional stability problem. The differential equation added is (see Eq. 8):

$$
\frac{d T_{g}}{d x}=\frac{H A\left(T-T_{g}\right)}{8 C p V_{g} A}
$$

For such an equation to be stable we must have

$$
\operatorname{PCpV}_{\mathbf{8}} A-A \Delta X H \geq 0
$$

or

$$
\Delta \mathrm{x} \leq \frac{\left(\rho \mathrm{Cp}_{\mathrm{g}}\right)}{\mathrm{H}}
$$

This stability criteria was also incorporated into CHART as part of the HGNEN subroutine. The modified method used in HEATING3 (see Ref. 11) was also used here 21 though reduced to the simpler case of Eq. (C-5). This eliminates the requirewent of using too many subdivisions along the direction of gas flow. 
Table C-1. Input Table for Chant

\begin{tabular}{|c|c|c|c|c|c|}
\hline Card & Col. & Formet & Variable Name & Veriable Menips & Unite \\
\hline$A$ & $\begin{array}{l}1-12 \\
13-24 \\
25-36 \\
37-48 \\
49-60 \\
61-72\end{array}$ & $\begin{array}{c}D 12.4 \\
0 . x \times x \times 0+x x\end{array}$ & $\begin{array}{ll}\text { BIGB1 } & (B-1) \star \\
\text { BIGB2 } & (B 2) \\
\text { BIGG } & (G) \\
\text { SMAB1 } & \left(b_{1}\right) \\
\text { SMLB2 } & \left(b_{2}\right)\end{array}$ & 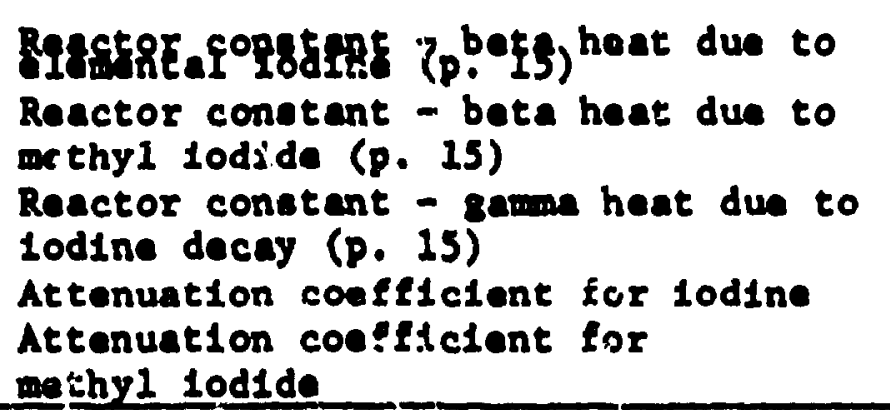 & 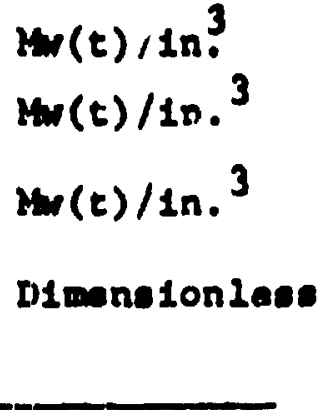 \\
\hline $\mathbf{B}$ & $\begin{array}{l}1-12 \\
13-24 \\
25-36 \\
37-48 \\
49-60 \\
61-72\end{array}$ & $0.020 \times 2.4$ & $\begin{array}{l}\text { GIT } \\
\text { GDER } \\
\text { GSPH } \\
\text { DELX } \\
\text { DIMA } \\
\text { DI:B }\end{array}$ & 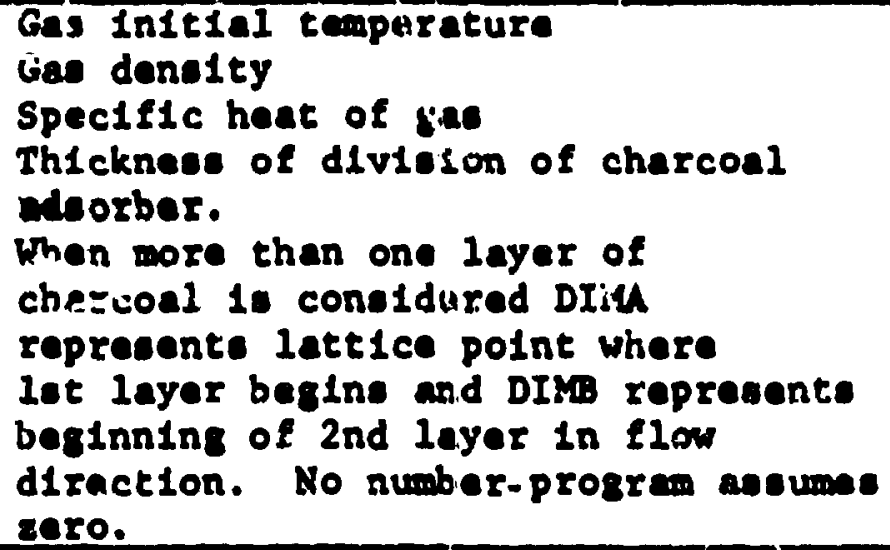 & $\begin{array}{l}1 \mathrm{~b} / \ln .^{3} \\
\text { Beu/1b-0 } \\
\text { Inches }\end{array}$ \\
\hline C & $\begin{array}{l}25-36 \\
37-48\end{array}$ & $0 . X X X X D+X X X$ & $\begin{array}{l}\text { BUCOEF } \\
\text { TMDLAY } \\
\text { BGGVEL } \\
\text { ACTVEL }\end{array}$ & 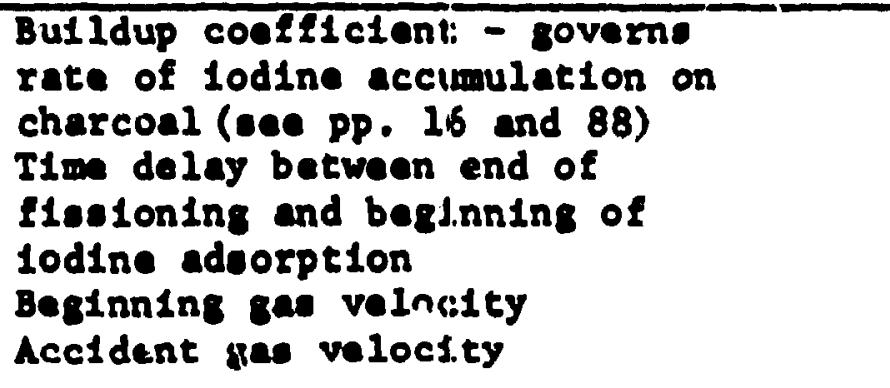 & $\begin{array}{l}\ln . / m 1 n \\
\ln . / \min \end{array}$ \\
\hline REPEA & $\begin{array}{l}1-15 \\
16-30 \\
\frac{31-45}{D_{2}, 53}\end{array}$ & $\begin{array}{r}0.000000 D \pm x x \\
\end{array}$ & 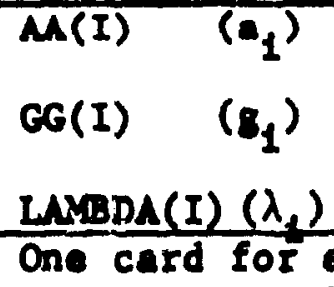 & 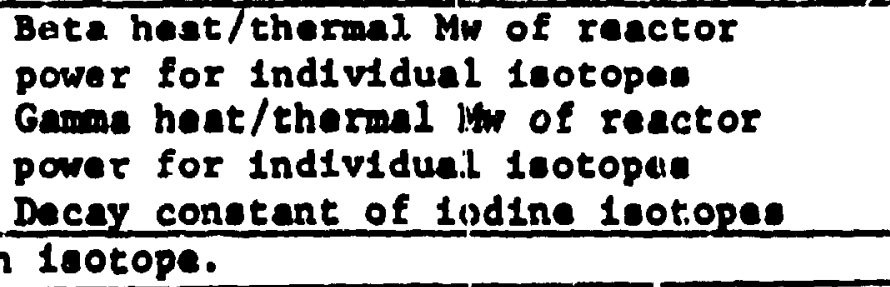 & $\begin{array}{l}\text { Btu/mtn-Mu (t) } \\
\text { Btu/m1n-M (t) } \\
1 / \mathrm{mln} \text {. }\end{array}$ \\
\hline
\end{tabular}

Carde for HEATING3 follow (notation ueed in text, see page 16 and Appendix D). 


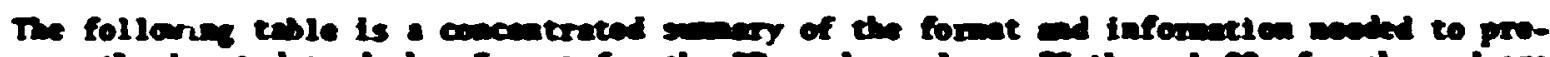

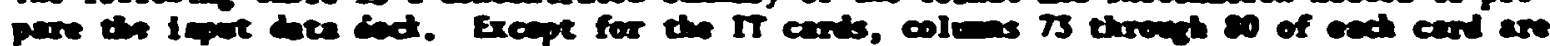

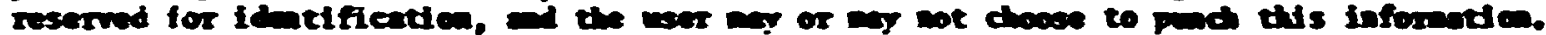

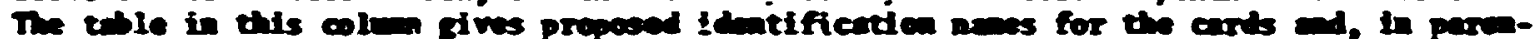

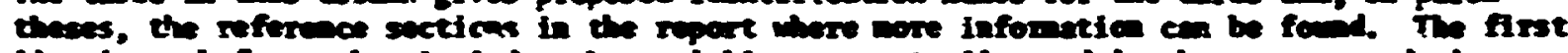

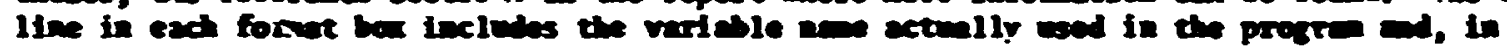

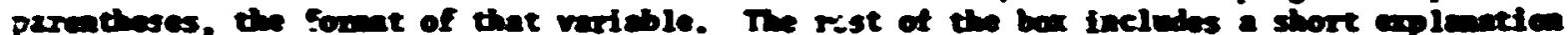

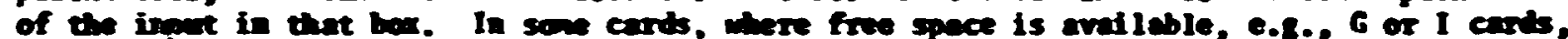

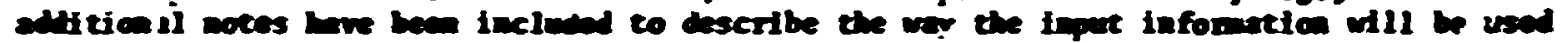
in tie progre itself.

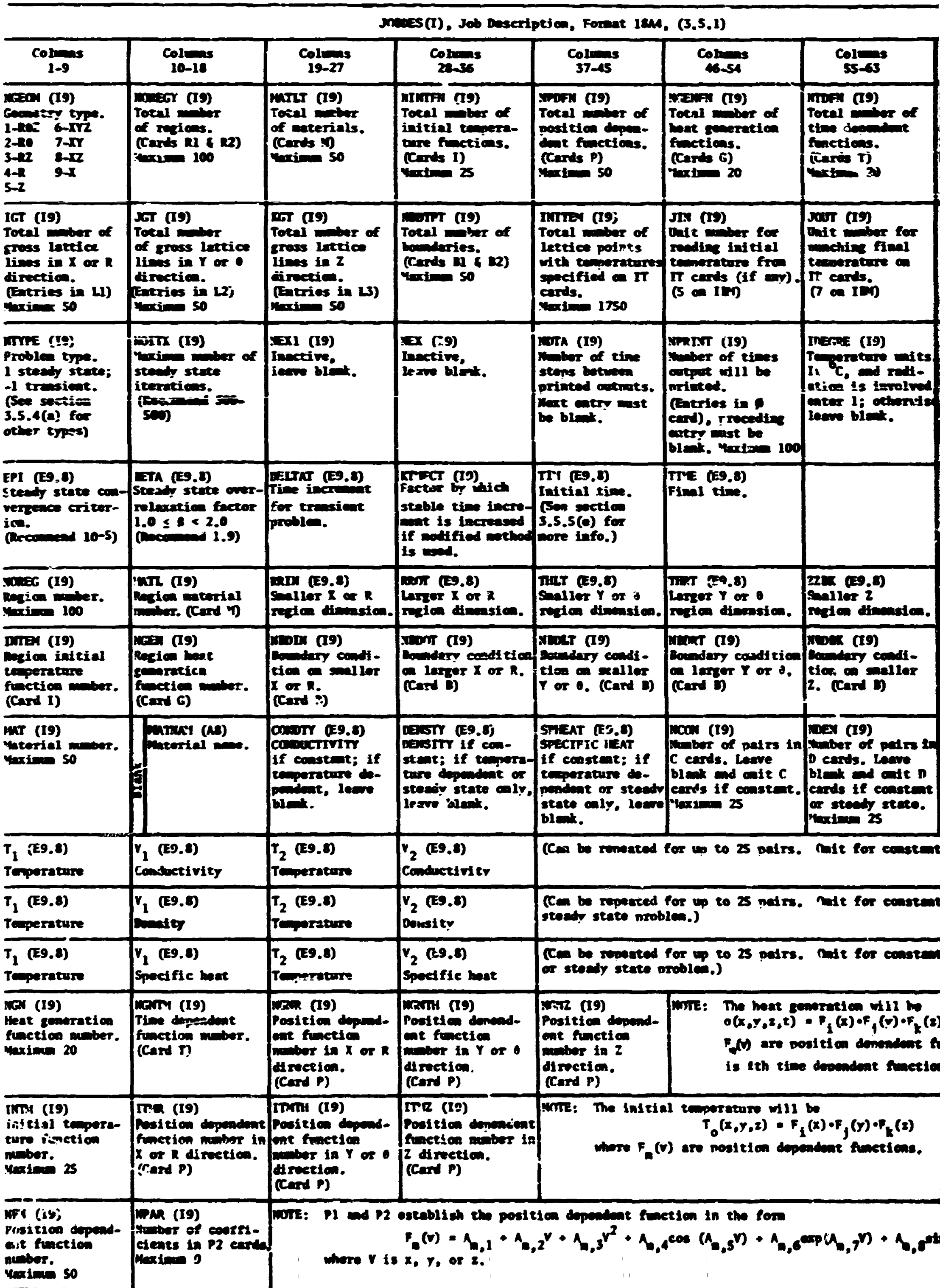




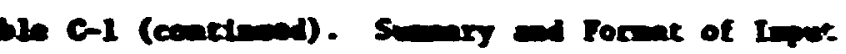

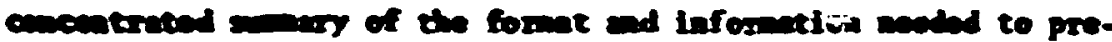

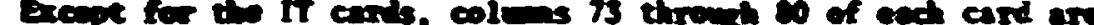

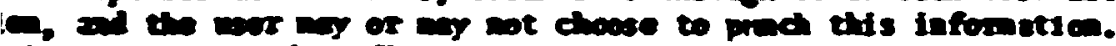

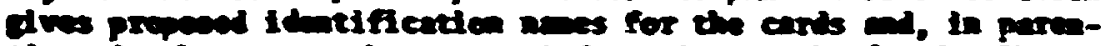

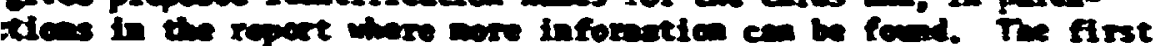

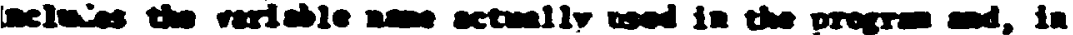

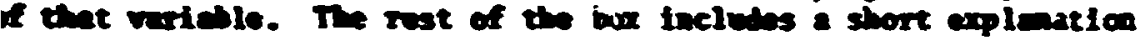

In son cants, were free spece is aveileble, 4.3., f or I cents,

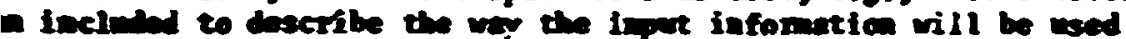

\section{E(x). Job aseruption, Forate 18M4, (3.5.1)}

Card 1

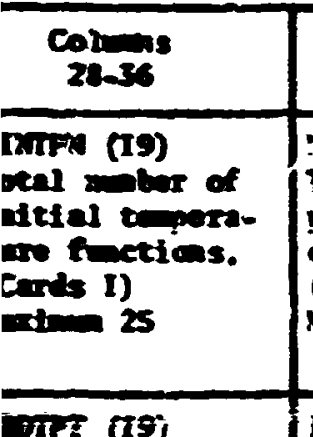

(II)

chinies.

Crinls 21 (2)

tim 50

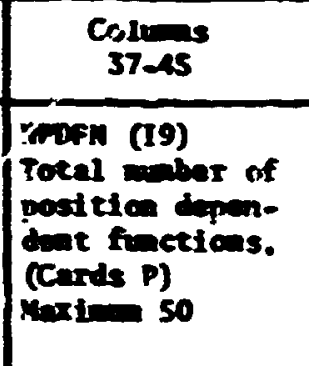

\begin{tabular}{l} 
colvins \\
46-54 \\
\hline
\end{tabular}

Total (19) bat genstretion fuctions. (Cands G)

Intion 20

INTher (19)

Total nuber of

Interien mestes

(Jine wor

Fith temeratures tomerature fro

spetified on IT

enter.

IT cerds (1f tesernture on

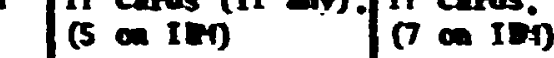

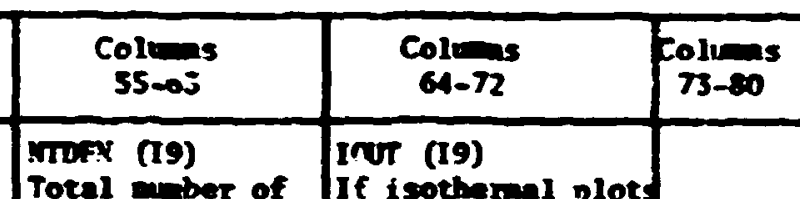

Total naber of If isothernal nlot?

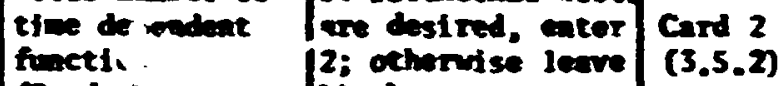

fend i;

unito 20

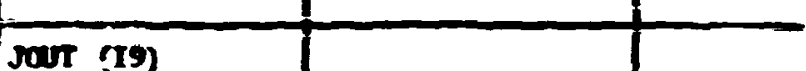

E (19)

netive,

1750

Dura (19)

thenter of tin

stens betamen

printed cotivents.

pext entry menst

be blent.

NoptrT (19)

theber of tines

oncper wil be

mrinted.

Entries in

card), proceding

entry mast be

tleik. Maxima 100

Pret as

vetor to indeh

table tine incre.

th is increnses

! nodifted motho:

1000

(II) (29.8)

पrex $x$ or $\mathrm{R}$

cien dimasio.

In (19)

madry condition

1 Iarzer $X$ or $R$

and

TIT (E9.8)

Intial tine

(Soe saction

3.5.5(e) for

now info,)

तथा (129.8)

Salle Y or

refica dimension.

xist (19)

TTE (E9.8)

Finel vine.

hoodary condi-

tion on sacijer

or 0. (Cand D)

Card 3

(3.5.3)

InEFo' (19)

Tenoreture vits

If ${ }^{\circ} C_{\text {. and }}$ radi -

ation is involved

enter 1; otherris.

leave blond.

WTY (E9.8)

ism if con.

SHEAT (C9.8)

STECIFTC IIEAT

if constait; if

experature de-

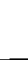

re dependent or

Dety state caly.

we blest.

state only, lewe

blenk.

(E).

cards if constent.

CON (19) MES (19) HSHT (19)

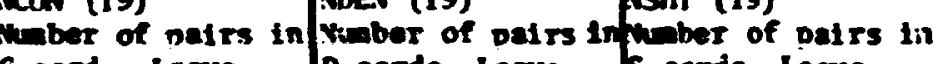

D cards. Leave 5 cards. Leave

blank and owit $n$ blank and onit $S$

cands if cosstent kands if constent

or steady state. Or steady state.

'inximan 25

Taxim 25

(Cen be remeated for us co 25 dairs. nit for constant conductivity.)

Card 4

$(3,5,4)$

monctivity

(E9.8)

astey

(9.8)

nelfle het

(14)

Hetea denoud

- fuceton

ther in $Y$ or

neticn,

(ad P)

3 (I9)

Mtion demondent

btion minber in

irvetion.

(P)

Jish the postion dopendent function in the forw

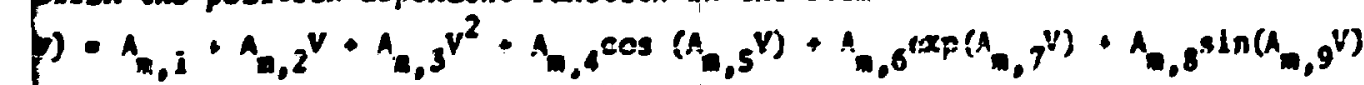

1. or $\therefore$

(Cen be repeated for up to 25 nairs. nat for constent density or steady state mroblem.)

(Cen be roweted for up to 25 nalrs. nite for constent smecific hext

or stendy state nroblei.)

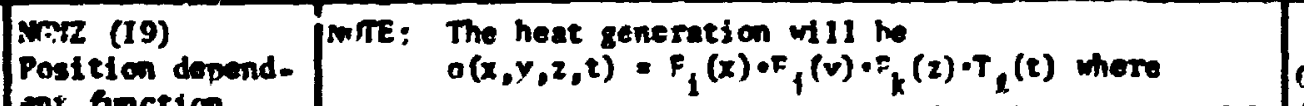

ant function $\quad F_{\text {n }}(v)$ are nosition demendent functions, and $T_{t}(t) \mid \begin{aligned} & G \\ & (3.5 .8)\end{aligned}$

direction. is eth tiwe deoendent function.

(Card P)

WME: The initial temperature wil be

$$
T_{0}(x, y, z)=F_{1}(x) \cdot F_{j}(y) \cdot F_{k}(z)
$$

where $F_{F}(v)$ are nosteion dependent functions. 


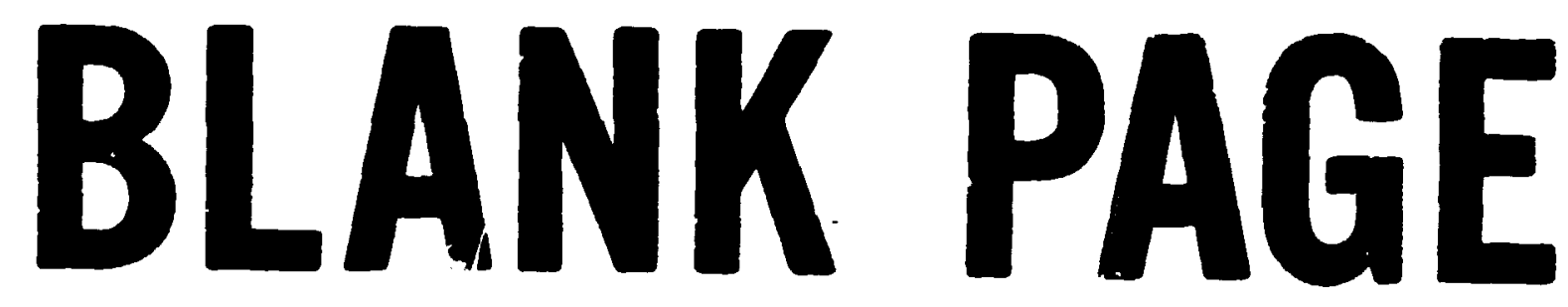




\begin{tabular}{|c|c|c|c|c|}
\hline$T_{1}(E 9.8)$ & $\begin{array}{l}\text { Y, (E9.8) } \\
\text { Specifin: hear }\end{array}$ & $T_{2}$ (E9.1) & $\begin{array}{l}r_{2}(E) \cdot n \\
\text { Spectific bas }\end{array}$ & (C) be roceated for 9 to 25 pairs. Mit for constent \\
\hline 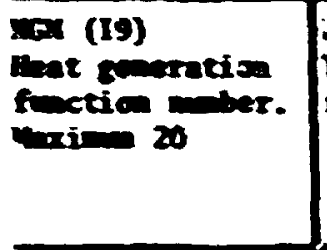 & 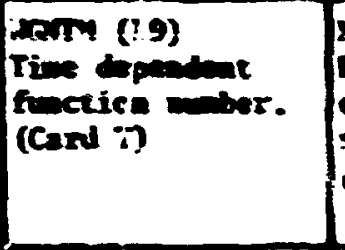 & 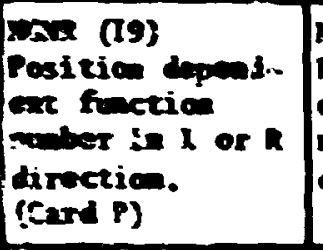 & 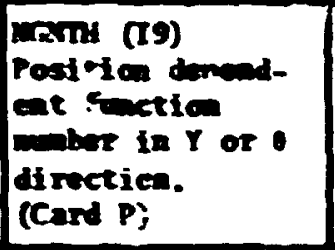 & 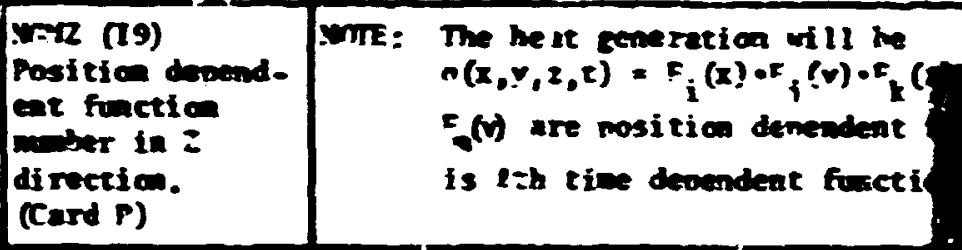 \\
\hline 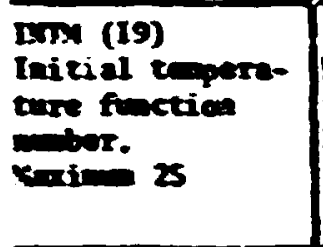 & 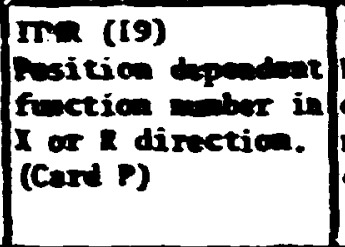 & 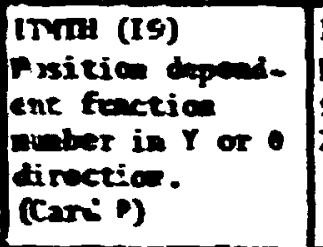 & 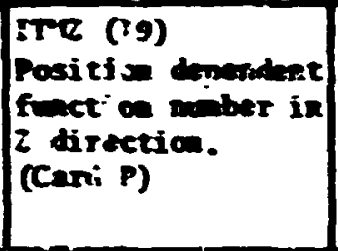 & $\begin{array}{l}\text { Wme: The initial temerature vill be } \\
\qquad T_{0}(x, y, x)=F_{i}(x) \cdot F_{j}(y) \cdot F_{k}(z) \\
\text { where } F_{n}(v) \text { are mosition dependent functions. }\end{array}$ \\
\hline 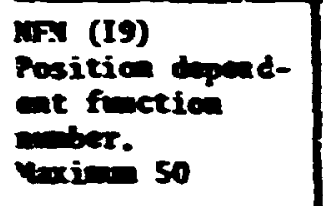 & 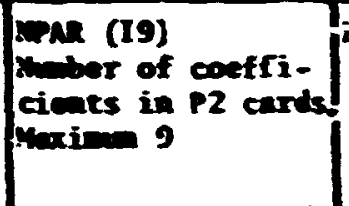 & $\begin{array}{l}\text { WOIE: } \\
\text { ?1 ad } P 2 \text { e: } \\
\text { mere } v \text { is }\end{array}$ & 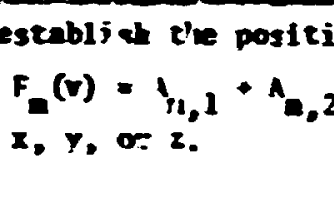 & 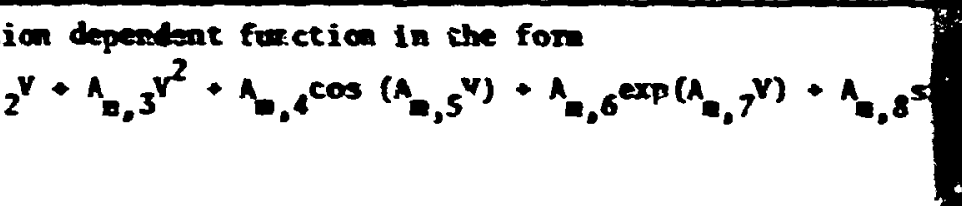 \\
\hline 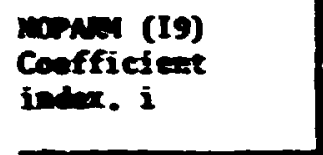 & $\begin{array}{l}\text { Wurt }(29.8) \\
\text { Cosfficiant } \\
\text { value. Am,i }\end{array}$ & $\begin{array}{l}\text { nophror (19) } \\
\text { Coerficient } \\
\text { index. i }\end{array}$ & $\begin{array}{l}\text { Wow (E9.8) } \\
\text { Coefficieat } \\
\text { raive. A,i }\end{array}$ & MrmE: Can be repeated for us to 9 cmaffirients. \\
\hline 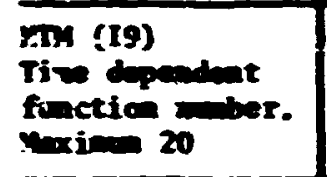 & $\begin{array}{l}\text { TLEP (19) } \\
\text { in ter of pairs } \\
\text { maie. is }\end{array}$ & $\begin{array}{l}\text { Trum (E9.8) } \\
\text { Tive. }\end{array}$ & $\begin{array}{l}\text { Tresen EQ.8) } \\
\text { Factor. }\end{array}$ & 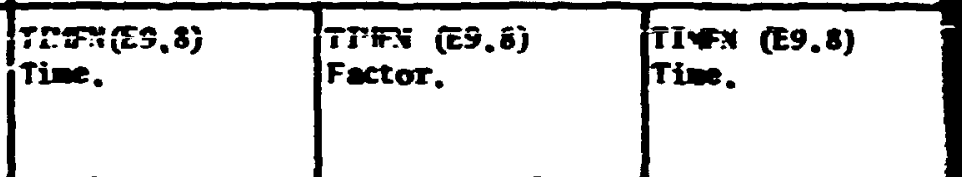 \\
\hline $\begin{array}{l}\text { TrFan (ES.8) } \\
\text { Tine. }\end{array}$ & $\begin{array}{l}\text { Trirs (E9.8) } \\
\text { Fector. }\end{array}$ & Sme: Can be rope & eated for up to 25 & padrs. This establishes the time denendent function i \\
\hline 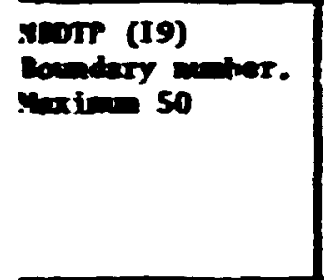 & 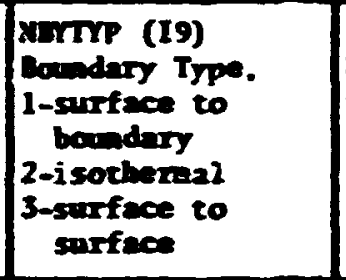 & 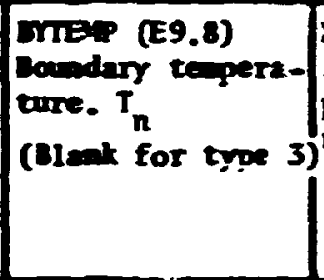 & 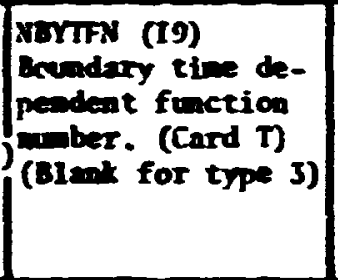 & $\begin{array}{l}\text { Boundary twanerature will be established as } \\
\qquad F_{n}(t)=T_{n} \cdot T_{l}(t) \\
\text { Where } T_{l}(t) \text { is tine derendent fonction. }\end{array}$ \\
\hline 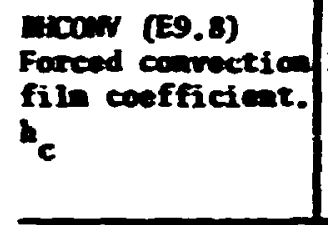 & 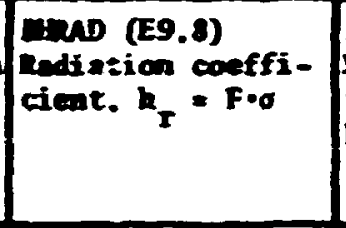 & $\begin{array}{l}\text { Dinht (E9.8) } \\
\text { Sabural coniec- } \\
\text { tion coeffigient. } \\
h_{n}\end{array}$ & \begin{tabular}{|l|} 
Exp (E9.8) \\
Xetural convection \\
exponent. he
\end{tabular} & 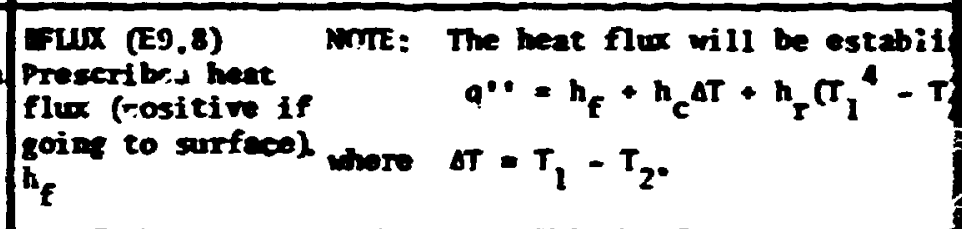 \\
\hline 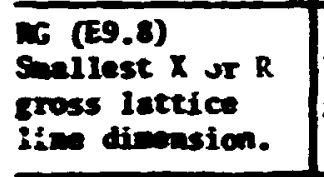 & $\begin{array}{l}\text { Xe (EY, } 8) \\
\text { Next } X \text { or } R \\
\text { gross lattice } \\
\text { live dinceasion. }\end{array}$ & $\begin{array}{l}\text { W (E9.8? } \\
\text { Next } X \text { Cr R } \\
\text { gross lattice } \\
\text { line dimeasion. }\end{array}$ & fan be reseated for & op to 50 gross lattice limes (but equal to entry one \\
\hline 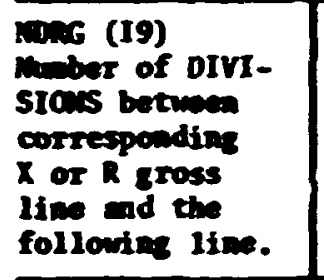 & $\operatorname{lom}(19)$ & xome (I9) & $\begin{array}{l}\text { Must have one less } \\
\text { direction). }\end{array}$ & entry than in 11 cards (ouxime of 100 fine lattice li \\
\hline $\begin{array}{l}\operatorname{Tix}(E 9.8) \\
\text { or } 0\end{array}$ & & & Sine as LI cards ex & excepe for $Y$ or direction. \\
\hline $\begin{array}{l}\text { Noritis (I9) } \\
\text { Y or } 6\end{array}$ & & & Sace as $\mathrm{N1}$ cards ex & axcent for $Y$ or 0 direction. \\
\hline $\begin{array}{l}20(E 9.8) \\
2\end{array}$ & & & Save as $l 1$ cards ex & except for 2 direction. \\
\hline 2 & & & Swe as vi cards ex & oxcept for 2 direction. \\
\hline $\begin{array}{l}\text { PRT IIE (E9.8) } \\
\text { First tis print } \\
\text { out is desired. }\end{array}$ & $\begin{array}{l}\text { PRTIME (E9.8) } \\
\text { Second time print- } \\
\text { out is desi red. }\end{array}$ & $\begin{array}{l}\text { PrTi'e (E9.8) } \\
\text { Third time print- } \\
\text { out is desired. }\end{array}$ & Can be repeated for & or up to 100 printout times but squal to entry six in C \\
\hline
\end{tabular}

Job Description, Fonat 18n4

\begin{tabular}{|c|c|c|c|c|c|c|c|}
\hline$\underset{1-5}{c}$ & ${ }_{6-15}^{\text {Colums }}$ & $\begin{array}{c}\text { Columens } \\
16-20\end{array}$ & $\begin{array}{c}\text { Colums } \\
21-J_{i 1}\end{array}$ & $\underset{31-35}{\text { Colums }}$ & $\operatorname{col}_{36.45}^{\text {Colmons }}$ & $\begin{array}{c}\text { Colums } \\
46-50\end{array}$ & $\begin{array}{c}\text { Columens } \\
51.60\end{array}$ \\
\hline $\begin{array}{l}N(15) \\
\text { Lattice point } \\
\text { nuber. }\end{array}$ & $\begin{array}{l}\text { Tl(N) (D10.0) } \\
\text { "specified initial } \\
\text { teiperature of that } \\
\text { point. }\end{array}$ & $\begin{array}{l}\text { N(!S) } \\
\text { Lattice point } \\
\text { maber. }\end{array}$ & $\begin{array}{l}\text { Tl(N) (D1).(1) } \\
\text { Specified i itial } \\
\text { tewperature of that } \\
\text { polnt. }\end{array}$ & $\begin{array}{l}\text { Can be rem } \\
\text { in Card 3) }\end{array}$ & ted un to & 750 lat & polnts \\
\hline
\end{tabular}

Blank cerd if additionel nroblew follows. 



\begin{tabular}{|c|c|c|c|}
\hline $\lim _{x}$ & 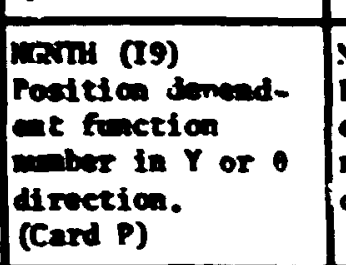 & 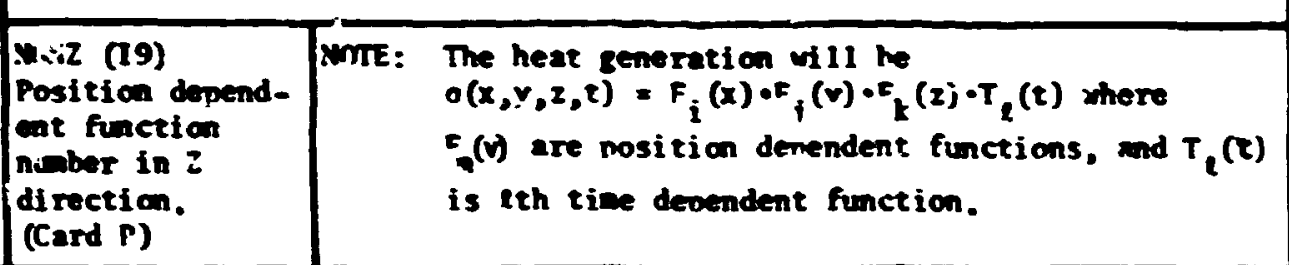 & G \\
\hline Yione- & 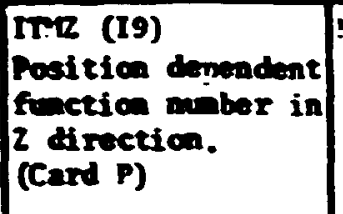 & $\begin{array}{l}\text { WmE: The initial temperature will be } \\
\qquad T_{0}(x, y, z)=F_{i}(x) \cdot F_{j}(y) \cdot F_{k}(z) \\
\text { where } F_{n}(r) \text { are nosition dependent functions. }\end{array}$ & $1(3.5 .9)$ \\
\hline \multicolumn{3}{|c|}{ 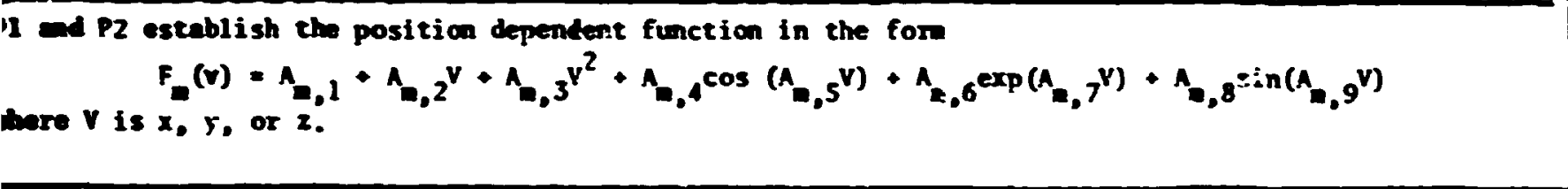 } & $P 1 \mid \begin{array}{ll}a \\
\text { in } \\
\text { in }\end{array}$ \\
\hline & $\begin{array}{l}\text { Whit (E9.8) } \\
\text { Coefficient } \\
\text { relo. A.i }\end{array}$ & NmE: Cm be repeated for up to 9 coefficients. & 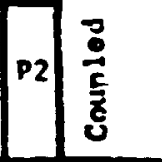 \\
\hline 9.8) & $\begin{array}{l}\text { TIYFI (E9.8) } \\
\text { facior. }\end{array}$ & \begin{tabular}{|l|l|l|} 
TIIFY (E9.8) & TIYFY (E9.8) & TIMFY (E9.8) \\
Factor. & Factor. \\
& &
\end{tabular} & TI \\
\hline \multicolumn{3}{|c|}{ En be repeated for up to 25 palrs. This establishes the time uenendest fisnction in the ford $T_{2}(t)$. } & 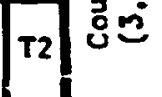 \\
\hline $\begin{array}{l}\text { E9.8) } \\
\text { torpera- }\end{array}$ & 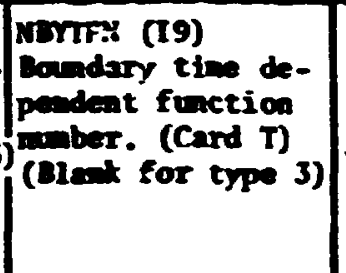 & $\begin{array}{l}\text { Boundary tounerature will be established as } \\
\qquad F_{n}(t)=T_{n} \cdot T_{l}(t) \\
\text { where } T_{2}(t) \text { is tine debendent function. }\end{array}$ & $\stackrel{a}{a}$ \\
\hline fo.8) & $\begin{array}{l}\text { Dixp (E9.8) } \\
\text { Daturei convection } \\
\text { exponent. he }\end{array}$ & 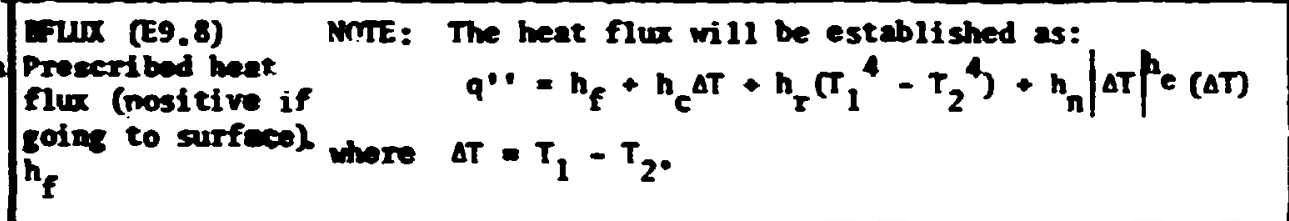 & $\int_{32}^{\frac{8}{2}}$ \\
\hline tension. & Can be renected for & or up to 50 gross lattice limes (but equal to entry one in Card 2). & $(3.5 .13)$ \\
\hline ) & $\begin{array}{l}\text { Yust have ane less } \\
\text { af rection). }\end{array}$ & 3 entry than in 11 cards (naxing of 100 fine lartice lines in each & nis. \\
\hline & Sem as $L 1$ cards ex & except for $Y$ or $\theta$ direction. & $(3.5 .13)$ \\
\hline & Son as yl cards ex & excent for $Y$ or 0 direction. & $\begin{array}{l}\mathrm{N2} \\
(3.5 .13)\end{array}$ \\
\hline & Sore as $\mathrm{Ll}$ cards ex & xxcept for $Z$ direction. & $(3.5 .13)$ \\
\hline & Swe as N1 :ards ar & acept for 2 direction. & $\begin{array}{l}\text { N3 } \\
(3.5 .13)\end{array}$ \\
\hline $\begin{array}{l}(E=9.8) \\
\text { insint- } \\
\text { insired. }\end{array}$ & Con the reposted for & or up to 100 printout times (but equal to entry six in Card 1). & $(3.5 .14)$ \\
\hline
\end{tabular}

Job Description, Format 1844 IT1

(3.5.15)

\begin{tabular}{|c|c|c|c|c|c|c|c|c|}
\hline $\begin{array}{c}\text { Colluass } \\
16-20\end{array}$ & $\begin{array}{c}\text { Colums } \\
21-30\end{array}$ & $\underset{31-35}{\text { Colums }}$ & $\underset{36-45}{\text { Colvens }}$ & $\begin{array}{c}\text { Colvons } \\
46-50\end{array}$ & $\begin{array}{c}\text { Columins } \\
51-60\end{array}$ & $\underset{61-65}{\text { Colums }}$ & $\begin{array}{c}\text { Collums } \\
66-75\end{array}$ & $\underset{76-8 C}{\text { Cnlums }}$ \\
\hline $\begin{array}{l}\text { 5) } \\
\text { seice potint }\end{array}$ & $\begin{array}{l}\text { T1(N) (D10.0) } \\
\text { Specified intrial } \\
\text { temperature of that } \\
\text { point. }\end{array}$ & $\begin{array}{l}\text { Con he ren } \\
\text { in Card 3) }\end{array}$ & ted un -0 & 1750 latei & Doints & it equal & entry $s$ & $\begin{array}{l}\text { IT2 } \\
\text { (3.5.15) }\end{array}$ \\
\hline
\end{tabular}

Blonk card if additional nroblea follows.

Cards for additional problom if desired. 


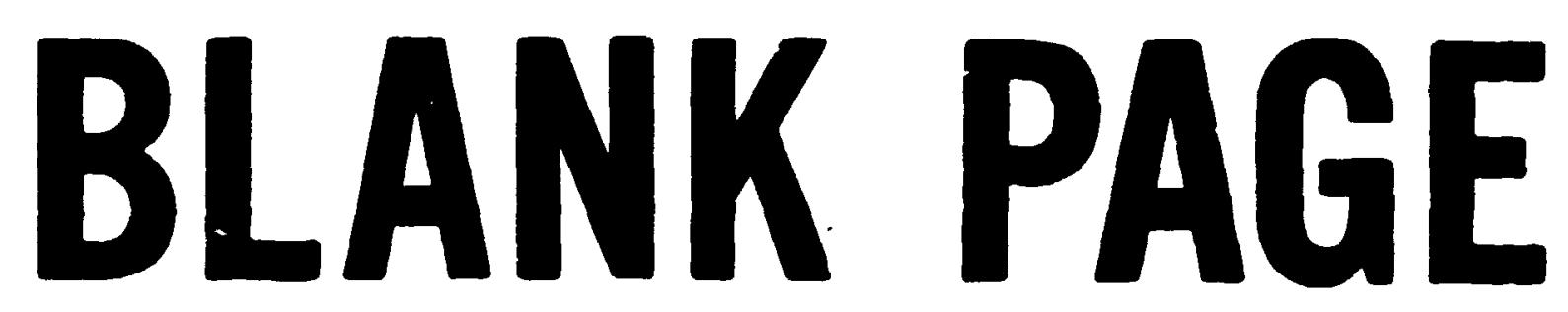


Appendix D. Application of CHART to a Research or Production Type Reactor

In this application of the procedure for estimating the temperature distribution in a charcoal adsorber, a different type of reaccor system is considered. The previous e:amples (Section $V$ ) were based on a pressurized-water power reactor but in this case we imagine a hypothetical reactcr system which more nearly fits the specifications of research reactors or some of the production reacror systems. Two major differe'sces are evident: first is the much lower reactor power and consequently iess charcoal area in the adsorber and secondly, the latter type drives air continuousiy through the filcers and out the stack rather than recirculating the exit air back into the containment building.

A second purpose of this application is to provide a step-by-step example of applying the calculational procedure which begins with the basic equation and ends with the data sards to be punched in order to run the program.

The two basic equations used in calculating the temperature distribution in the charcoal adsorber are:

$$
\rho_{b} C_{p_{b}} \frac{\partial T_{b}}{\partial t}=k_{b}\left[\frac{\partial^{2} T_{b}}{\partial x^{2}}+\frac{\partial^{2} T_{b}}{\partial y^{2}}+\frac{\partial^{2} T_{b}}{\partial z^{2}}\right]+q^{\cdots}-H\left(T_{b}-T_{g}\right)
$$

and

$$
\rho_{\mathbf{g}} \mathrm{P}_{\mathbf{g}} v_{\mathbf{g}} \frac{\partial \mathrm{T}_{\mathbf{g}}}{\partial \mathrm{x}}=\mathrm{H}\left(\mathrm{T}_{\mathrm{b}}-\mathrm{T}_{\mathbf{g}}\right) \text {. }
$$

from which the value of $t_{g}$ may be decermined.

The heat generation term in Eq. (D-1) is developed on page 16 of the text and in the general form becomes:

$$
q^{\prime \prime \prime}(x)=\frac{F P(t)}{V_{b}}\left(a_{1}+f_{g_{1}}\right) e^{-i_{1}(t+t D)} \text { Btuimin-in. } 3
$$

The heat generated by the decay of the lodine is ionsidered in t\%o parts; that generated by beta adsorption (ai) and the gamma adsorption $\left(g_{1}\right)$. Because of the penetration of the gamma rays the heat produced by their adsorption is considered to be uniform throughout the charcoal volime. Beta radiation, however, is adsorbed in the immediate vicinity 
where it is produced. Most of the elemental lodine is deposited on the air inlet side of the bed and the part of the lodine which becomes $\mathrm{CH}_{3} \mathrm{I}$ is less concentrated. For this reason the lodine deposit for beta heat generation must be considered in more detail as outlined on page 17 of the text. This is reflected in the following equation:

$$
\begin{aligned}
& q_{i}^{\prime \prime \prime}(x, t)=\frac{F_{1} P(t)}{V_{b}}\left[\left(\frac{\beta_{1} b_{1} l}{1-e^{-b_{1}^{d}}} e^{-b_{1} x}+\frac{\beta_{2} b_{2} l}{1-e^{-b_{2} l}} e^{-b_{2} x}\right) a_{1}\right. \\
& \left.+F_{2} g_{1}\right] e^{-\lambda_{1}\left(t+t_{D}\right)} \text { Btu/min-in. }{ }^{3} .
\end{aligned}
$$$$
\text { D-4 }
$$

where the two terms in parentheses represent the location of the elemental methyl iodide, respectively. For any particular reactor system these terms are constant and are given the designation $B_{1}$ and $B_{2}$. The terms are expressed here and are calculated for this particular problem on page 85.

$$
\begin{aligned}
& B_{1}=\frac{P(t) \ell B_{1} b_{1}}{V_{b}\left(1-e^{-b_{1} l}\right)} \\
& B_{2}=\frac{P(t) \ell B_{2} b_{2}}{V_{b}\left(1-e^{-b_{2} l}\right)}
\end{aligned}
$$

The terms representing the gamma heat generation is

$$
G=\frac{P(t)}{V_{b}} \mathbf{f}
$$

At this point $q^{\prime \prime \prime}$ is calculated as a function of time and position in the charcoal. If we wish to include the practical consideration, that the iodine accumulates on the charcoal over a period of time depending on air flow rate we need to add a term which determines the fraction of the total iodine that has been adsorbed at any time (see page 18 of text).

Fraction of total lodine adsorbed $=1-\mathrm{e}^{-(\mathrm{aRT} / \mathrm{V})}$

Including this factor and summing the heat generation due to all the individual isotopes of lodine, we have: 


$$
\begin{aligned}
\mathcal{A}^{\prime \prime}(x, t) & =F_{1}\left[\left(B_{1} e^{-b_{1} x}+B_{2} e^{-b_{2} x}\right) \ddot{i}_{i=1}^{m} a_{i} e^{-\lambda_{1}\left(t+t_{D}\right)}\right. \\
+G & \left.\sum_{i=1}^{m} B_{i} e^{-\lambda_{i}\left(t+t_{D}\right)}\right]\left(1-e^{-(a R / v t)}\right.
\end{aligned}
$$

where

$$
\begin{aligned}
& q^{\prime \prime}(x, t)=\text { heat generation rate per unit volume of charcoal bed, } \\
& x=\text { distance frcm front face of charcoal bed in direction of gas flow } \\
& t=\text { time elapsed from beginning of iodine adsorption by the charcoal } \\
& \text { bed } \\
& t_{D}=\text { time delay between end of fissioning and beginning of lodine }
\end{aligned}
$$

Table D-1. Data for Calculating the Temperature Distribution in the Charcoal Adsorber of the Hypothetical Production Reactor System

Specifications of the Leactor System

Reactor Power $350 *(t)$

Charcoal Adsorber

Area of charcoal

$600 \mathrm{ft}^{2}$

Thickness of charcoal

2 in. (1)

Volume of charcoal

100 ft $3\left(1.7280 \times 10^{5}\right.$ in. $\left.^{3}\right)\left(v_{b}\right)$

Normal air velocity

$40 \mathrm{ft} / \mathrm{min}$ (R)

Containnent volume

$451,880 \mathrm{ft}^{3}(\mathrm{~V})$

Other Constants

$B_{1}=0.9$ (fraction of $I_{2}$ )

$B_{2}=0.1$ (fraction of $\mathrm{CH}_{3} \mathrm{I}$ )

$b_{1}=9.21041 / \mathrm{n}\left(I_{2}\right.$ attenuation coefficient)

$b_{2}=1.02341 / n\left(\mathrm{CH}_{3} \mathrm{I}\right.$ attenuation coefficient) 
Time elapse between reactor shut town and beginning of lodine acisorption $=10 \mathrm{~min}$

$a=0.99$ (fraction of iodine adsorbed as the air passes through the charcoal)

Calculation of Injut Data for Computer Program

$$
\begin{aligned}
& B_{1}=\frac{P(t)}{V_{b}}\left(\frac{\beta_{1} b_{1} l}{1-e^{-b_{1} l}}\right)=\frac{350}{1.7280 \times 10^{5}} \times \frac{\dot{u} .9 \times 9.2104 \times 2}{1-e^{-(9.2104 \times 2)}}=3.3578 \times 10^{-2} \\
& B_{2}=\frac{P(t)}{V_{b}}\left(\frac{\beta_{2}{ }^{b} 2^{2}}{1-e^{-b_{2} l}}\right)=\frac{350}{1.7280 \times 10^{5}} \times \frac{0.1 \times 1.0234 \times 2}{1-e^{-(1.0234 \times 2)}}=4.7608 \times 10^{-4} \\
& G=\frac{P(t)}{V_{b}} 0.5=1.0127 \times 10^{-3}
\end{aligned}
$$

The terms $a_{1}$ and $g_{1}$ in Eq. (D-5) refer to the fraction of the decay power of the iodine which is due to beta and gama, respectively. They are calculated for each isotope and the jimensions are Btu/ain-Ku(t). A samie calculation for ${ }^{131}$ I is as follows: (refer to Table D-2 for decay power of lodine isotopee at reactor shutdown).

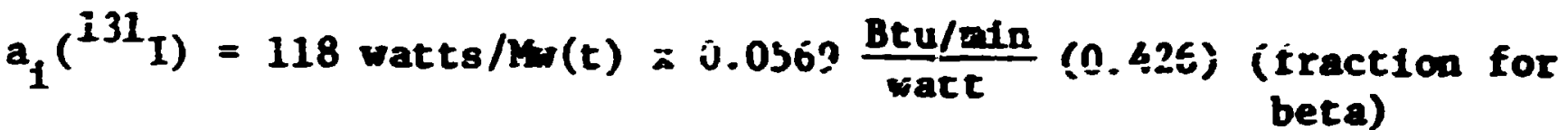

$$
\begin{aligned}
& g_{1}\left({ }^{131} I\right)=118 \text { watts } / W(t) \times 0.0569 \frac{\text { Btu/nin }}{\text { watt }}(0.0574) \text { (fraction for } \\
& =3.8540 \frac{B t u / n i n}{\sin (t)} \text {. }
\end{aligned}
$$

Corresponding values for all the lsotopes and the decay constant are listed in Table D-3. 
Tablo D-2. Constantp for Iorine Isotopes Produced In a Reactor

\begin{tabular}{|c|c|c|c|c|c|c|c|}
\hline $\begin{array}{l}\text { Iodine } \\
\text { Isotope }\end{array}$ & $\begin{array}{l}\text { Decay Cor } \\
\left(\mathrm{eec}^{-1}\right)\end{array}$ & $\left(m n^{-1}\right)$ & $\begin{array}{l}\text { Fraction of Decas } \\
\text { Beta }\end{array}$ & $\begin{array}{l}\text { Heat Due to } \\
\text { Gamma }\end{array}$ & $\begin{array}{l}\text { Watte } / \text { we }(t) \\
\text { Diecharge }\end{array}$ & $\begin{array}{l}\text { of Renctor } \\
\text { From Beta }\end{array}$ & $\begin{array}{l}\text { Power } \\
\text { Pror Gamana }\end{array}$ \\
\hline $\begin{array}{l}127 \\
128 \\
129 \\
130 \mathrm{~m} \\
130 \\
131 \\
132 \\
133 \\
134 \\
135 \\
136 \\
137 \\
138 \\
139\end{array}$ & $\begin{array}{l}4.62 \mathrm{E}-04 \\
1.29 \mathrm{E}-15 \\
1.26 \mathrm{E}-03 \\
1.55 \mathrm{E}-05 \\
9.97 \mathrm{E}-07 \\
8.37 \mathrm{E}-05 \\
9.17 \mathrm{E}-06 \\
2.19 \mathrm{E}-04 \\
2.67 \mathrm{E}-05 \\
8.35 \mathrm{E}-03 \\
3.06 \mathrm{E}-02 \\
1.17 \mathrm{E}-01 \\
3.47 \mathrm{E}-01\end{array}$ & $\begin{array}{l}2.77 \mathrm{E}-02 \\
7.74 \mathrm{E}-14 \\
7.56 \mathrm{E}-02 \\
9.30 \mathrm{E}-04 \\
5.98 \mathrm{E}-05 \\
5.02 \mathrm{E}-03 \\
5.50 \mathrm{E}-04 \\
1.31 \mathrm{E}-02 \\
1.72 \mathrm{E}-03 \\
5.01 \mathrm{E}-01 \\
1.84 \mathrm{E}-00 \\
7.02 \mathrm{E}-00 \\
2.08 \mathrm{E}-01\end{array}$ & $\begin{array}{l}0.827 \\
1 \\
1 \\
0.220 \\
0.426 \\
0.220 \\
0.490 \\
0.186 \\
0.160 \\
0.480 \\
1 \\
1 \\
1\end{array}$ & $\begin{array}{l}0.173 \\
0.0 \\
0.0 \\
0.780 \\
0.574 \\
0.780 \\
0.510 \\
0.814 \\
0.840 \\
0.520 \\
0.0 \\
0.0 \\
0.0\end{array}$ & 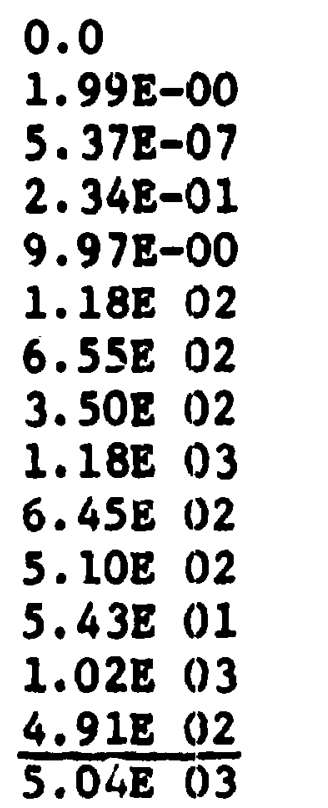 & 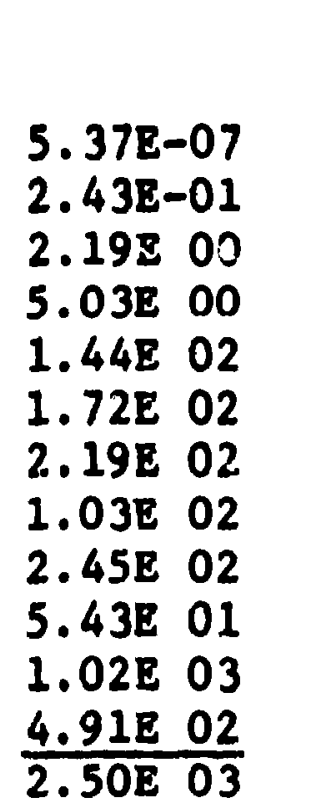 & $\begin{array}{ll}7.78 \mathrm{E} & 00 \\
6.778 & 0.1 \\
5.11 \mathrm{E} & 02 \\
1.79 \mathrm{E} & 02 \\
9.61 \mathrm{E} & 02 \\
5.42 \mathrm{E} & 02 \\
2.65 \mathrm{E} & 02\end{array}$ \\
\hline
\end{tabular}


Table D-3. Decay Power for the Iudine Isotgpes

\begin{tabular}{|c|c|c|c|}
\hline Iodine Isotope & $\frac{a_{i}}{B t u / m i n / H_{w}(t)}$ & $\begin{array}{c}\mathbf{B}_{\mathbf{i}} \\
\text { Btu/mir } / \mathbf{K}_{\mathbf{w}}(t)\end{array}$ & $\begin{array}{c}\lambda_{i} \\
\text { Decay Constant, } \\
\text { I/nin }\end{array}$ \\
\hline 128 & 0.0936 & 0.0196 & $2.7667 \times 10^{-2}$ \\
\hline 130 & 0.1248 & 0.4425 & $9.2562 \times 10^{-4}$ \\
\hline $\mathbf{1 3 i}$ & 2.8602 & 3.8540 & $5.9795 \times 10^{-5}$ \\
\hline 132 & 8.1992 & 29.0702 & $5.0245 \times 10^{-3}$ \\
\hline 133 & 9.7584 & 10.1569 & $5.5005 \times 10^{-4}$ \\
\hline 134 & $12 . i_{1} 384$ & 54.6539 & $1.3079 \times 10^{-2}$ \\
\hline 135 & 5.8720 & 30.8284 & $1.7253 \times 10^{-3}$ \\
\hline
\end{tabular}


The last tere of $\mathrm{Bq}$. (D-5), which deternines the fraction of the to:al lodine adsorbed, is calculated by the computer using values of a:r velocity and tise which s.re specified in the data cards. Therefore, the exponential is expressed in these terns by substituting for $R$ :

$R$ = air velozity ( $v$ ) $x$ area of charcoal bed

so that we have: $1-e^{-(a \times 600 v t / v)}$. Substituting values from Table $D-1$ gives

$$
1-e^{-\left[\frac{0.99 \times(600 \times 144) \mathrm{in.}^{2} v t}{451.880 \times 1728 \mathrm{in.}^{3}}\right]}
$$

or

$$
1-e^{-1.0954 \times 10^{-4}} v t
$$

The figure $1.0954 \times 10^{-4}$ is the first entry in data card (c) and 18 referred to as the buildup coefficient (BUCOEF). To assune instant loading of the lodine on the charcoal the factor $10^{-4}$ can be changed to $10^{4}$ and the fraction will always be one.

The information needed to punch the cards for this problen is listed in Table C-1 (Appendic C). These cards are punched as indicated in Table D-4 and placed in the order listed at the end of the main deck. If it is desired to run wore than one case, a second data deck is prepared with the necessary changes and placed after the first data deck with one blank card separating then. The last two cards shown on the Fortran Sheet (Table D-4) appear only once (after the last case).

Samples of the output for tais problen are shown in Table D-5. Figure D-1 is a plot of maximun temerature vo time for air flows of 4 , 20 and $40 \mathrm{ft} / \mathrm{an}$. The temperature represented in this graph assurmes that the avallable lodine 18 adsorbed lamediately at tine 0 . Tables D-6 and $D-7$ are samples of the printout of variables that are associated with each problem. 
Table D-4. Date Deck whlch was Ueed to Make the Calculation of Temperature Distribution with Invtant Loading and Alr Flow $4 \mathrm{ft} / \mathrm{min}$.

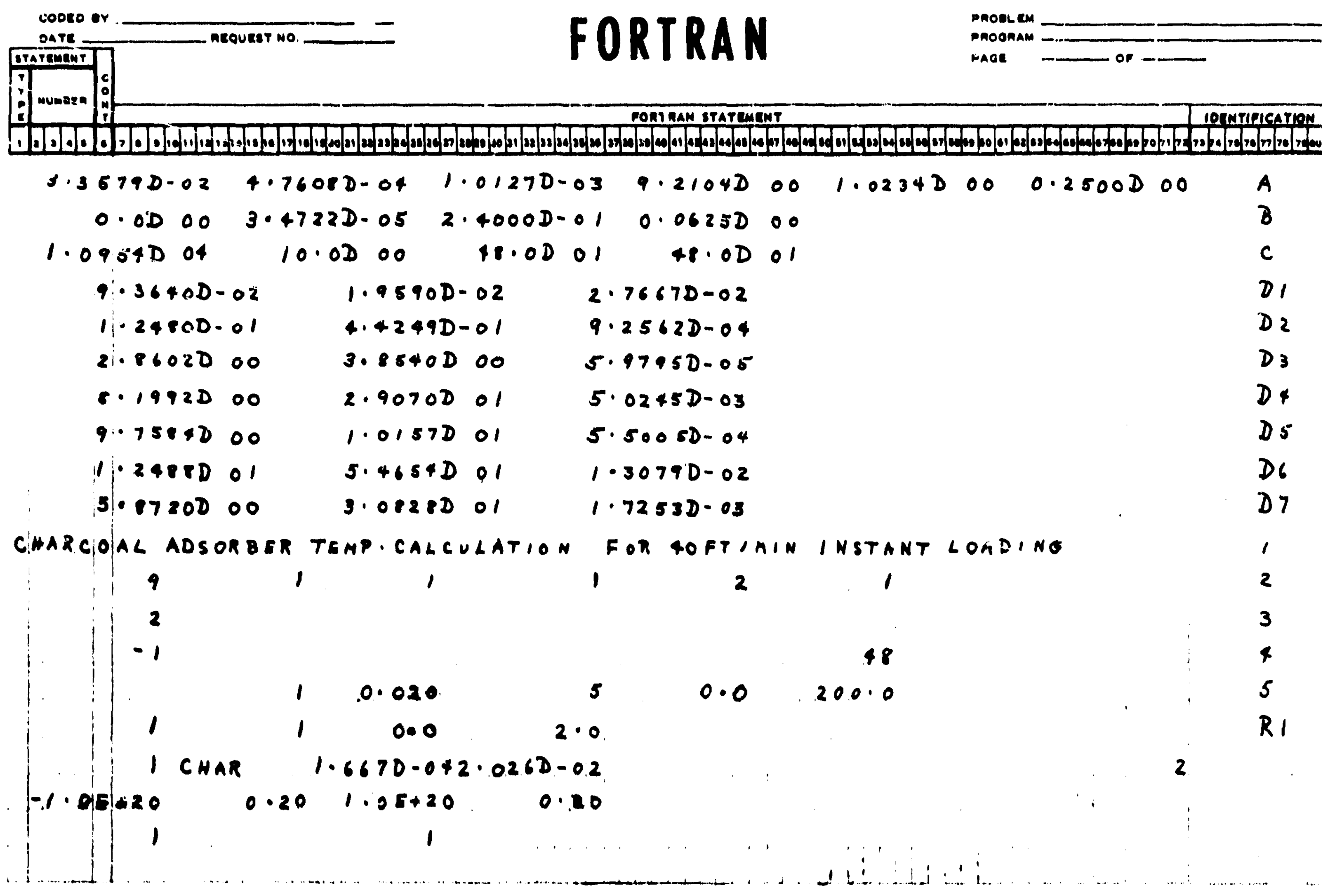


Table D-4 (continued)

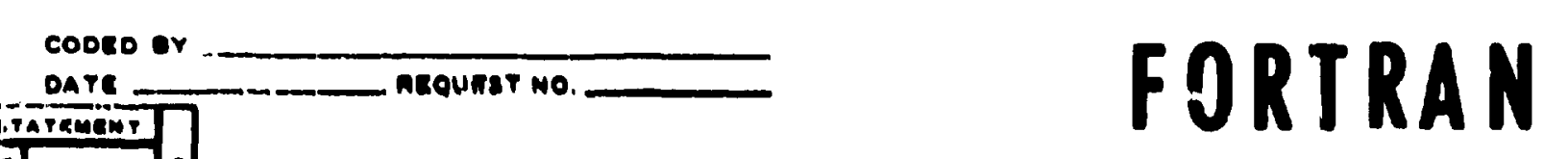

\section{FORTRAN}

PnoOL CM

moonam

paoe

montman itatement

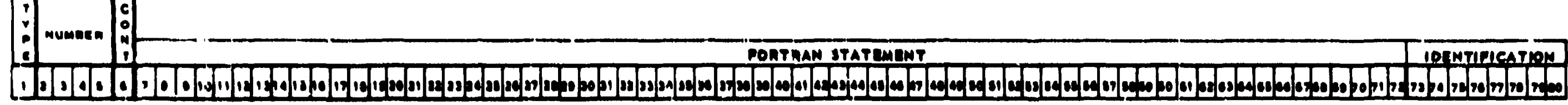

: numaren

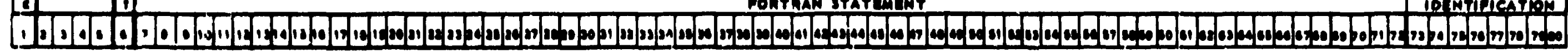

$\begin{array}{rr}1 & 2 \\ 1 & 1 \\ 1 & 1.0 \\ 2 & 1 \\ 1 & 0.0 \\ 0.0 & 2.0\end{array}$

32

$0 \cdot 0 \quad 2 \cdot 0$

$16.0 \quad 18 \cdot 0$

$32.0 \quad 34.0$

2

$4.0 \quad 50.0$

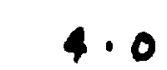

$6 \cdot 0$

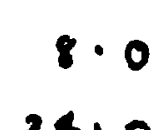

$10 \cdot 0$

$12 \cdot 0$

90.0100.

$20.0 \quad 22.0$

24.0

$26 \cdot 0$

$28 \cdot 0$

14.0

$36 \cdot 0$

38.0

$40 \cdot 0$

$42 \cdot 0$

$44 \cdot 0$

$30 \cdot 0$

$100 \cdot 0$

$55 \cdot 0$

60.0

$65 \cdot 0$

$70 \cdot 0$

$75 \cdot 0$

$46 \cdot a$

$170 \cdot 0$

$180 \cdot 0$

$110.0 \quad 120.0$

$130 \cdot 0$

$140 \cdot 0$

150.0

$80 \cdot 9$

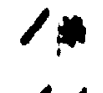

$200 \cdot 0$

t) 
Table D-5. Printout of the Temperature Profile of the Charcoal F11ter

8 min after Iodine was Doposited

DIME - OSBSUTS BBCM TRANSIBNT CALCULATICNS

rime - .00 ogs 70 oc

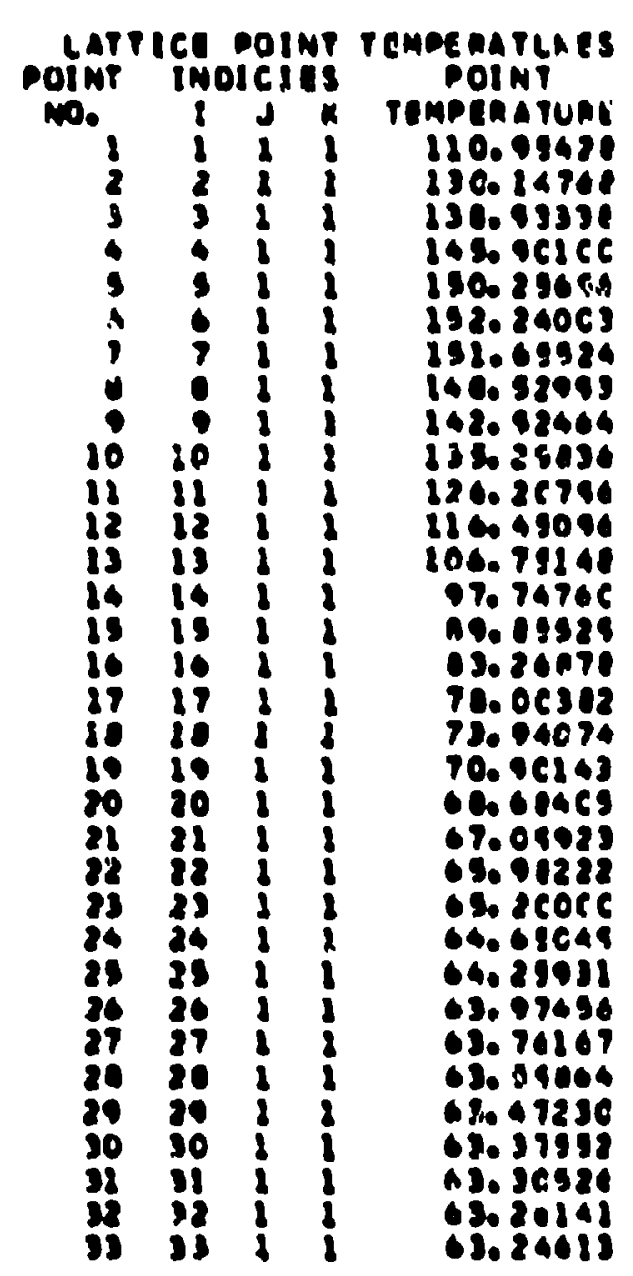

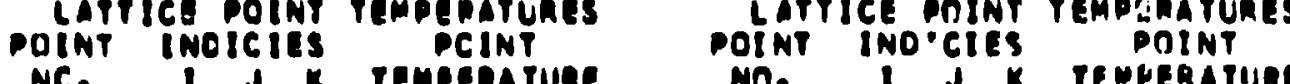

LATTICE PRINT TEMPERATURES NC. I I K Tempenatuate NC. I J J TEMPERATURE

Moter PoInte 1 and 33 Indleate the temperature

of the alr lalet and outlot, reopoetively,

of the charcosl tileer. 
Table D-6. Variable which can be Changed without Altering the Computer Code and Which are Printed out with Each Problem.

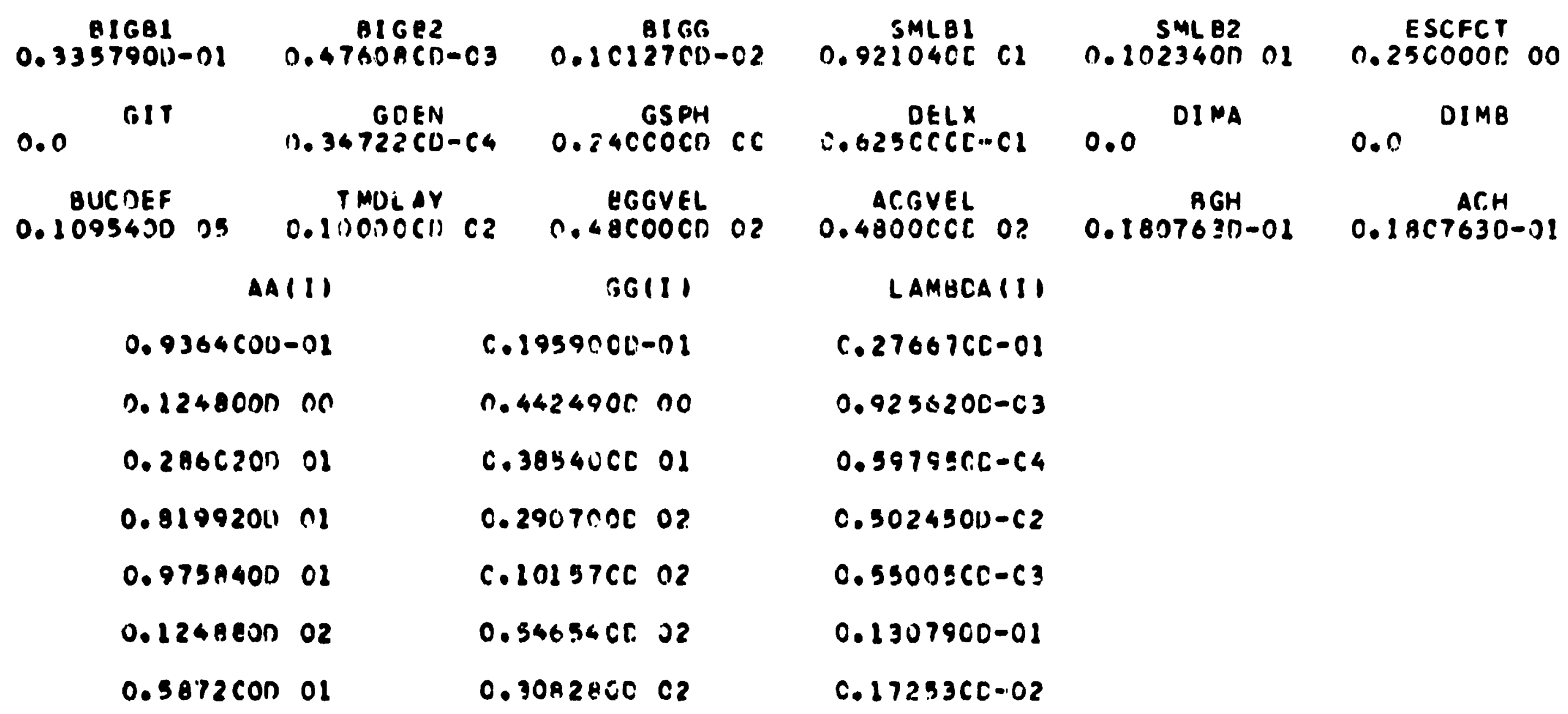

$\stackrel{1}{b}$ 
Table D-7. A Printout of Viajables for the Heat Transíer Sectio: of Computer Code.

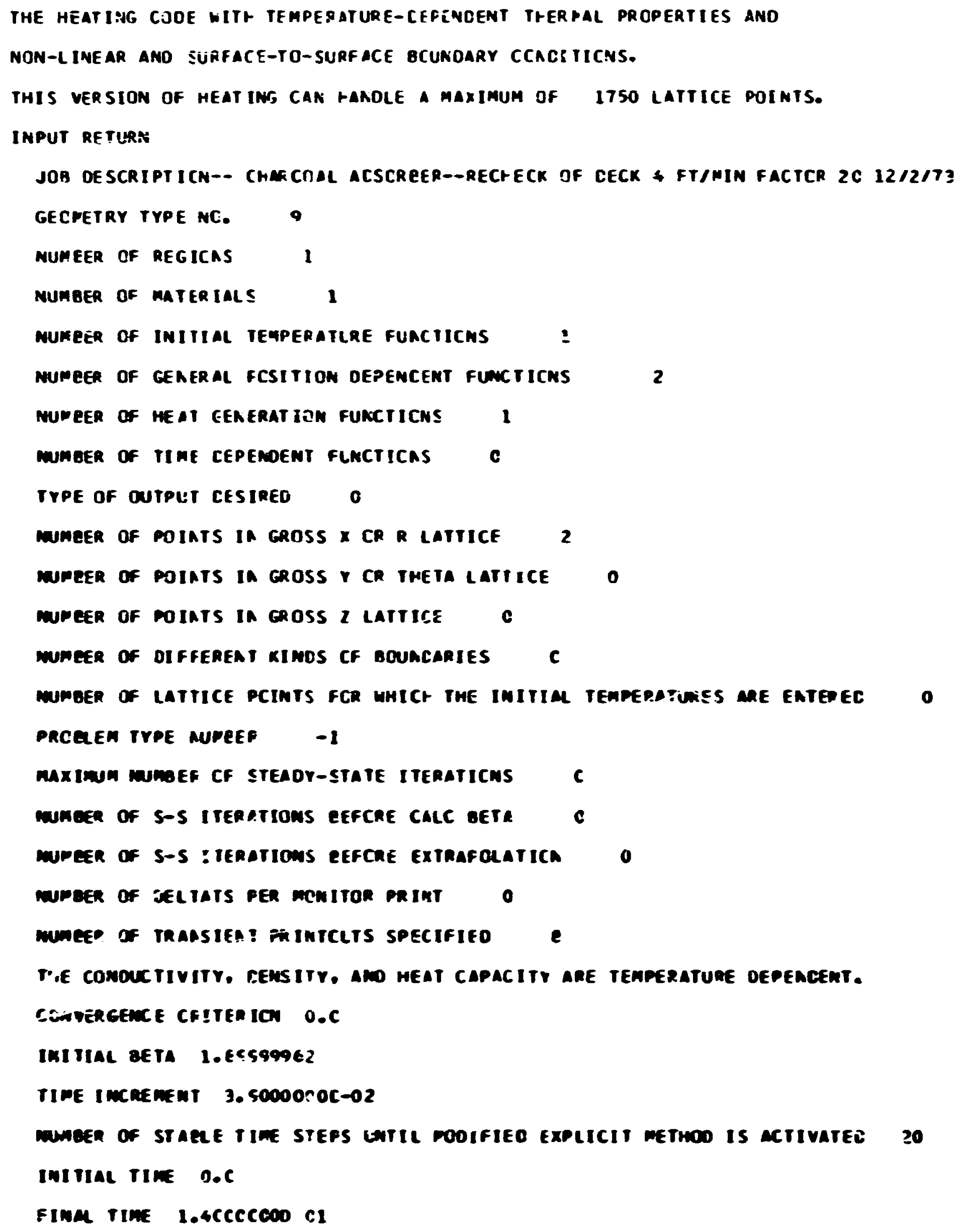




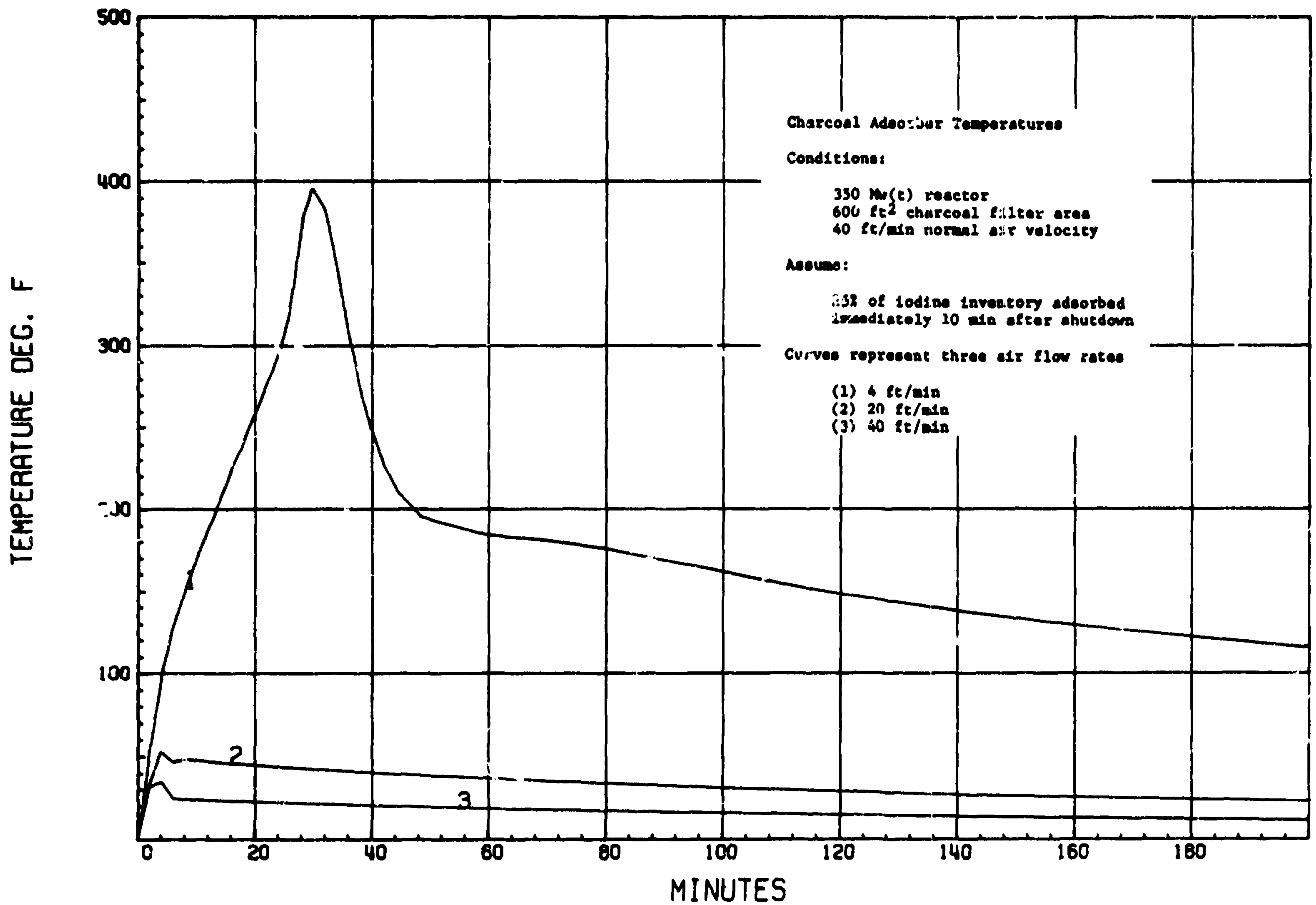

Figure D-1. Max Temperature vs Time For Varlous A1r F'low Rates 
Appendix E. STACK: An XTRAN Computer Program for Calculating Stack Parameter vs Fraction of Decay Heat Removed from Charcoal Adsorbers.

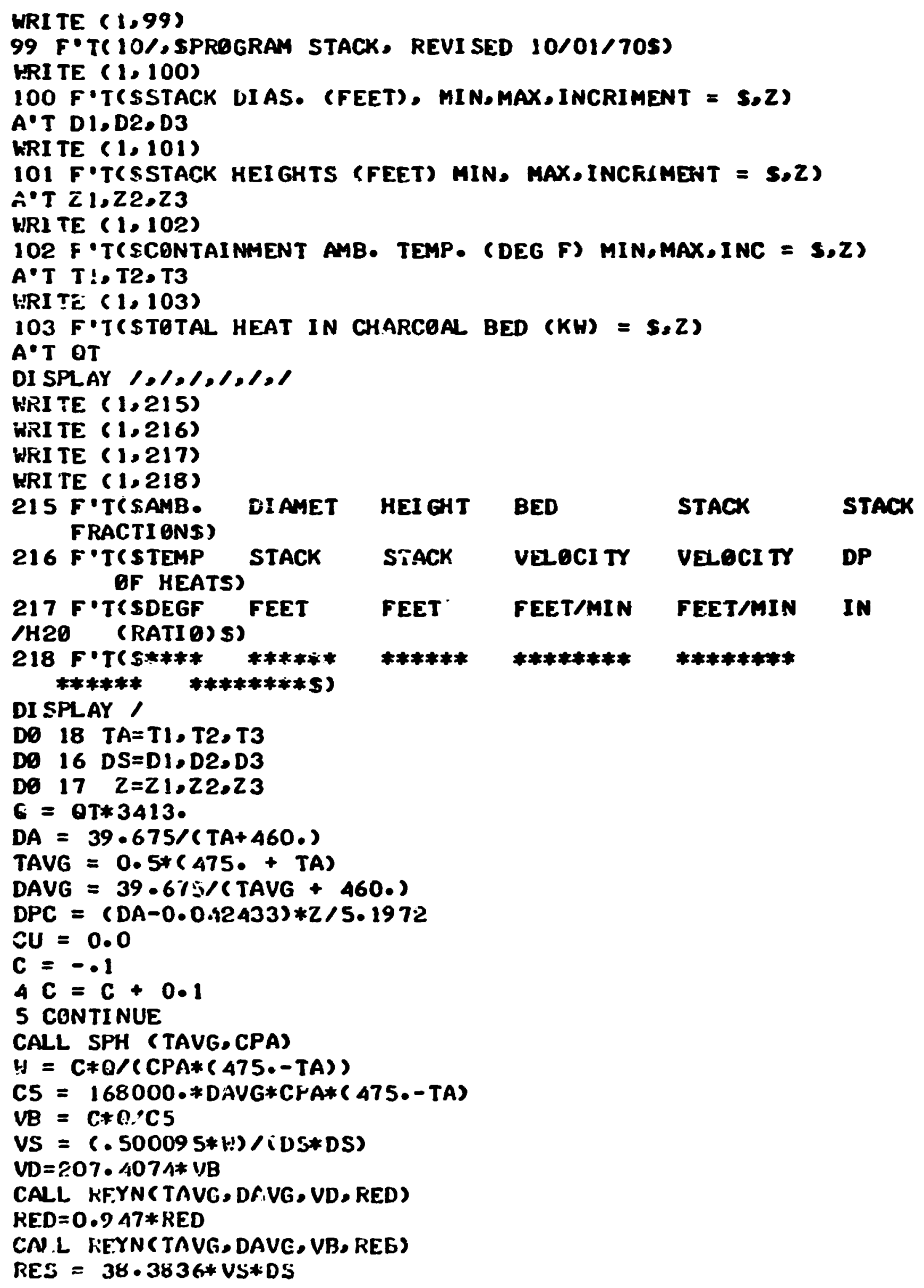


IF(RED.LT. 1500.) FD $=16 . / R E D$

IF:RED.6T. 1500..AND.RED.LE. 3000.) FD = .011

IF (RED - GT - 3000.) FD $=.0014 t+125 /($ RED* * . 32)

DPD: $.00002325 * F D * V D * V D * D A V G$

IF(RES.LE. 1500.) FS = 16./RES

IF (RES.6T.1500..AND.RES.LE - 3000.) FS $=.011$

IF (RES.GT.3000.) FS $: .0014+.125 /$ (RES**.32)

DPS $=(1.4104 E-7 *$ VS*VS*Z*FS/DS) $+(5.2882 E-8 * V S * V S)$

IF (REB.LE. 400.) FB $=24000 . / R E B$

IF(REB.GT.AO0..AND. REB.LE.3000.) FB $=2601.75 /$ (REB**.629)

IF (REB.GT.3000.) FB $=99.375 /($ REB**.225)

$D P B=.00010692 *$ FB*VB*VB*DAVG + .0000270*VB*VB*DAVG

$\mathrm{DPT}=\mathrm{DPB}+\mathrm{DPS}+\mathrm{DPD}$

IF(DPT.GT.DPC) GO TO 6

$C=C$

DPTL $=D P T$

IFCCJ.EO.0.0) COTO 4

G $T 07$

$6 \mathrm{CU}=\mathrm{C}$

DPTU $=$ DPT

$7 F R=(A B S(D P T-D P C)) / D P C$

IF(FR.LT•0.000001) GO TS 25

$C=(\mathrm{CU}+\mathrm{CL}) / 2$.

Go To 5

25 WRI TE( 1,205$)$ TA, DS, Z, VB, VS, DPT,C

$205 F \cdot T(1 X, 13,3 X, F 6,3,3 X, F 6,2,3 X, F B \cdot 3,3 X, F 8,3,3 X, F 6,4,3 X, F 6,4)$

17 CONTINUE

16 CantINUE

18 Centinue

END

SUBROUTINE REYN(X, DAVG, VB, REB)

IF X.LE.0.0) VIS $=.03939$

IF ( $(X \cdot G T \cdot 0 \cdot 0) \cdot A N D \cdot(X \cdot L E \cdot 100)$.$) VI S=.03939+.0000655 *(100 \cdot-X)$

IF ( $(X \cdot G T \cdot 100$.$) .AND. (X \cdot L E \cdot 200)$.$) VIS =.04594+$

$.0000599 *\left(200 \cdot-x^{\prime}\right)$

IF $(X \cdot G T \cdot 200 \cdot) \cdot$ AND. $(X \cdot L E \cdot 300)$.

VI $=.05193+.0000555 *(300 .-X)$

IF $(X \cdot G T \cdot 300 \cdot)$. AND. $(X \cdot L E \cdot 400)$.

VIS $=.05748+.0000518 *(400 .-X)$

IF ( $(X \cdot G T \cdot 400 \cdot) \cdot A N D \cdot(X \cdot L E \cdot 475)$.

$v_{i} S=.06266+.000048933 *(475 \cdot-x)$

IF(X-GT-475.) VIS $=.06633$

IF (X.GT.475.) WRITE $(1,295)$

295 F.TCSSTUPID, YEUR AMBIENT TEMP IS GREATEK THAN THE

IGNITION TEMP JF YGUR CHARCOAL BEDS)

$\mathrm{DB}=.00517$

REB $=$ DB*2880**VB*DAVG/VIS

RETURN

END

SUBROUTINE SPH (Y,CPA)

IF(Y.LE.100.) CA $=.2406$

IF( (Y.GT. 100.) -AND . $(Y \cdot L E \cdot 200).) \quad C P A=.2406+.000009 *(Y-100$.

IF(CY.GT•?00.). AND. $\left.\left(Y \cdot L E_{\cdot} \cdot 300.\right)\right) \quad C P A=.2415+.000016 *(Y-200$.

IF( (Y.GT.300.) -AND. $(Y \cdot L E \cdot 400).) \quad C F A=.2431+.000021 *(Y-300$.

IF( (Y.GT. 400.) .AND. $(Y \cdot L E \cdot 475).) \quad C P A=.2452+.000025 *(Y-400$.

RETURN

END

*? 
PFOGRAM STACK, REVI SED 10/01/70

STACK UIAS. (FEET). MINOMAX,INCRIMENT $=140.5$

STACK HEIGHTS (FEET) MIN, MAX,INCRIMENT $=51005$

CONTAINMENT AMB. TEMP. (DEG F) MIN,MAX,INC; = 1001000

TOTAL HEAT IN CHARCJAL BED (Y:W) $=732$

\begin{tabular}{|c|c|c|c|c|c|c|}
\hline $\begin{array}{l}\text { AMB. } \\
\text { TEMP } \\
\text { DEGF } \\
+* * *\end{array}$ & $\begin{array}{l}\text { DI AMET } \\
\text { STACK } \\
\text { FEET } \\
* * * * * *\end{array}$ & $\begin{array}{l}\text { HEI GHT } \\
\text { STACK } \\
\text { FEET } \\
* * * * * *\end{array}$ & $\begin{array}{l}\text { BED } \\
\text { VELOCI TY } \\
\text { FEETMIN } \\
* * * * * * * *\end{array}$ & $\begin{array}{l}\text { STACK } \\
\text { VELOCI TY } \\
\text { FEET/MIN } \\
* * * * * * * *\end{array}$ & $\begin{array}{l}\text { STACK } \\
\text { DP } \\
\text { IN/HEO } \\
\text { ******* }\end{array}$ & $\begin{array}{l}\text { FRACTIO } \\
\text { OF HEAT } \\
\text { CRATIGS } \\
* * * * * * *\end{array}$ \\
\hline $\begin{array}{l}100 \\
100 \\
100 \\
100 \\
100 \\
100 \\
100 \\
100 \\
100 \\
100 \\
100 \\
100 \\
100 \\
100 \\
100 \\
100 \\
100 \\
100 \\
100 \\
100 \\
100 \\
100 \\
100 \\
10 C \\
10 C \\
100 \\
100 \\
100 \\
100 \\
100 \\
100 \\
100 \\
100 \\
100 \\
100 \\
100 \\
110 \\
100 \\
100\end{array}$ & $\begin{array}{l}1.000 \\
1.000 \\
1.000 \\
1.000 \\
1.000 \\
1.000 \\
1.000 \\
1.000 \\
1.000 \\
1.000 \\
1.000 \\
1.000 \\
1.000 \\
1.000 \\
1.000 \\
1.000 \\
1.000 \\
1.000 \\
1.000 \\
1.000 \\
1.500 \\
1.500 \\
1.500 \\
1.500 \\
1.500 \\
1.500 \\
1.500 \\
1.500 \\
1.500 \\
1.500 \\
1.500 \\
1.500 \\
1.500 \\
1.500 \\
1.500 \\
1.500 \\
1.500 \\
1.500 \\
1.500\end{array}$ & $\begin{array}{r}5.00 \\
10.00 \\
15.00 \\
20.00 \\
25.00 \\
30.00 \\
35.00 \\
40.00 \\
45.00 \\
50.00 \\
55.00 \\
60.00 \\
65.00 \\
70.00 \\
75.00 \\
80.00 \\
85.00 \\
90.00 \\
95.00 \\
100.00 \\
5.00 \\
10.00 \\
15.00 \\
20.00 \\
25.00 \\
30.00 \\
35.00 \\
40.00 \\
45.00 \\
50.00 \\
55.00 \\
60.00 \\
65.00 \\
70.00 \\
75.00 \\
80.00 \\
85.00 \\
90.00 \\
95.00\end{array}$ & $\begin{array}{l}0.151 \\
0.208 \\
0.249 \\
0.281 \\
0.307 \\
0.329 \\
0.348 \\
0.365 \\
0.390 \\
0.393 \\
0.405 \\
0.416 \\
0.426 \\
0.435 \\
0.443 \\
0.451 \\
0.458 \\
0.465 \\
0.471 \\
0.477 \\
0.333 \\
0.470 \\
0.570 \\
0.651 \\
0.718 \\
0.777 \\
0.828 \\
0.875 \\
0.916 \\
0.954 \\
0.989 \\
1.021 \\
1.051 \\
1.079 \\
1.104 \\
1.129 \\
1.151 \\
1.173 \\
1.193\end{array}$ & $\begin{array}{r}672 \cdot 618 \\
929 \cdot 459 \\
1110 \cdot 755 \\
1252 \cdot 407 \\
1368 \cdot 683 \\
1467 \cdot 040 \\
1551 \cdot 969 \\
1626 \cdot 419 \\
1692 \cdot 455 \\
1751 \cdot 581 \\
1804.933 \\
1853 \cdot 393 \\
1897 \cdot 654 \\
1938 \cdot 281 \\
1975 \cdot 734 \\
2010 \cdot 391 \\
2042 \cdot 571 \\
2072 \cdot 547 \\
2100 \cdot 546 \\
2126 \cdot 765 \\
660 \cdot 022 \\
932 \cdot 329 \\
1130 \cdot 535 \\
1289 \cdot 722 \\
1423 \cdot 714 \\
1539 \cdot 686 \\
1641 \cdot 965 \\
1733 \cdot 402 \\
1816 \cdot 004 \\
1891 \cdot 239 \\
1960 \cdot 227 \\
2023 \cdot 836 \\
2.682 \cdot 799 \\
2137 \cdot 658 \\
2188 \cdot 877 \\
2236 \cdot 857 \\
2281 \cdot 925 \\
2324 \cdot 371 \\
2364 \cdot 434\end{array}$ & $\begin{array}{l}0.0273 \\
0.0547 \\
0.0820 \\
0.1093 \\
0.1367 \\
0.1640 \\
0.1914 \\
0.2187 \\
0.246 C \\
0.2734 \\
0.3007 \\
0.3280 \\
0.3554 \\
0.3827 \\
0.4101 \\
0.4374 \\
0.4647 \\
0.4921 \\
0.5194 \\
0.5467 \\
0.0273 \\
0.0547 \\
0.0820 \\
0.1093 \\
0.1367 \\
0.1640 \\
0.1914 \\
0.2187 \\
0.2460 \\
0.2734 \\
0.3007 \\
0.3280 \\
0.3554 \\
0.3827 \\
0.4101 \\
0.4374 \\
0.4647 \\
0.4921 \\
0.5194\end{array}$ & $\begin{array}{l}0.0490 \\
0.0678 \\
0.0810 \\
0.0913 \\
0.0998 \\
0.1070 \\
0.1131 \\
0.1186 \\
0.1234 \\
0.1277 \\
0.1316 \\
0.1351 \\
0.1383 \\
0.1413 \\
0.1440 \\
0.1466 \\
0.1489 \\
0.1511 \\
0.1531 \\
0.1551 \\
0.1083 \\
0.1529 \\
0.1854 \\
0.2116 \\
0.2335 \\
0.2526 \\
0.2693 \\
0.2843 \\
0.2979 \\
0.3102 \\
0.3215 \\
0.3320 \\
0.3417 \\
0.3507 \\
0.3591 \\
0.3669 \\
0.3743 \\
0.3813 \\
0.3879\end{array}$ \\
\hline
\end{tabular}




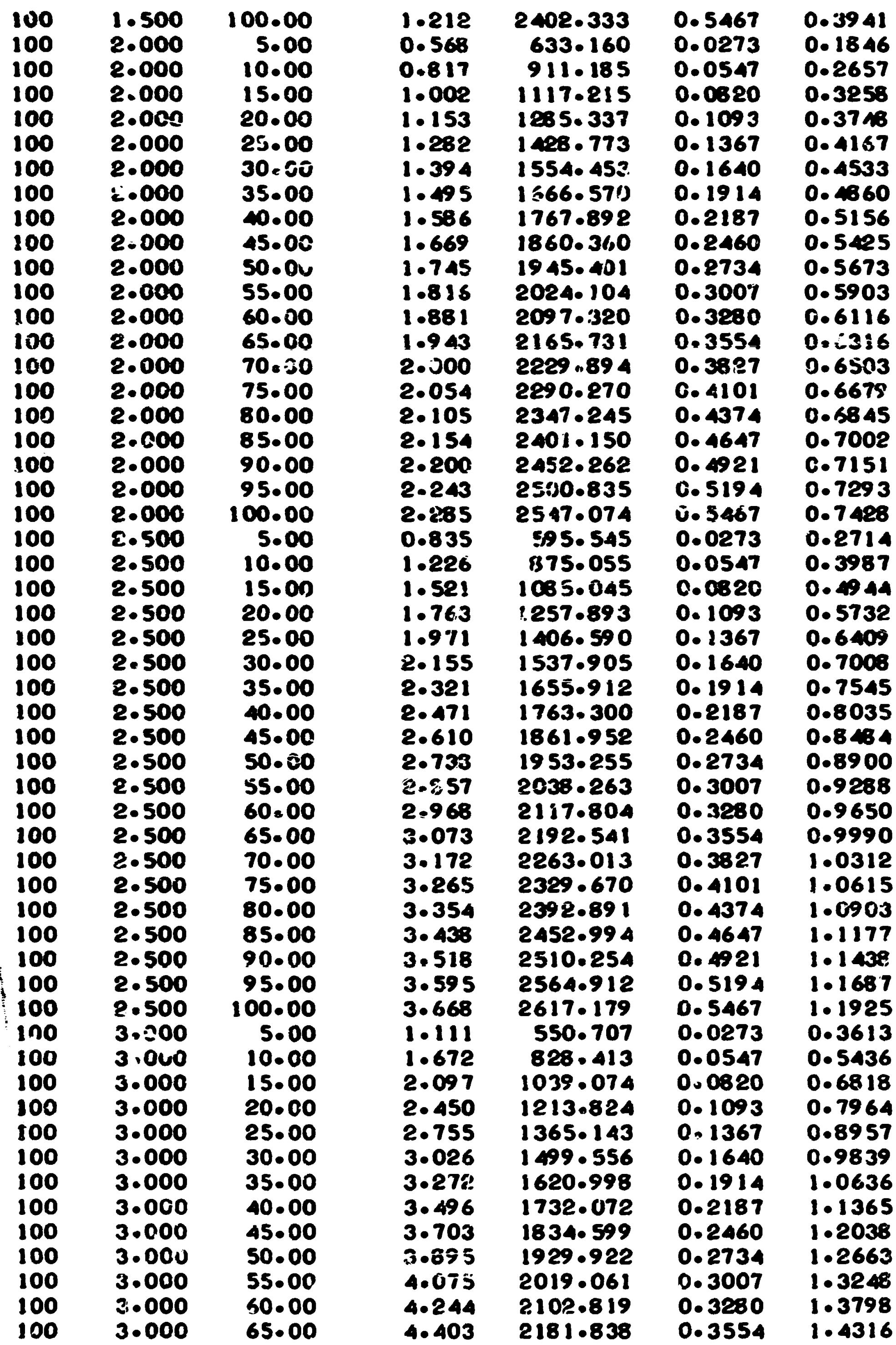




\begin{tabular}{|c|c|c|c|c|c|c|}
\hline $\begin{array}{l}100 \\
110 \\
100 \\
100 \\
100 \\
100 \\
100 \\
100 \\
100 \\
100 \\
100 \\
100 \\
100 \\
100 \\
100 \\
100 \\
100 \\
100 \\
100 \\
100 \\
100 \\
100 \\
100 \\
100 \\
100 \\
100 \\
100 \\
100 \\
100 \\
100 \\
100 \\
100 \\
100 \\
100 \\
100 \\
100 \\
100 \\
100 \\
100 \\
100 \\
100 \\
100 \\
100 \\
100 \\
100 \\
100 \\
100 \\
100 \\
100\end{array}$ & 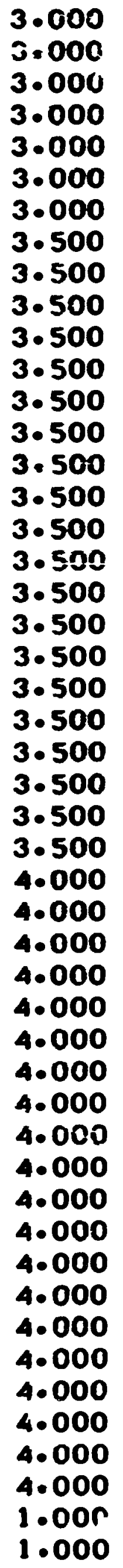 & 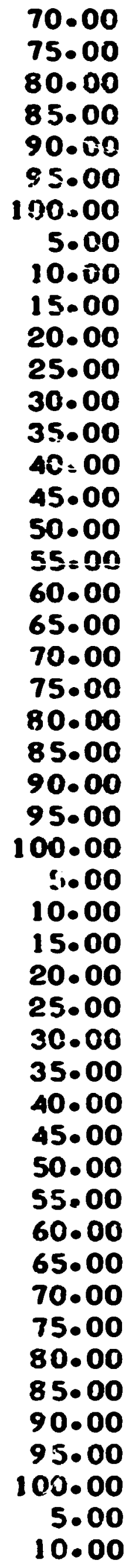 & $\begin{array}{l}4 \cdot 554 \\
4 \cdot 698 \\
4 \cdot 834 \\
4 \cdot 964 \\
5 \cdot 089 \\
5 \cdot 203 \\
5 \cdot 322 \\
1.379 \\
2 \cdot 126 \\
2 \cdot 699 \\
3 \cdot 178 \\
3 \cdot 595 \\
3 \cdot 968 \\
4 \cdot 306 \\
4 \cdot 616 \\
4 \cdot 904 \\
5 \cdot 172 \\
5=494 \\
5 \cdot 661 \\
5 \cdot 886 \\
6 \cdot 099 \\
6 \cdot 303 \\
6 \cdot 496 \\
6 \cdot 682 \\
6 \cdot 860 \\
7 \cdot 031 \\
7 \cdot 195 \\
1.622 \\
2 \cdot 563 \\
3 \cdot 295 \\
3 \cdot 912 \\
4 \cdot 452 \\
4 \cdot 937 \\
5 \cdot 378 \\
5 \cdot 785 \\
6 \cdot 163 \\
6 \cdot 517 \\
6 \cdot 851 \\
7 \cdot 166 \\
7 \cdot 465 \\
7 \cdot 749 \\
8 \cdot 021 \\
8 \cdot 281 \\
8 \cdot 530 \\
8 \cdot 770 \\
9 \cdot 001 \\
0 \cdot 223 \\
0 \cdot 208\end{array}$ & $\begin{array}{r}2256 \cdot 638 \\
2327 \cdot 659 \\
2395 \cdot 264 \\
2459 \cdot 764 \\
2521 \cdot 430 \\
2580 \cdot 491 \\
2637 \cdot 152 \\
502 \cdot 054 \\
773 \cdot 898 \\
982 \cdot 564 \\
1156 \cdot 939 \\
1308 \cdot 865 \\
1444 \cdot 370 \\
1567 \cdot 402 \\
1680 \cdot 390 \\
1785 \cdot 032 \\
1882 \cdot 773 \\
1974 \cdot 443 \\
2060 \cdot 865 \\
2142 \cdot 656 \\
2220 \cdot 321 \\
2294 \cdot 280 \\
2364 \cdot 866 \\
2432 \cdot 439 \\
2497 \cdot 198 \\
2559 \cdot 389 \\
2619 \cdot 205 \\
451 \cdot 964 \\
714 \cdot 353 \\
918 \cdot 471 \\
1090 \cdot 363 \\
1240 \cdot 914 \\
1375 \cdot 932 \\
1498 \cdot 960 \\
1612 \cdot 356 \\
1717 \cdot 780 \\
1816 \cdot 460 \\
1909 \cdot 333 \\
1997 \cdot 132 \\
2030 \cdot 453 \\
2159 \cdot 776 \\
2235 \cdot 502 \\
2307 \cdot 971 \\
2377 \cdot 468 \\
2444 \cdot 244 \\
2570 \cdot 511 \\
672 \cdot 660 \\
929 \cdot 459\end{array}$ & $\begin{array}{l}0.3827 \\
0.4101 \\
0.4374 \\
0.4647 \\
0.4921 \\
0.5154 \\
0.5467 \\
0.0273 \\
0.0547 \\
0.0820 \\
0.1093 \\
0.1367 \\
0.1640 \\
0.1914 \\
0.2187 \\
0.2460 \\
0.2734 \\
0.3007 \\
0.3280 \\
0.3554 \\
0.3827 \\
0.4101 \\
0.4374 \\
0.4647 \\
0.4481 \\
0.5194 \\
0.5467 \\
0.0273 \\
0.0547 \\
0.0820 \\
0.1093 \\
0.1367 \\
0.1640 \\
0.1914 \\
0.2187 \\
0.2460 \\
0.2734 \\
0.3007 \\
0.3280 \\
0.3554 \\
0.3827 \\
0.4101 \\
0.4374 \\
0.4647 \\
0.4921 \\
0.5194 \\
0.5467 \\
0.0273 \\
0.0547\end{array}$ & $\begin{array}{l}1.4807 \\
1.5273 \\
1.5716 \\
1.6140 \\
1.6544 \\
1.6932 \\
1.7304 \\
0.4484 \\
0.6912 \\
0.8775 \\
1.0333 \\
1.1689 \\
1.2900 \\
1.3998 \\
1.5007 \\
1.5942 \\
1.6815 \\
1.7634 \\
1.8405 \\
1.9136 \\
1.9829 \\
E .0490 \\
2.1121 \\
2.1724 \\
2.2302 \\
2.2853 \\
2.3392 \\
0.5272 \\
0.8333 \\
1.0714 \\
1.2719 \\
1.4475 \\
1.6050 \\
1.7485 \\
1.8808 \\
2.0038 \\
2.1189 \\
2.2272 \\
2.3296 \\
2.4268 \\
2.5193 \\
2.6077 \\
2.6922 \\
2.7733 \\
2.8512 \\
2.9261 \\
2.9984 \\
0.0490\end{array}$ \\
\hline
\end{tabular}

ESC: (SMAINS) 205 


\section{REFERENCES}

1. C. E.Miller and R. P. Shields, Ignition of Cinarcoal Adsorbers by Plssion Fraduct Decay Heat, USAEC Report ORh,-40?1, 0 k Ridge National Laboratory, Decenber 1966.

2. R. P. Shields and C. E. Miller, "The Effects of Fission Products on Charcoal Ignition (In-P1le Experiment)," USAEC Report ORWL-TI-1739, January 1967, Oak Ridge Naticnal Laboratory.

3. R. P. Shields and R. E. Adam, "The Effects of Fission Products on Ignition of Iodized Charcosl (In-P1le Experiment IGR-3)," iShEC Report ORKL-TY-2321, Decemer 1968, Oak Ridge Nat’́onal Laboratory.

4. R. P. Shields, "Ignitiois of Charcoal Adsorbers by Fission Product Decay Heat," Proceedings of the 11th Air Cleaning Conference, Banford, Washington, Aug. 31-Sept. 3. 1970.

5. C. A. Burchsted and A. B. Fuller, "Design, Construction, and TestinB of High Efficiency Afr Filtration System for Nuclear Applications;" USAEC Report ORNL-HSIC-65, January 1970, Oak Ridge National Laboratory.

6. C. R. Usike and 0. A. Hougen, "Mass Transfer in the Flow of Gases Through Granular Solids Excended to Low Modified Reynolds Nubers," Trans. AIChE, 41, 445-451 (1945).

7. B. H. Gerson, G. Thodoe and O. A. Hougen, "Hear, Mass and Morent un Transfer in the Flow of Gases Through Granular Solids," Trans. AIChE, 39, 1-35 (1943).

8. L. R. Mclune and R. H. WHheln, "Kass and Momentum Transfer in Solldilquid Systems (Fixed and Fluidized Beds)," Ind. Eng. Chem. (Industrial Edtion), 41, 1124-1134 (1949).

9. J. E. Coppage, a.D. Thesis in Mechanical Engineering, Stanford University, 1952.

10. W. D. Turner and J. S. Crowe11, "Notés on kRATING - An IBM 360 Heat Conduction Program," Computing Technology Center Report CTC-INP-980, Novembet 1969, Oak Ridge Gaseous Diffusion Plant.

11. H. D. Turner and M. Siman-Tov, "HEATING3 - An IBM 360 Heat Conduction Program," USAEC Report ORIL-TM-3208, Oak Ridge National Laboratory.

12. H. R. Browning, C. R. MAller, R. P. Shields, and B.F. Roberts, "Simulated Lass-of-Coolant Accident in the ORR," PP. 109-118 in Niclear Safety Semiannual Progress Report for Period Ending Vecember 31, 1964, USARC Report ORNL-3776. 
13. M. J. Bell, Chenical Technology Divisiou Progress Report for Period Ending May 31, 1969, USAEC Report ORAL-4422, Oak Ridge National Laboratory. 